\title{
OTIMIZAÇÃO DE SISTEMAS DE IRRIGAÇÃO LOCALIZADA UTILIZANDO PROGRAMAÇÃO NÃO-LINEAR
}

\author{
JOÃO CARLOS CURY SAAD \\ Engenheiro Agrónomo
}

Orientador: Prof. Dr. JOSE ANTONIO FRIZZONE

Tese apresentada à Escola Superior de Agricultura "Luiz de Queiroz", da Uni versidade de Săo Paulo, para obtenção do título de Doutor em Agronomia, Area de Concentração: Irrigação e Drenagem.

\author{
P I R A C I C A B A \\ Estado de São Paulo - Brasil \\ Novembro - 1993
}


Ficha cataloorafica oreoarada cela secao de Livros da Divisab de Eiblioteca e Documentacáa - FCLR/USF

\footnotetext{
Saad. Joăo Carlos Eury

Al1 lo Otimizacáo de sistemas de irrigacaro localizada utilizando prouramacao năo-1inear. Firacicaba. 1993.

1140. i1 145.

TESE - ESALQ

Hibliogratia.

1. Irrigacáo localizada - Sistema - Qtimizacào z. Frodramacá ráa linear I. Escola Suderior de Aoricul tura Luiz de Gueiroz. Firacicaba

$$
\text { CDD } \quad 6.1 .7
$$
}




\section{OTIMIZAÇÃO DE SISTEMAS DE IRRIGAÇÃO LOCALIZADA UTILIZANDO PROGRAMAÇÃO NÃO-LINEAR}

JOAO CARLOS CURY SAAD
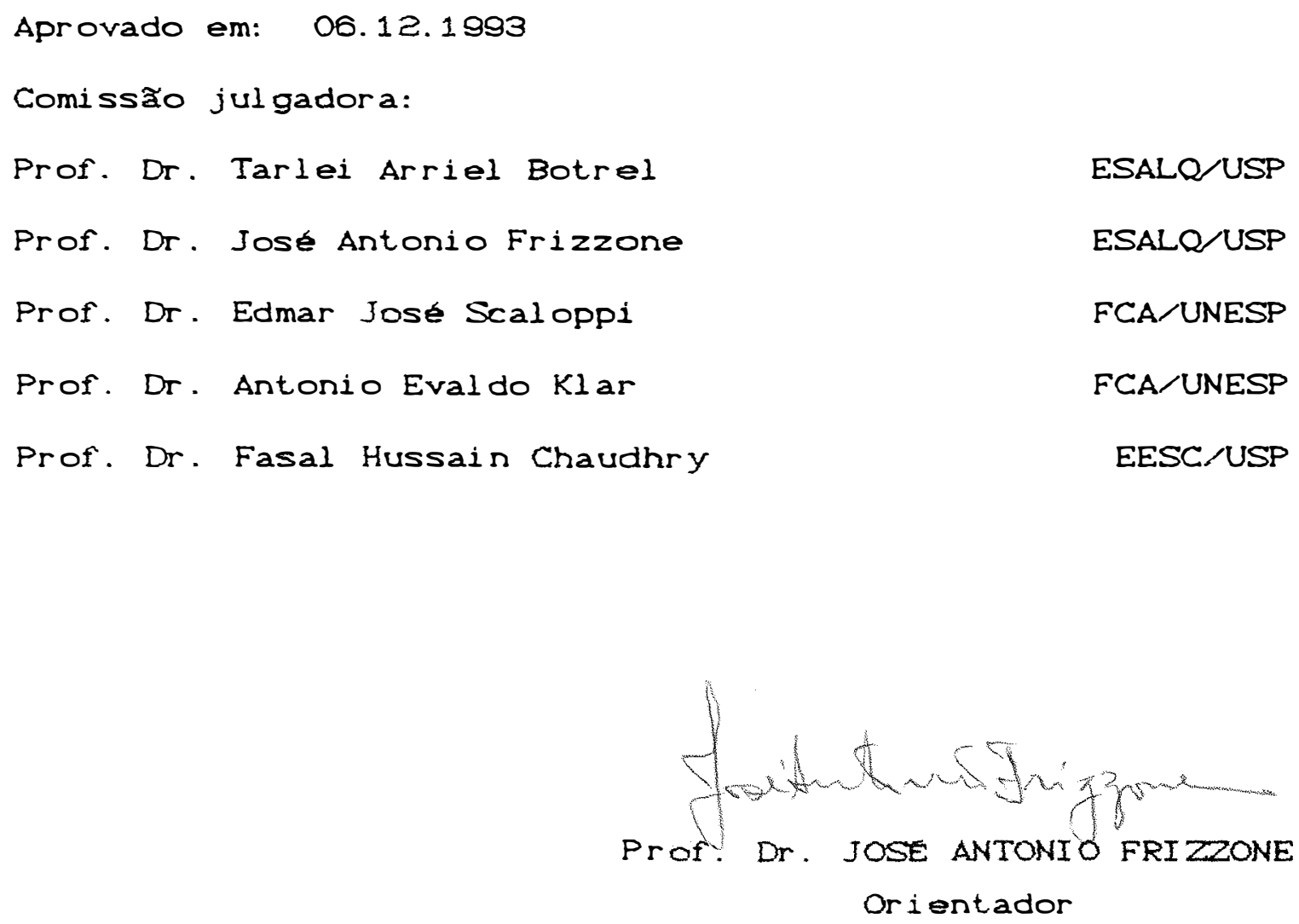


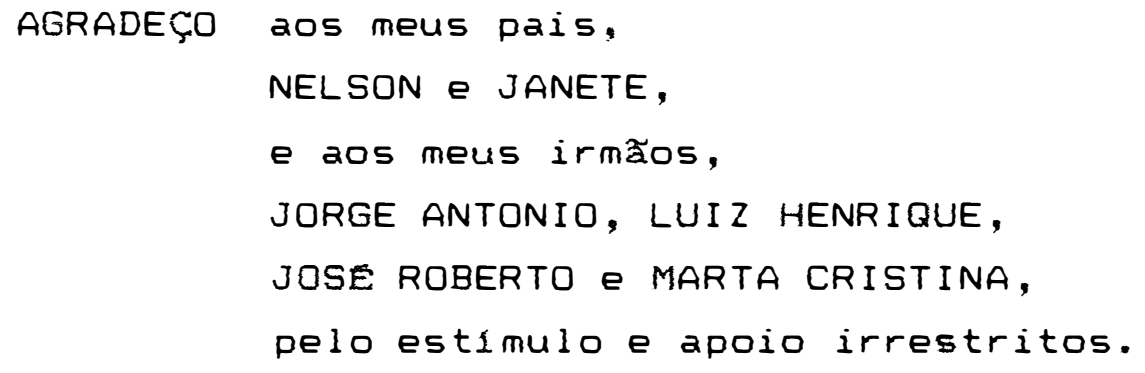

DEDICO à mintia querida esposa BEATRIZ, pelo constante incentivo, pelo incessante apoio e por tudo que ela representa para mim. 


\section{AGRADEC IMENTOS}

AGRADEÇO

- a DEUS, por mais esta graça;

- ao Prof. Dr. José Antonio Frizzone, pela orientação segura, pelo incentivo e pelo privilégio de poder desfrutar de sua tão valiosa amizade;

- à Escola Superior de Agricultura "Luiz de Queiroz" - ESALQ/USP e à Coordenação do curso de Pós-Graduação em Irrigação e Drenagem, pela acolitida e apoio dispensados;

- ao Conseltio Nacional de Desenvolvimento Cientifico e Tecnólogico - CNPQ, pela auxilio financeiro;

- à Duratex S.A., na pessoa do Engo José Antonio Dorini, pelo total apoio e incentivo;

- ao Prof. Dr. Antonio Evaldo Klar, que me orientou na iniciação cientifica e, assim, possibilitou-me - primeiro contato com a área de Irrigação e Drenagem, pela amizade e pelo constante incentivo;

- ao Prof. Dr. Edmar Jose Scaloppi, pela importancia fundamental que sempre teve em minha formação técnico-cientifica e pela grande amizade que nos une; 
- ao Prot. jor. Antonio Fernando Lordelo 011tta, Coordenador do curso de fos-Graduação em irrıqação e Urenagem, delo apolo e dela contianga em mim depositada:

- aos protessores e tuncionarios do Departamento de Engenharia Fural da ESALU/USF, dela dedıcação e amızade :

- as empresas Larborundum S.A. - Sistemas de Irrigação, liqre S.A. e kSB Bombas Hidráulicas G.A.. Delo formecimento das intormaços técnicas e económicas que tornaram Dossivel este trabalno:

- a bibliotecarra Eliana M. G. Sabino dela revisăo das referencias bibliograficas;

- aos colegas do curso de Dos-graduação em Irrigagão e Lrenagem e a todos que contriouiram direta ou indiretamente para a realização deste trabalho. 
LISTA DE SIMBOLOS ......................

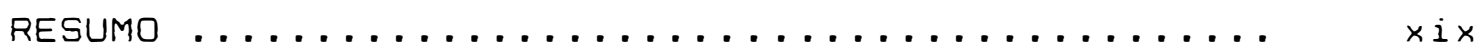

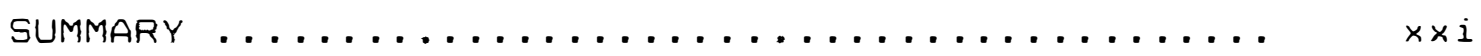

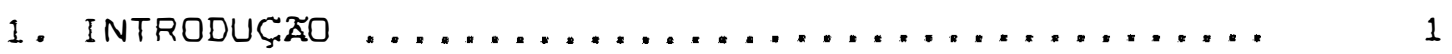

2. REVISto de literatURA .................

2.1. Aspectos gerais ................ s

2.2. Otimização do dimensionamento .......... b

2.3. Utilização de técnicas de Pesquisa

Operacional na otimização dos sistemas pressurizados de irrigação ......... g

2.3.1. Utilização da Programação Linear .. 9

2.3.2. Utilização da Programação

Não-Linear ............... 12

3. MAterial e metodos ........................ 20

3.1. Hipoteses do modelo ................ 20

3.2. Formulação matemática do problema de maximização na programação não-linear. $\quad 24$

3.3. Função-otjetivo ................ 25

3.3 .1 . Receita bruta .............. 25

3.3.2. Custo de produção da laranja..... 28

3.3.3. Custo do sistema de irrigação ..... 28 
Página

3.3.3.1. Relações custo do componente $\times$ dimensăo caracteristica .......

3.3 .3 .2 . Equações de totalizaçăo dos componentes do sistema .............

3.4. Equaçōes de perda de carga .............

3.4.1. Perda de carga nas linhas laterais

3.4.1.1. Perda de carga na linha lateral em aclive......

3.4.1.2. Perda de carga na linha lateral em declive.....

3.4.2. Perda de carga na linha de derivaçăo $\ldots \ldots \ldots \ldots \ldots \ldots . . .$.

3.4.2.1. Perda de carga na linha de derivação em aclive

3.4.2.2. Perda de carga na linha de derivaçăo em declive

3.4.3. Perda de carga na linha secundaria

3.4.4. Perda de carga na linha principal

3.4.4.1. Perda de carga na linha

principal em aclive...

3.4.4.2. Perda de carga na linha

$$
\text { principal em declive }
$$


3.4.5. Balanço de perdas e gantios de de carga hidráulica nas linhas
em aclive e declive..........

3.5. Equaçóses referentes aos critérios hidráulicos de dimensionamento ........

3.5.1. Dimensionamento das linhas

laterais e de derivação com

base na uniformidade de emissão

3.5.2. Dimensionamento das linhas

secundária e principal com

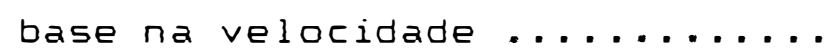

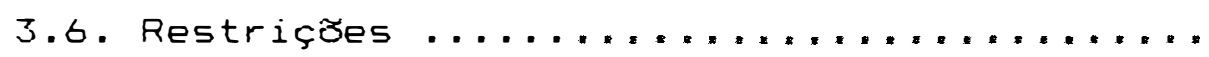

3.6.1. Restrição referente ao turno de irrigaçăo $\ldots \ldots \ldots \ldots \ldots \ldots$

3.6.2. Restrição referente ao tempo diário disponivel para irrigação 48

3.6.3. Restrição quanto à vazão disponivel

3.6.4. Restrição que assegura pelo menos

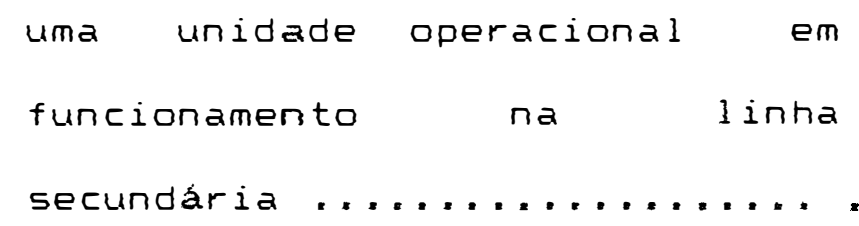

3.6.5. Restrição referente à ocupação

total da área disponivel. ...... 
3.6.6. Restrição referente à produção

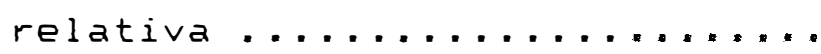

3.7. Dados de entrada .................

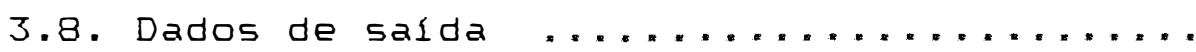

3.9. Valores dos dados de entrada utilizados...

3.10. Parâmetros de entrada utilizados na análise de sensibilidade da função

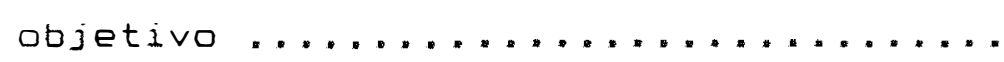

3.11 . Soluçăo do modelo . ................

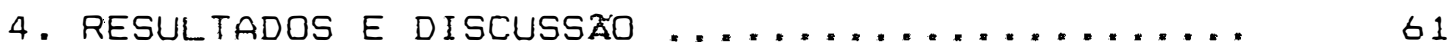

4.1. Resultados ..................... 61

4.2. Configuração de maior receita liquida anual versus configuração de menor

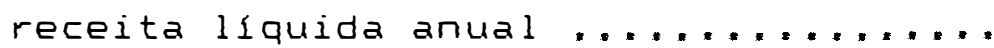

4.3. Efeito do tamantio e do formato da area na receita liquida anual ..............

4.4. Efeito da vazão do microaspersor na receita liquida anual ............ 69

4.5. Efeito da declividade na receita liquida anual $\ldots \ldots \ldots \ldots \ldots \ldots \ldots \ldots \ldots \ldots$

4.6. Relação da uniformidade de emissão (UE) com o formato e com a declividade ...... 76 
Página

4.7. Relação entre o numero de unidades operacionais e o tamanho e o formato da

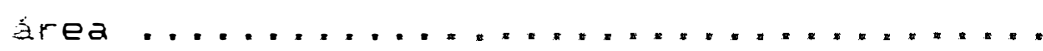

4.8. Situações em que o modelo não encontrou uma soluçăo otima $\ldots \ldots \ldots \ldots \ldots \ldots \ldots$

4.9. SugestZ̃es para continuidade ............ 82

5. CONCLUSOES ........................ 83

REFERENCIAS BIBLIGGRAFICAS ..............

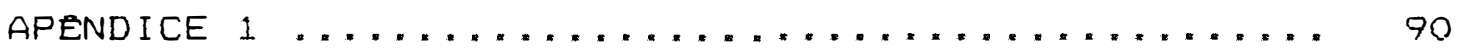

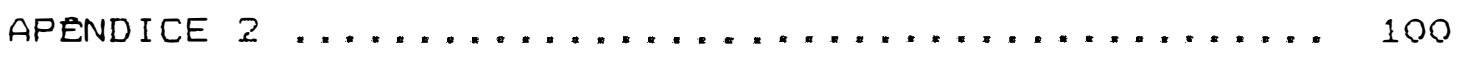

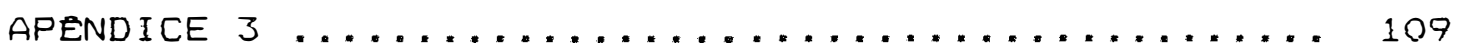




\section{LISTA DE SIMBOLOS}

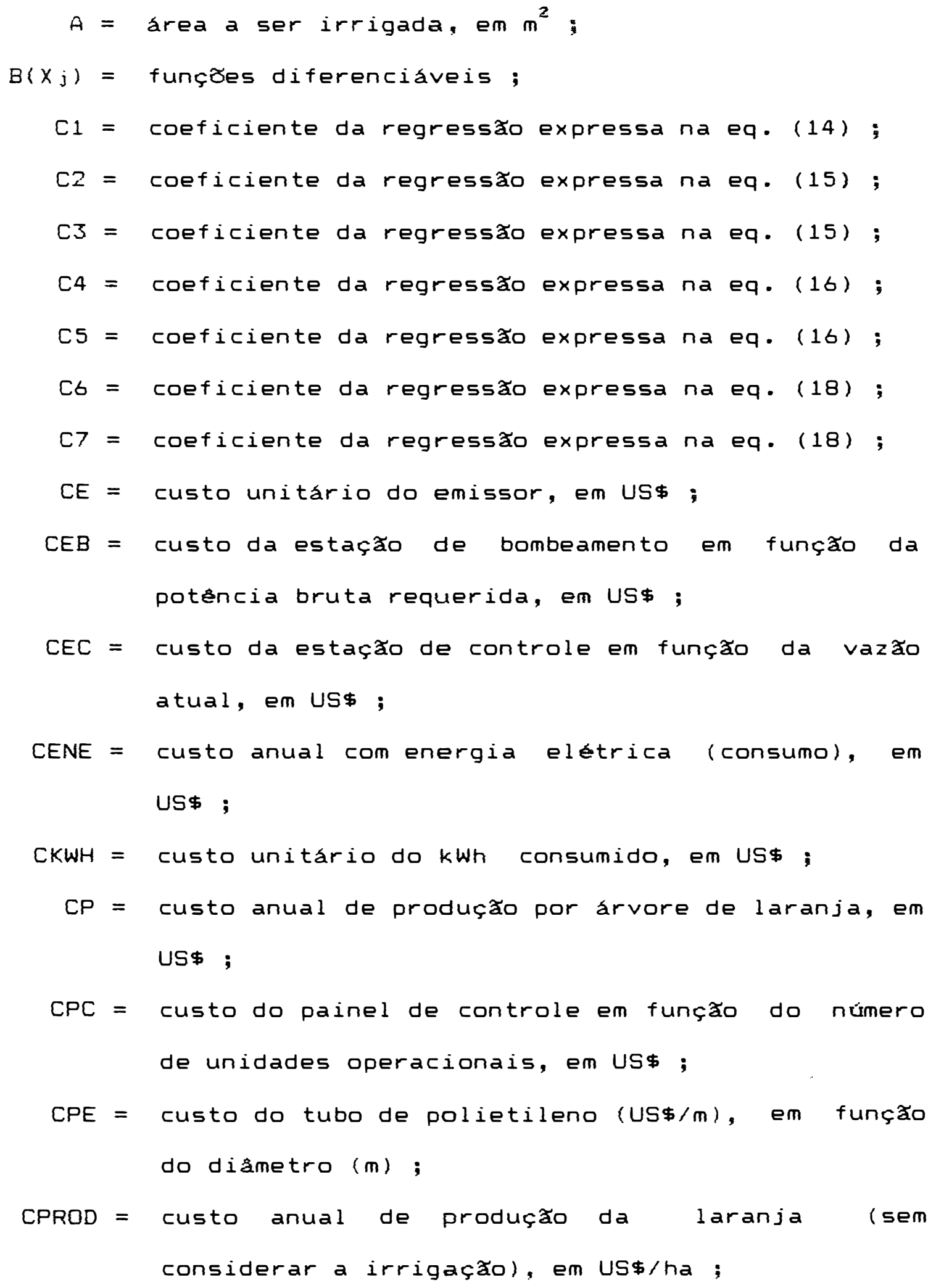




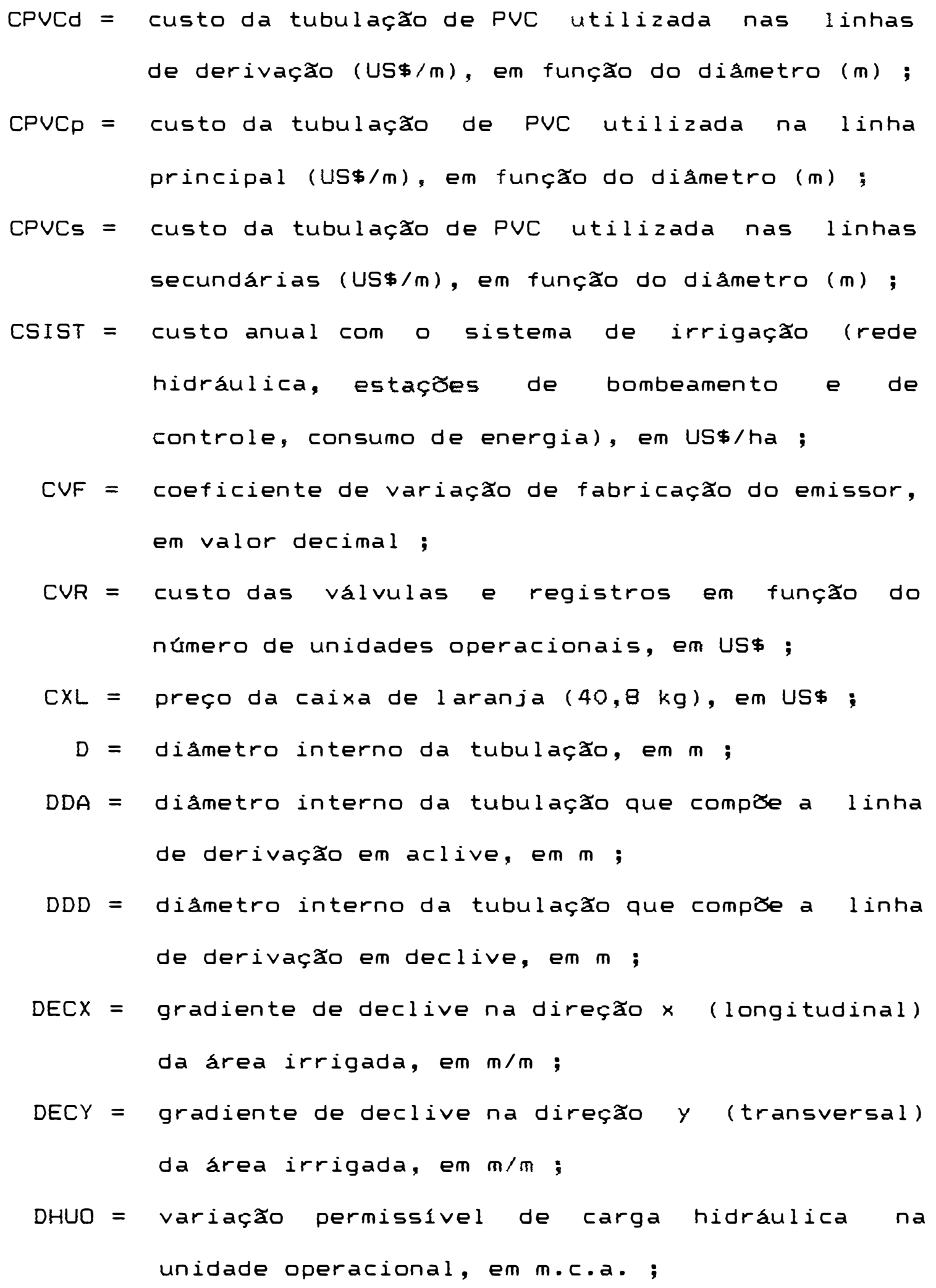




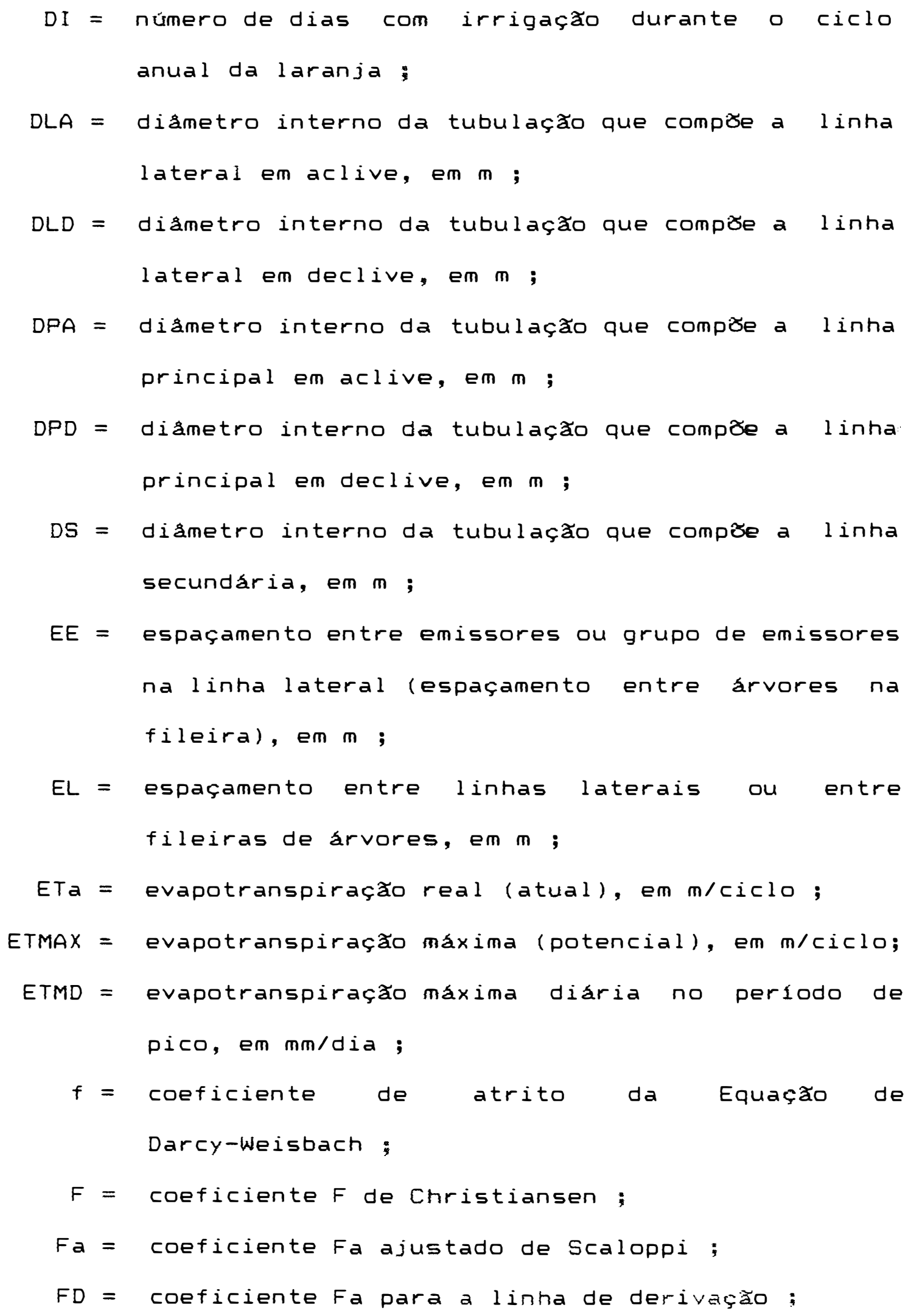




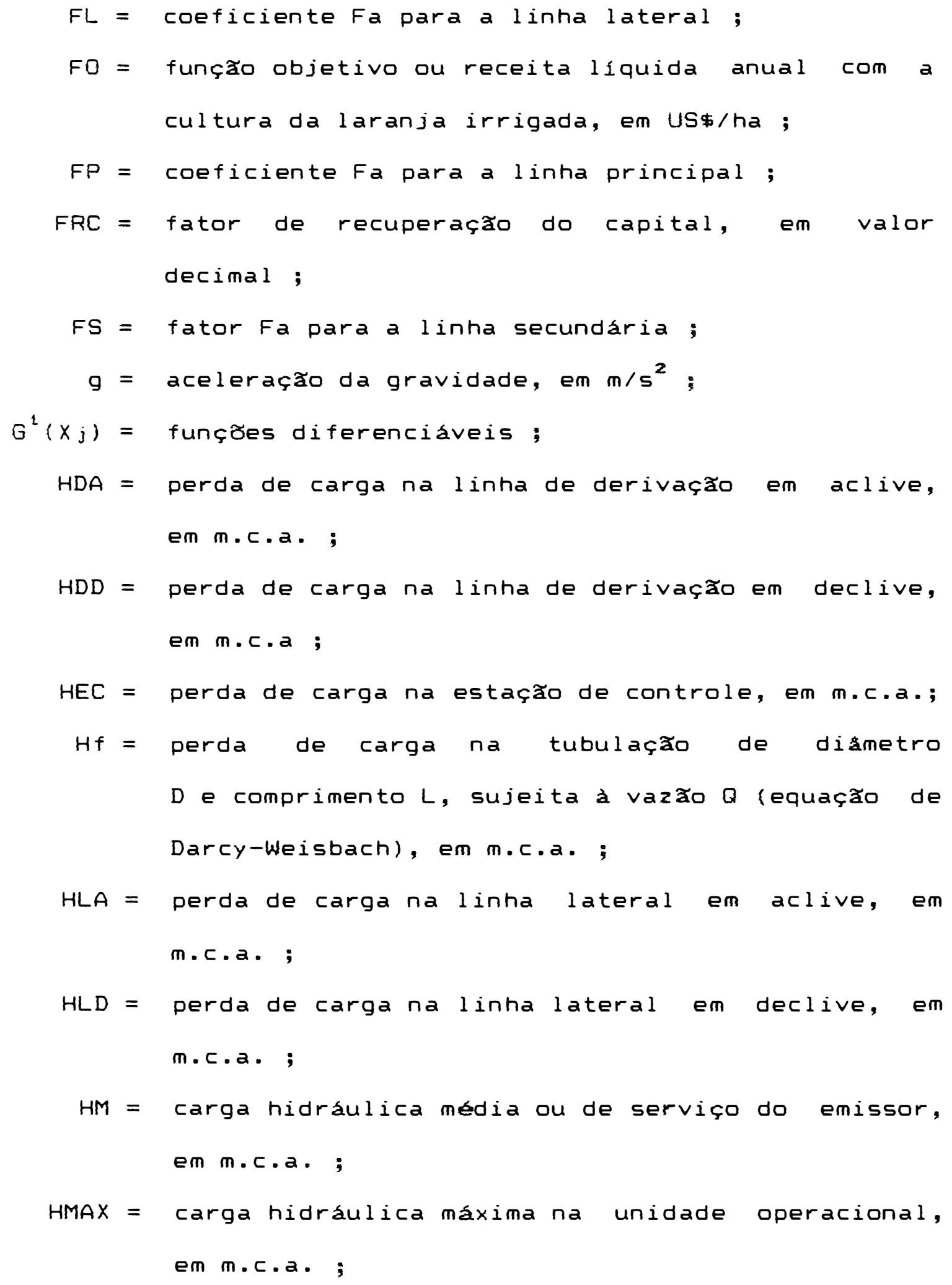




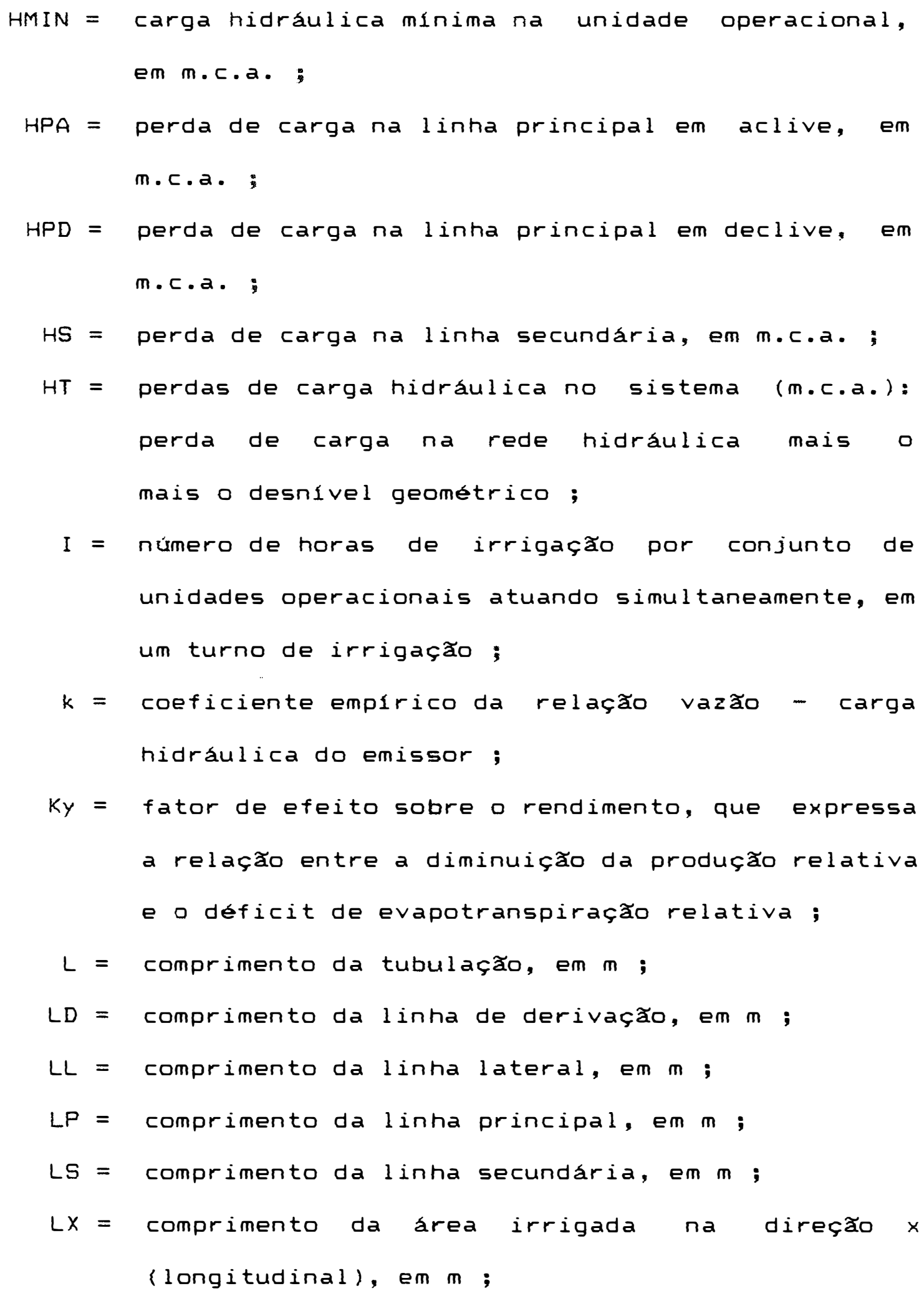




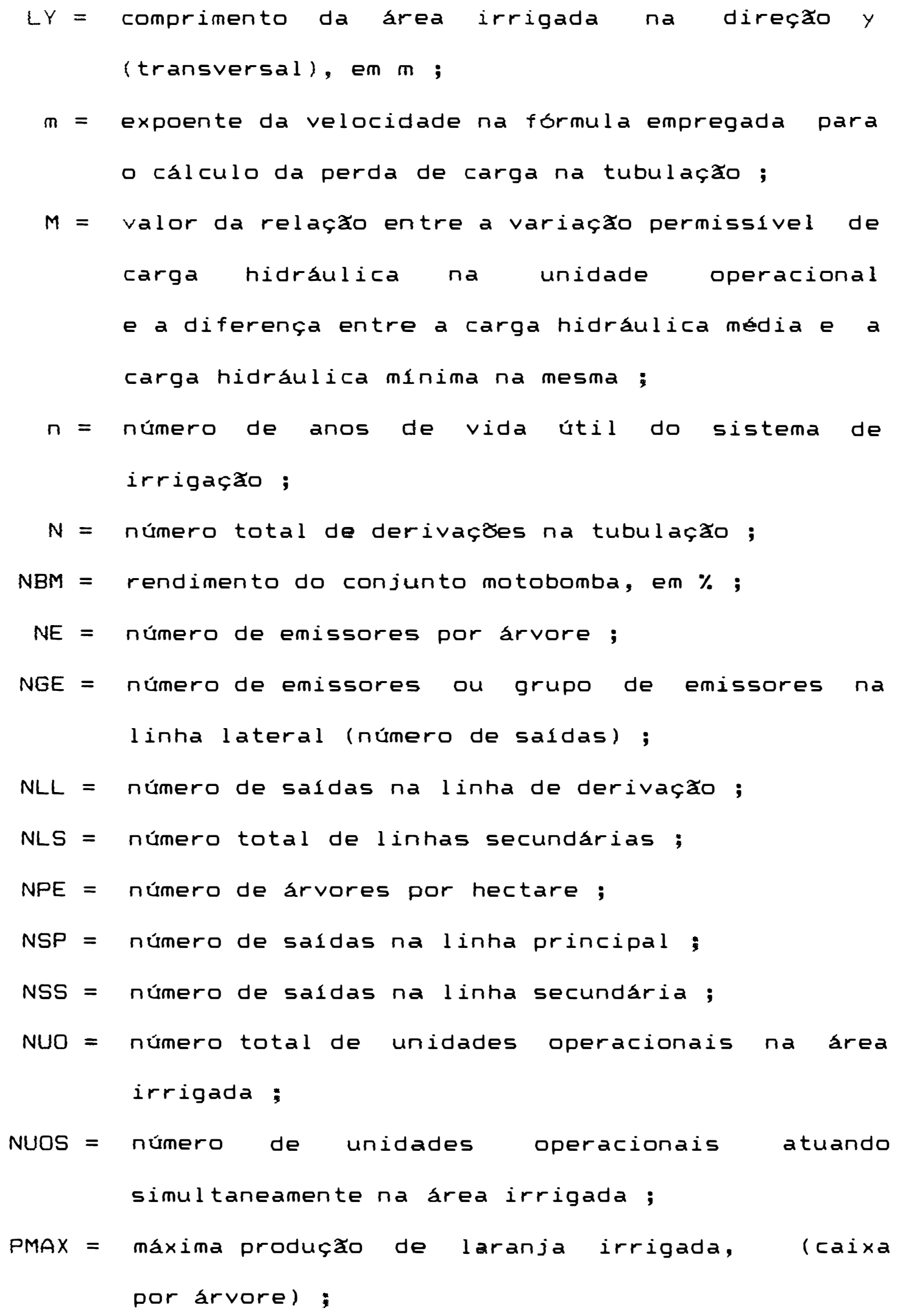




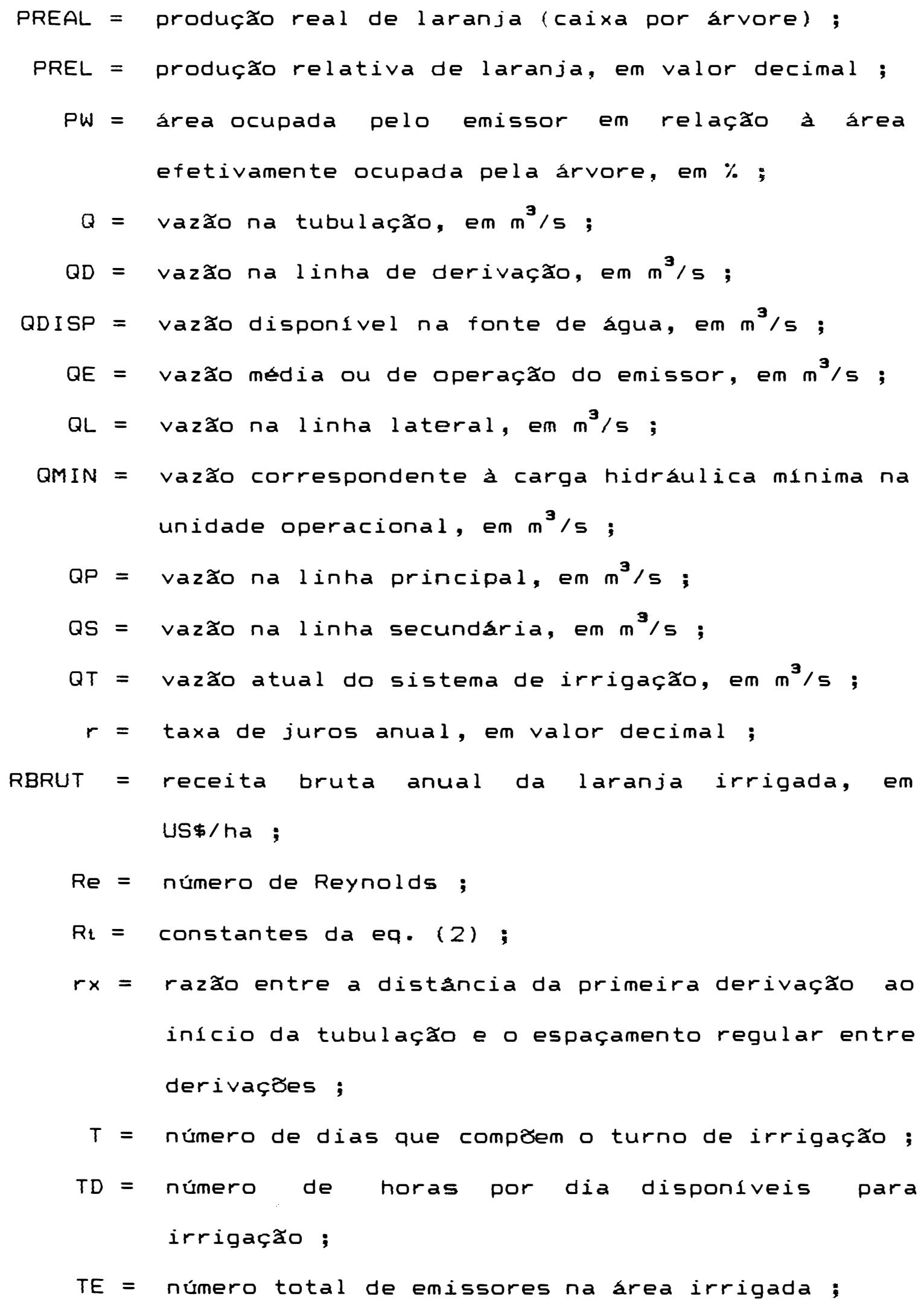


TLD = extensão total de linhas de derivação na área irrigada, em m ;

TLL = extensão total de linhas laterais na área irrigada, em m ;

TLP = extensão total de linhas principais na área irrigada, em $m$;

TLS = extensão total de linhas secundárias na área irrigada, em m ;

$T X=$ número máximo de dias que pode ter o turno de irrigação ;

UE = uniformidade de emissão, em valor decimal;

$v_{a}=$ volume de água aplicado por árvore, em mªciclo;

$V P A=$ velocidade na linha principal em aclive, em $\mathrm{m} / \mathrm{s}$;

VPD = velocidade na linha principal em declive, em $\mathrm{m} / \mathrm{s}$;

$v_{r}=$ volume de água requerido por árvore, em $\mathrm{m}^{3} / c i c l o$;

$V S=$ velocidade na linha secundária, em $\mathrm{m} / \mathrm{s}$;

$x=$ coeficiente empirico da relaçăo vazăo - carga hidráulica do emissor ;

$x_{j}=$ variáveis de decisão;

$\phi=$ maximizando (o que vai ser maximizado). 


\title{
OTIMIZAÇÃO DE SISTEMAS DE IRRIGAÇÃO LOCALIZADA UTILIZANDO PROGRAMAÇÃO NÃO-LINEAR
}

\author{
Autor: JOÃO CARLOS CURY SAAD \\ Orientador: PROF. DR. JOSE ANTONIO FRIZZONE
}

\section{RESUMO}

o objetivo deste trabalho foi desenvolver e resolver um sistema de equaçós não-lineares, adaptável ao modelo de programação matemática não-linear, visando determinar a configuração e a operação ótimas de um sistema de irrigação localizada, sob o enfoque da maximização da receita liquida obtida com a cultura irrigada. Utilizando o modelo proposto, foi realizada uma aplicação junto a cultura da laranja desenvolvida na região de Limeira, SP.

0 modelo consiste de uma função-objetivo que maximiza a receita liquida da cultura irrigada e que está sujeita a uma série de restriçoes de natureza operacional, geométrica e hidráulica. Este sistema de equações não-lineares aplica-se a áreas retangulares em nivel ou com declividade uniforme.

Os principais dados de entrada requeridos são: função de produção da cultura para o fator água, função de custo das componentes do sistema de irrigação, custo da energia elétrica, custo do produto agricola e 
variáveis de dimensionamento fpor exemplo: área total, extensăo e declividade do terreno nas direçőes $x e(y)$ : Por sua vez, os dados de saida de maior relevância săo: receita liquida anual, número total de unidades operacionais, número de unidades atuando simultaneamente, uniformidade de emissăo, e comprimento e dismetro da tubulaçåo em cada linta do sistema de irrigação.

Para solucionar o modelo proposto e realizar a análise de sensibilidade da funçăo-objetivo em relaçăo aos parámetros estabelecidos, utilizou-se o programa computacional GAMS/MINOS. Os parámetros de entrada avaliados foram: tamanho $(8,294 \mathrm{ha}$ e $23,04 \mathrm{ha})$ e formato (relaçăo comprimento - largura igual a $0,25,0,44,1$, 2,25 e 4) da área, declividade $(0,1,3$ e $5 \%$ e modelo do microaspersor em funçăo de sua vazăo 135 l/h, 56 l/h e $871 / h)$.

Os resultados obtidos foram consistentes com a conformação definida nas hipóteses básicas do modelo, o que demonstra a eficácia do sistema de equaçôs nălineares proposto. A receita liquida decresceu tanto em função do aumento da declividade, como em funçăo do uso de microaspersores de maior vazăo. 0 formato mais rentável para a área de $8,294 h a$ foi o quadrangular, enquanto que para a área de 23,04ha a maior rentabilidade correspondeu a valores de relação comprimento - largura entre 0,44 e 1. 


\title{
OPTIMIZATION OF LOCALIZED IRRIGATION SYSTEMS USING NONLINEAR PROGRAMMING
}

\author{
Author: JOAO CARLOS CURY SAAD \\ Adviser: PROF. DR. JOSE ANTONIO FRIZZONE
}

\section{SUMMARY}

The purpose of this paper was to develop a nonlinear model that provided the optimization of lay-out, design and management of localized irrigation systems, under the condition of crop irrigated profit maximization. To illustrate the capability of the model, a sensitivity analisys of the citrus orchard field net benefit was evaluated under different conditions (inputs).

The localized irrigation design model consists of an objective function that maximizes profit at the farm level, subject to appropriate geometric and hidraulic conditions. The model can be applied in rectangular shape fields, with uniform slope or in level.

The basics inputs required are: the crop-water-production function, the cost function and cost of system components, the energy cost, the price of the products, and design variables ctotal area, length and slope of the field in the $x$ and $y$ directions, the emitter discharge, number of irrigation hours per days. The mainly outputs are: net benefit, total number of subunits, number 
of subunits working simultaneously, emission uniformity, pipe diameter, pipe lenght, number of emitters in each lateral, number of laterals in a manifold, and irrigation time per set.

$$
\text { The optimization model ran on AT-486 }
$$
microcomputer using the GAMS-MINOS package and was applied in a citrus orchard field situated in Limeira, Sao Paulo, Brazil, to evaluate the net benefit under different conditions of the total area $\left(82944 \mathrm{~m}^{2}\right.$ and $\left.230400 \mathrm{~m}^{2}\right)$, slope CO, 1,3 and $5 \%$, emitter discharge $\left(9.72 E-6 \mathrm{~m}^{3} / \mathrm{s}, 1.55 \mathrm{E}-5\right.$ $\mathrm{m}^{3}$ 's and 2. 42E-5 $\mathrm{m}^{3} / \mathrm{s}$ ) and shape of the field (field width to"lenght ratio of $0.25,0.44,1,2.25$ and 4 .

The model's results were consistent with the basic assumptions. This showed the efficacy of the proposed model. The net benefit per unit area decreased as the slope increased and as the emitter discharge increased. The most profitable shape of the field was the square cfield width to lenght ratio equal 1), for the $82944 \mathrm{~m}^{2}$ area. For the $230400 \mathrm{~m}^{2}$, the field width to lenght ratio between 0.44 and 1 resulted in the best values. 


\section{INTRODUÇス̃}

A citricultura na região de Limeira, SP, é muito desenvolvida técnica e economicamente. Na busca de uma atividade cada vez mais competitiva, os citricultores frequentemente questionam a viabilidade económica da adoçăo da irrigação localizada (microaspersão e gotejamento) em seus pomares.

Como um projetista poderia definir o dimensionamento e a operação ótimos de um sistema de irrigaçăo por microaspersão, de tal forma a maximizar a receita liquida da cultura da laranja irrigada para aquela regiăo ? Como obter uma análise de sensibilidade da receita liquida da citricultura irrigada em função do tamanto e formato da área irrigada, da vazão do microaspersor e da declividade nas direçăes $x$ e y ? Como responder a estas perguntas, que poderiam estar vinculadas a outras culturas para as quais a irrigação localizada é tecnicamente compativel, constitui-se no problema de pesquisa que este trabalino procura resolver.

Os sistemas de irrigaçăo localizada
apresentam-se como uma forma conveniente e eficiente de


fornecimento de água às culturas. A possibilidade de aplicação de produtos quimicos, a pequena necessidade de mão-de-obra, o fornecimento de água somente na área efetivamente cultivada e o elevado potencial para automaçăo parcial ou total, săo alguns dos fatores que contribuem para a expansão do uso destes sistemas. Por outro lado, suas principais limitaçōes săo o risco de obstruçăo parcial ou total dos emissores e o elevado custo inicial.

a aspecto económico é cada vez mais importante no dimensionamento e operação de projetos de irrigação. Caracteriza-se como dimensionamento o processo de reunião de componentes individuais compativeis entre si que, ao se unirem, irão produzir um sistema de irrigação aplicável a uma determinada área e situação. A otimização deste dimensionamento consiste em promover este processo de agregação sob o enfoque de minimização do custo total do sistema ou de maximização da receita liquida da atividade agricola desenvolvida utilizando irrigação, respeitando-se critérios hidráulicos e restriçzes geométricas e operacionais.

A implantação de um sistema de irrigaçăo localizada, assim como dos demais métodos, envolve a escolita da configuraçăo do equipamento no campo, o dimensionamento de seus componentes (tubulaçăo, emissores, válvulas, etc.), e a definiçăo das condiçơes operacionais (por exemplo: turno de irrigaçăo). Embora seja complexa a 
definição de todos estes aspectos, é possivel desenvolver modelos de otimizaçăo, do tipo năo-linear, que realizem tal processo de forma eficiente, ajudando o projetista na escoliha da melhor solução. Há no mercado programas computacionais capazes de solucionar tais modelos.

As principais variáveis a serem definidas pelos modelos de otimização dos sistemas de irrigação localizada săo: diâmetro e comprimento das tubulações, número de emissores ou de grupos de emissores em cada linha lateral, número de linhas laterais ligadas em uma linha de derivação, número total de unidades operacionais, número de unidades operacionais atuando simultaneamente, turno de irrigação e tempo de irrigação por grupo de unidade operacional em funcionamento. A definição destes tópicos é afetada por outras variáveis de projeto, tais como: dimensơes e declividade da área, vazão do microaspersor e custos da tubulaçăo, energia e do produto agricola.

A resolução dos modelos de programação não-linear por meio de programas computacionais especlficos, possibilita a análise de sensibilidade da receita liquida de uma determinada cultura irrigada em relação às variáveis envolvidas no projeto, resultando numa série de recomendaçōes que facilitarão o processo de tomada de decisăo, o qual é fundamental na fase de elaboração dos projetos de irrigação localizada. 
Os objetivos deste trabalino são:

- desenvolver e resolver um sistema de equaçð̋es não-lineares, adaptável ao modelo de programação matemática năo-linear, visando determinar a configuraçăo, o dimensionamento e a operação ótimos de um sistema de irrigação localizada, sob o enfoque da maximização da receita liquida obtida com a cultura irrigada;

- Utilizando o modelo proposto, analisar a sensibilidade da função-objetivo em relação às variáveis envolvidas no projeto, tais como: declividade, tamanho e relação largura-comprimento da área em estudo, e microaspersor (em função de sua vazão de operação). Será utilizada como exemplo a irrigaçăo por microaspersão aplicada à cultura da laranja, desenvolvida na região de Limeira, SP. 
5.

\section{REVISÃO DE LITERATURA}

\subsection{Aspectos gerais}

Os sistemas de irrigação localizada caracterizam-se pela aplicaçă de água a uma parte, apenas, do volume efetivamente ocupado pelo sistema radicular das plantas cultivadas. A configuraçăo tipica do sistema é composta pela estaçăo de captação e bombeamento, estação de controle, linha(s) principal(is), secundária(s), de derivaçăo e laterais (as quais contêm os emissores), além dos acessórios (válvulas, registros e reguladores de vazão e presså).

A irrigação localizada foi inicialmente adotada em culturas altamente produtivas e em pomares, situados em regibes onde a água era escassa e cara. Atualmente, tal sistema é utilizado numa ampla relação de culturas e, também, em áreas onde o recurso água não é fator limitante (HOLZAPFEL et al., 1990).

A expansão do uso da irrigação localizada deve-se, entre outros fatores, às suas vantagens potenciais que, segundo Bucks et at. (1982), são: maior eficiéncia no uso da água; possibilidade de obtenção do uma maior 
produtividade; pode ser utilizado com água salina ou em solos salinos; maior eficiencia na adubação; limita o crescimento de plantas daninhas; pequena necessidade de mão-de-obra; não interfere nas praticas culturais; e menor requerimento de energia em relação a outros sistemas pressurizados de irrigação. As principais limitaçơes, por sua vez, são: possibilidade de obstrução total ou parcial dos emissores (principalmente os gotejadores); 0 sistema radicular concentra-se no volume de solo úmido, ocasionando, em alguns casos, uma diminuição da estabilidade das plantas; acúmulo de sal na periferia do bulbo molhado; e elevado custo inicial.

Para HOLZAPFEL et al. (1990), a principal desvantagem dos sistemas de irrigação por gotejamento é o seu elevado custo inicial, o qual se deve, basicamente, ao custo do conjunto de tubos, acessórios e emissores.

\subsection{Otimização do dimensionamento}

$$
\text { Os sistemas fixos de irrigação pressurizada }
$$

englobam os componentes: equipamento, energia e mão-de-obra (ORON, 1982). Na irrigação localizada, entende-se por equipamento o conjunto composto pela rede de tubulação, emissores e acessórios, além das estaçžes de bombeamento e de controle. Nestes sistemas a rede hidráulica é fixa e está distribuida em toda a area a ser irrigada, o que evidencia a grande participaçăo do componente equipamento 
no custo inicial dos mesmos.

$$
\text { Para PLEBAN \& AMIR (1981), o custo com }
$$

equipamento e o custo com energia săo determinantes no dimensionamento de redes de distribuiçăo de água, sendo que estes fatores 5 ăo, de certa forma, antagónicos, uma vez que tubos de diåmetros menores apresentam menor custo, porém, resultam em maior perda de carga e, consequentemente, em maior consumo de energia. De maneira oposta, tubos de maior diámetro fornecem menor perda de carga e menor consumo de energia, todavia, apresentam maior custo. Pode-se, entå, deduzir, que uma forma de minimizar o custo dos sistemas fixos de irrigaçăo pressurizada consiste em otimizar sua rede hidráulica e a energia por ela consumida.

o fato da tubulação ser fixa nestes sistemas, possibilita o uso de muitas combinaçóes envolvendo diåmetros distintos e diferentes comprimentos, nos diversos trechos da rede hidráulica. En decorrencia disto, há possibilidade de ocorrencia de várias configurações hidráulicas do sistema, dentre as quais ocorre a de menor custo.

BERNARDO (1986) cita tres procedimentos para - dimensionamento económico de tubulaçơes de irrigaçăo: o metodo das tentativas, o das tentativas simplificado e o de Keller. O Método das Tentativas consiste em se determinar o custo fixo anual por metro de tubulação, para todos os diåmetros possiveis de serem utilizados, e o custo anual 
relativo à energia consumida na forma de perda de carga, em cada segmento da rede hidráulica. A combinação de diåmetros que apresentar o menor custo total será a solução económica. Por sua vez, o método das tentativas simplificado baseia-se na determinaçăo do custo total anual por 100m de tubulação de diversos diåmetros, para cada vazão que ocorrerá nos diferentes segmentos. A solução económica é encontrada pelo processo de tentativas, à semelhança do procedimento anterior.

KELLER (1965) propós um método que leva seu nome e que se caracteriza por ser mais rápido, simples e eficiente que os processos por tentativas. 0 método consiste na confeç̧ăo de um nomograma que apresenta no eixo das ordenadas a perda de carga, e no eixo das abcissas, a vazăo. Traçam-se, entăo, as retas que relacionam a perda de carga com a vazão, para os diversos diåmetros. Entre as retas referentes a diåmetros sucessivos, insere-se uma linha tracejada que indica a diferença de perda de carga entre os mesmos, nas várias vazbes. Uma vez confeccionado o nomograma, pode-se selecionar o diåmetro mais económico para qualquer vazå.

Os procedimentos de identificação da solução ótima económica descritos anteriormente, são muito trabalhosos e fornecem poucas informaçðes adicionais (nåo trazem subsidios para a análise de sensibilidade dos recursos utilizados). 
2.3. Utilização de técnicas de Pesquisa Operacional na otimização dos sistemas pressurizados de irrigação

2.3.1. Utilização da Programação Linear

Com a finalidade de se proceder a uma análise mais eficaz, eficiente e completa do problema de otimização de redes hidráulicas de sistemas fixos de irrigação pressurizada, partiu-se para a utilização de técnicas de Pesquisa Operacional.

A Programação Linear é, atualmente, a técnica de Pesquisa Operacional mais utilizada nos problemas de otimizaçăo, em decorrância de sua versatilidade e do fato de aplicar fundamentos matemáticos pouco sofisticados, ou seja, a análise e resolução de sistemas de equaçơes lineares (LANZER, 1988).

Inicialmente, a Programaçăo Linear foi adotada na otimização de redes de distribuição de água. KARMELI et al. (1968) sabendo que, em uma configuração definida de distribuição de água, a vazão em cada trecho da rede é conhecida e, também, que a perda de carga e o custo de um determinado tubo são linearmente proporcionais ao seu comprimento, estabeleceram um modelo de programação linear visando à otimização do sistema. Desta forma, as variáveis de decisão do modelo eram os diametros selecionados previamente e os comprimentos que eles assumiriam na rede 
hidráulica. Este modelo aplicável a redes de distribuiçăo que apresentam uma única fonte de fornecimento de água.

A extensão do modelo anterior para o caso de sistemas de distribuição com demanda variável com o tempo e a consideração do custo da energia dissipada na forma de perda de carga, foi realizada por CASE \& WHITE (1972). Por sua vez, a solução de problemas envolvendo redes de distribuição de água tendo várias fontes de fornecimento de água, utilizando a Programaçăo Linear, foi desenvolvida por GUPTA et al. (1972), com base na analogia a teoria de redes elétricas.

Utilizando o conceito de caminho critico, BHAVE (1979) desenvolveu um método de seleção de grupos ótimos de diâmetros de tubo, visando, desta forma, diminuir - tamanto dos modelos de Programação Linear utilizados na otimizaçăo de redes ramificadas de distribuiçăo de água.

Usando a Programação Linear, PLEBAN \& AMIR (1981) desenvolveram um programa computacional iterativo visando otimizar o dimensionamento de redes hidráulicas de sistemas de irrigação pressurizados, de tal forma que a combinação económica ótima entre os fatores custo do equipamento e custo da energia seja encontrada.

ORON \& KARMEL I (1981) apresentaram um modelo de Programação Linear visando à otimização da rede hidráulica de sistemas fixos pressurizados laspersão, microaspersão e gotejamento). A função objetivo era de 
minimização do custo dos componentes do sistema, quais sejam, os aspersores ou emissores lna irrigaçăo localizada), toda a rede de tubulaçăo e os acessorios (válvulas e reguladores de pressão). As restrições relacionavam-se com a geometria da área, pressão requerida ao longo do sistema e uniformidade de distribuição da água. o modelo năo considerou o custo da energia dissipada na forma de perda de carga. Dentro desta mesma linha, BENAMI \& OFEN (1984) apresentaram a Programação Linear como uma técnica de otimização da rede hidráulica de sistemas de irrigação pressurizados, com especial atenção para as linhas principal e secundária.

o uso da Programação Linear na minimização do custo da rede hidráulica de sistemas de irrigaçăo tem alguns aspectos vantajosos, dentre os quais se destacam a facilidade de utilização, a riqueza de informaçốes adicionais (análise de sensibilidade) e o fato de trabalhar com o diámetro do tubo na forma de variável discreta (diåmetros comercialmente disponiveis). Porém, a exigência de que a configuração do sistema de irrigação no campo esteja previamente definida é uma séria limitaçăo, posto que o processo de otimização fica restrito à escolha da combinação mais económica envolvendo diâmetro e comprimento do tubo.

o interesse em otimizar a configuraçăo, o dimensionamento e a operaçăo dos sistemas fixos de 
12.

irrigação pressurizada, fez com que os pesquisadores buscassem novas técnicas, dentre as quais encontra-se a programação não-linear.

\subsubsection{Utilizaçăo da Programaçăo Năo-Linear}

CHIANG (1982) considera a Programação Linear um progresso em relação ao contexto da otimização clássica, uma vez que as restriçठৈes podem entrar no problema na forma de desigualdades e, assim, faz-se explicitamente a introdução das condiçơses de năo-negatividade no mesmo. Entretanto, a necessidade de confinar a funçăo-objetivo e as restriçðes ao modelo linear pode, às vezes, ser uma limitação significativa. Desta forma, um progresso adicional seria uma estrutura de otimização que pudesse trabalihar com funçð̋es-objetivo e restriçסes em forma de desigualdades que não sejam lineares, sendo que tal estrutura é encontrada na programaçăo năo-linear. o autor afirma, ainda, que a programação não-linear difere da programação linear em pelo menos cinco aspectos, alguns deles relacionados entre si, ou seja: o campo de escolita abrange toda a região possivel, não somente o conjunto de seus pontos extremos; o número de restriçðes que são exatamente satisfeitas le, também, as condiçరes de não-negatividade) pode ser igual ao número de variáveis de escoliha; um deslocamento contínuo em uma direção uniforme pode năo conduzir a valores continuamente crescentes (ou 
decrescentes) da funçăo-objetivo; a região possivel pode não ser um conjunto convexo; um ótimo local pode não ser um ótimo global.

Segundo GIL et et. (1981), os modelos de programaçăo năo-linear podem ser resolvidos utilizando os programas computacionais já desenvolvidos e disponiveis no mercado. Com a utilização destes modelos, a otimização dos sistemas de irrigaçăo passou a abranger, também, a escolna da melhor configuraçăo do equipamento na área a ser irrigada, bem como a melhor condiçăo operacional (por exemplo, a definiçăo do número de unidades operacionais operando simultaneamente).

ORON \& KARMELI (1979) descreveram os sistemas de distribuição de agua por meio de equaçőes não lineares e de variáveis continuas e discretas. Para solucionar este modelo não-linear, os autores utilizaram a Programação Geométrica Generalizada e a técnica do "Branch and Bound". O modelo foi aplicado no dimensionamento de um sistema de aspersão $f i \times o$, tendo como variáveis a serem definidas: os diametros de tubo e os comprimentos associados, o número de saidas nas linhas laterais e de derivação (determinam o tamanho e o número de unidades operacionais na área), e a capacidade de bombeamento.

Trabalhando, desta vez, com sistemas fixos de irrigação pressurizada, KARMELI \& ORON (1979) utilizaram a Programação Geométrica Generalizada e a técnica do 
"Branch and Bound" na minimizaçăo da funçăo de custo do projeto, a qual envolve os componentes equipamento, energia e mão-de-obra. As restriçơes visavam limitar as perdas hidráulicas, assegurar que determinados limites operacionais pré-estabelecidos fossem respeitados e, também, possibilitar a determinaçăo do número de unidades operacionais no campo (a configuração do sistema).

ORON (1982), à semel hança de ORON \& KARMELI (1979), sugere que as áreas que serão irrigadas por meio de sistemas fixos de irrigaçăo pressurizada devam ser divididas em unidades operacionais, as quais săo compostas pelas linhas auxiliar, de derivaçăo e laterais (contem os emissores), além dos acessórios, tais como válvulas e tês.

$$
\text { Para GOEHRING (1976) e ORON \& WALKER }
$$

(1981), a divisăo do projeto da área a ser irrigada em unidades operacionais traz aspectos vantajosos, tais como: permite irrigar partes da área ao longo do tempo, o que confere maior flexibilidade a irrigaçăo, posto que nem sempre se dispße de água suficiente para suprir todo o projeto simultameamente; geralmente se obtén uma maior uniformidade de emissão, uma vez que as diferenças de nível săo menores dentro de cada unidade operacional; permite o uso de tubos de menor diámetro, reduzindo, assim, o custo inicial do sistema; a automaçăo torna-se mais economica. BUSTOS (1988) destaca, também, a vantagem de possibilitar o aumento do número de emissores por planta durante os 
estádios de desenvolvimento, principalmente, de plantas frutiferas. Porém, o maior problema associado à subdivisão da área a ser irrigada em unidades operacionais é a dificuldade em selecionar as dimensores otimas das mesmas (ORON \& KARMELI, 1979 ).

A largura da unidade operacional (direção das linhas laterais) dos sistemas de irrigaçăo localizada é governada pelo espaçamento e vazão dos emissores, pela economia devido ao uso de linhas laterais de menor diåmetro, pelas variaç⿸̋es de pressão permissiveis, pelo comprimento das linhas e número de unidades operacionais operando simultaneamente, além da topografia. De forma similar, o comprimento da unidade operacional (direção da linha de derivaçăol depende do espaçamento e vazão das linhas laterais, economia devido ao uso de tubos de menor diåmetro, variaçðes de pressão permissiveis, número de linhas laterais e número de unidades operacionais em operação, bem como da topografia da área (KELLER \& BL IESNER, 1990) .

Para estes autores, ainda, a configuraçăo final dos sistemas de irrigaçăo localizada deve satisfazer a uma série de objetivos de dimensionamento, os quais nem sempre săo compativeis entre si. A configuração ideal deve ter: um número minimo de unidades operacionais e pontos de controle de vazão ou de pressão; uma configuração conveniente e economica da linha principal, para atender às 
unidades operacionais; a mesma vazão total em cada grupo de unidades operacionais que atuam simultaneamente; configuraçôes da unidade operacional uniformes na forma e no tamanho; linhas laterais de diámetro único variando de $12 \mathrm{~mm}$ a, no máximo, $20 \mathrm{~mm}$; linhas de derivação com vários diåmetros, sendo de $100 \mathrm{~mm}$ o valor máximo; variações de pressão que năo excedam o valor permissivel estabelecido, a fim de que se tenta a uniformidade de emissăo desejada.

$$
\text { ORON \& WALKER (1981) utilizaram um modelo de }
$$

programação năo-linear, inteira-mista, o qual foi solucionado pela Programação Geométrica e pela técnica do "Branch and Bound", na minimizaçăo do custo de sistemas fixos de irrigação pressurizada. Os autores aplicaram o modelo a um projeto de aspersão em citros e analisaram a sensibilidade da funçăo custo total do projeto em relação às variáveis geometria da área, uso consuntivo, pressão disponivel na fonte de água e vazão do aspersor, possibilitando, assim, identificar a configuraçăo ótima do sistema e orientar a respeito de como melhora-la, para as condiçớes verificadas no estudo. Eles concluiram que: năo houve diferença significativa entre a soluçăo otima continua e a ótima inteira-mista; o custo do sistema de irrigação por unidade de área acompantia o aumento da área total; o formato de área mais económico é o quadrangular, posto que o custo minimo encontra-se na faixa de relação comprimento-largura de 0,4 a 1,25; utilizando o formato 
mais economico, verificou-se que o uso consuntivo afeta o custo do sistema de forma crescente e linear; o aumento conjunto da pressăo e vazão do aspersor está associado a um significativo acréscimo no custo total; a aumento da pressăo na fonte de água é linearmente acompanhado por um acréscimo no custo do sistema; o número de linhas secundárias, paralelas às linhas de plantas, aumenta parabolicamente com a relaçăo comprimento-largura, para todos os tamanhos de área analisados; o número de unidades operacionais ao longo da largura da área diminui hiperbolicamente com a relação comprimento-largura; o número de unidades operacionais atuando simultaneamente aumenta com a diminuição da pressăo disponivel na fonte de água, mas aumenta não linearmente com os acréscimos no uso consuntivo.

ORON (1982) comparou tamanhos distintos de unidades operacionais de sistemas fixos de irrigação pressurizada, para uma mesma área total, tendo encontrado grandes variaçós na porcentagem relativa das linhas de derivaçăo, auxiliar, secundária e principal, o que, evidentemente, afeta em menor ou maior escala o custo do sistema. Para uma área de $180 L^{2}$, onde $L$ é a unidade de comprimento, adotou-se quatro configuraçóes de unidades operacionais, tendo-se encontrado variaçбes no comprimento, expresso como porcentagem da extensão total da tubulação (excluindo as linhas laterais), de 47,6 a $62,1 \%$ nas linhas 
18.

de derivação, de 11,6 a $23,8 \%$ nas linhas auxiliares, de 20,1 a $24,1 \%$ nas linhas secundárias e de 4,3 a 4,7\% nas linhas principais.

Ao longo desta revisão, verifica-se uma evolução no sentido de estender o processo de otimização a todos os aspectos inerentes a um sistema fixo de irrigação pressurizada, ou seja, inicialmente, atendeu-se apenas ao dimensionamento, passando-se, então, à configuração e ao manejo. Porém, em todos os trabalhos até aqui analisados, o objetivo era a minimização da função custo do sistema, o que não garante que a solução encontrada seja aquela que maximiza a receita liquida da cultura irrigada, sendo que o lucro máximo é, verdadeiramente, o objetivo final de uma empresa rural.

ALLEN \& BROCKWAY (1984) recomendam a receita liquida como o principal critério a ser observado na configuraçăo, dimensionamento e operação de sistemas de irrigação. Foi nesta linha, que HOLZAPFEL et al.(1990) apresentaram um modelo não-linear de otimização do dimensionamento e operação de sistemas de irrigaçăo por gotejamento. As variáveis de decisão eram: comprimento e diåmetro da tubulação, número de emissores em cada linha lateral, número de linhas laterais ligadas à linha de derivação, número total de unidades operacionais, número de unidades operacionais atuando simultaneamente, tempo de irrigação por grupo e vazão do emissor. 0 modelo 
desenvolvido foi resolvido utilizando o pacote computacional GAMS/MINOS e aplica-se a áreas em nivel.

Visando ilustrar a potencialidade do modelo, estes autores fizeram uma aplicação do mesmo no dimensionamento de um pomar de pera. Os resultados indicaram que o custo do sistema e de sua operação foi pequeno quando comparado à receita obtida. Isto se deve, principalmente, ao fato da produtividade marginal da água ser maior que o custo marginal da tubulação e operação. A análise de sensibilidade dos resultados revelou que um aumento de $50 \%$ no custo dos tubos reduz o lucro em $0,7 \%$. Por sua vez, diminuindo-se o preço do produto para $1 / 4$ do seu valor inicial ocorre uma redução de $77,6 \%$ no lucro e, finalmente, um aumento de $100 \%$ no custo da energia reduz o valor da funçăo-objetivo em $1,4 \%$. 0 modelo mostrou, também, que ao se maximizar lucro, a rede hidráulica obtida não forneceu o custo minimo e que o diåmetro da linha lateral $(16,8 \mathrm{~mm})$ foi maior que o menor diåmetro comercialmente disponivel $(12,7 \mathrm{~mm})$.

o diåmetro das linhas laterais obtido a partir de modelos que minimizam custo, é sempre o menor valor disponivel no mercado (GOEHRING, 1976 ; ORON, 1982 e BUSTOS, 1988). Portanto, o modelo apresentado por HOLZAPFEL et al. (1990) constatou que os resultados năo produzem custo minimo do sistema quando a receita marginal é maior que o custo marginal. 


\section{MATERIAL E METODOS}

\subsection{Hipóteses do modelo}

0 modelo assume as seguintes hipóteses

básicas:

- a área deve ser retangular;

- o gradiente de declive da área irrigada deve ser uniforme tanto na longitudinal como na transversal. O sentido do gradiente na longitudinal é da esquerda para a direita, enquanto na transversal é de cima para baixo;

- as estações de bombeamento e de controle devem situar-se na metade do comprimento da área (longitudinal) ;

- as linhas laterais são de polietileno e as demais de PUC;

- nas tubulações com múltiplas saidas a razăo entre a distancia do inicio da tubulaçăo até a primeira derivaçăo e o espaçamento regular entre derivaçōes é igual a 0,5 ; 
- deve-se ter, no minimo, uma unidade operacional atuando em cada linha secundária, durante todo - periodo efetivo de irrigação ;

- no infcio das unidades operacionais há reguladores de pressão ou de vazåo ;

- o número de unidades operacionais deve ser igual ou múltiplo do número de unidades que estão atuando simultaneamente;

- a razåo entre o número total de unidades operacionais e o número de linhas secundárias deve ser um número par ;

- a razăo entre o número de unidades operacionais atuando simultaneamente e o número de linhas secundárias deve ser um número inteiro;

- a largura e o comprimento da área irrigada devem ser múltiplos do espaçamento entre grupos de emissores na linha lateral e do espaçamento entre linhas laterais;

- a unidade operacional e composta pelo regulador de pressão ou de vazão, linha de derivação, linhas laterais e emissores, tendo como configuraçăo padrão aquela representada na figura 1 ;

- as conformaçós assumidas pelo modelo obedecem a lógica observada nas figuras 2 e 3. 


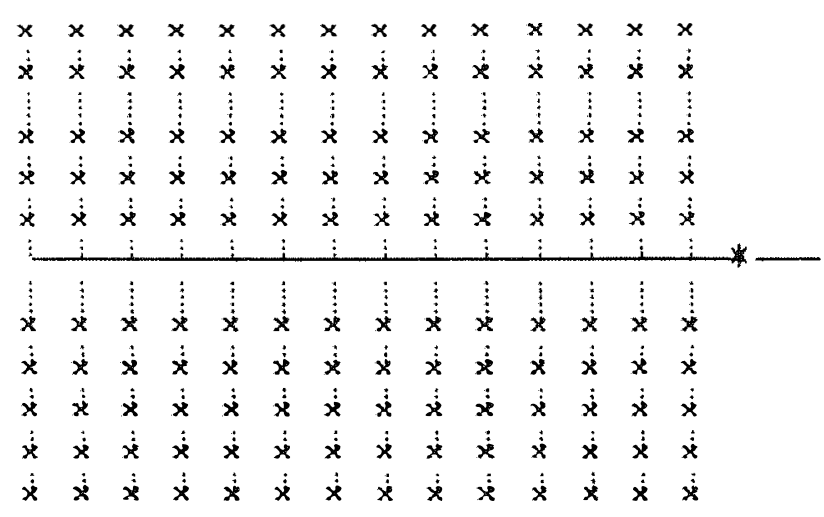

............ Iinha lateral com microaspersores

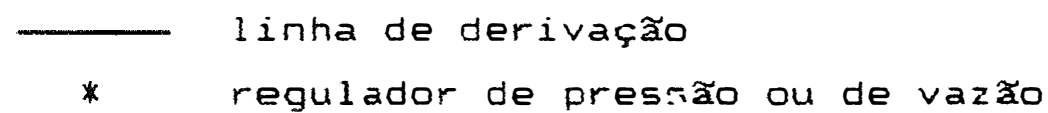

Figura 1 - Representação esquemática de uma unidade operacional

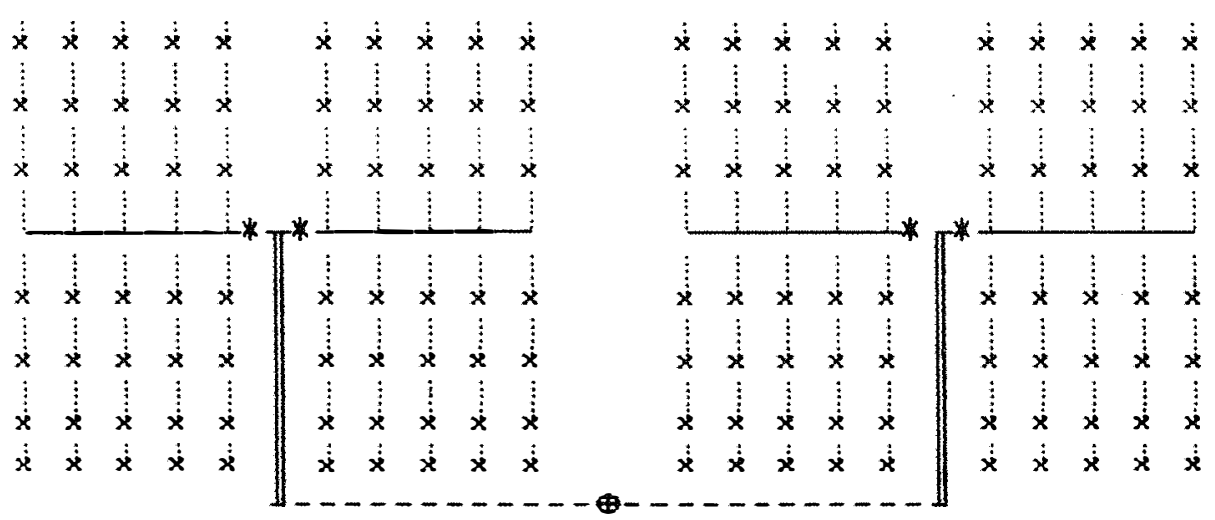

* estaçães de bombeamento e de controle

* regulador de pressão ou de vazão

......... Iinha lateral com microaspersores

- linha de derivação

- linha secundária

--- lintia principal

Figura 2 - Exemplo de configuração gerada pelo modelo, com 4 unidades operacionais e 2 inhas secundarias. 
23.

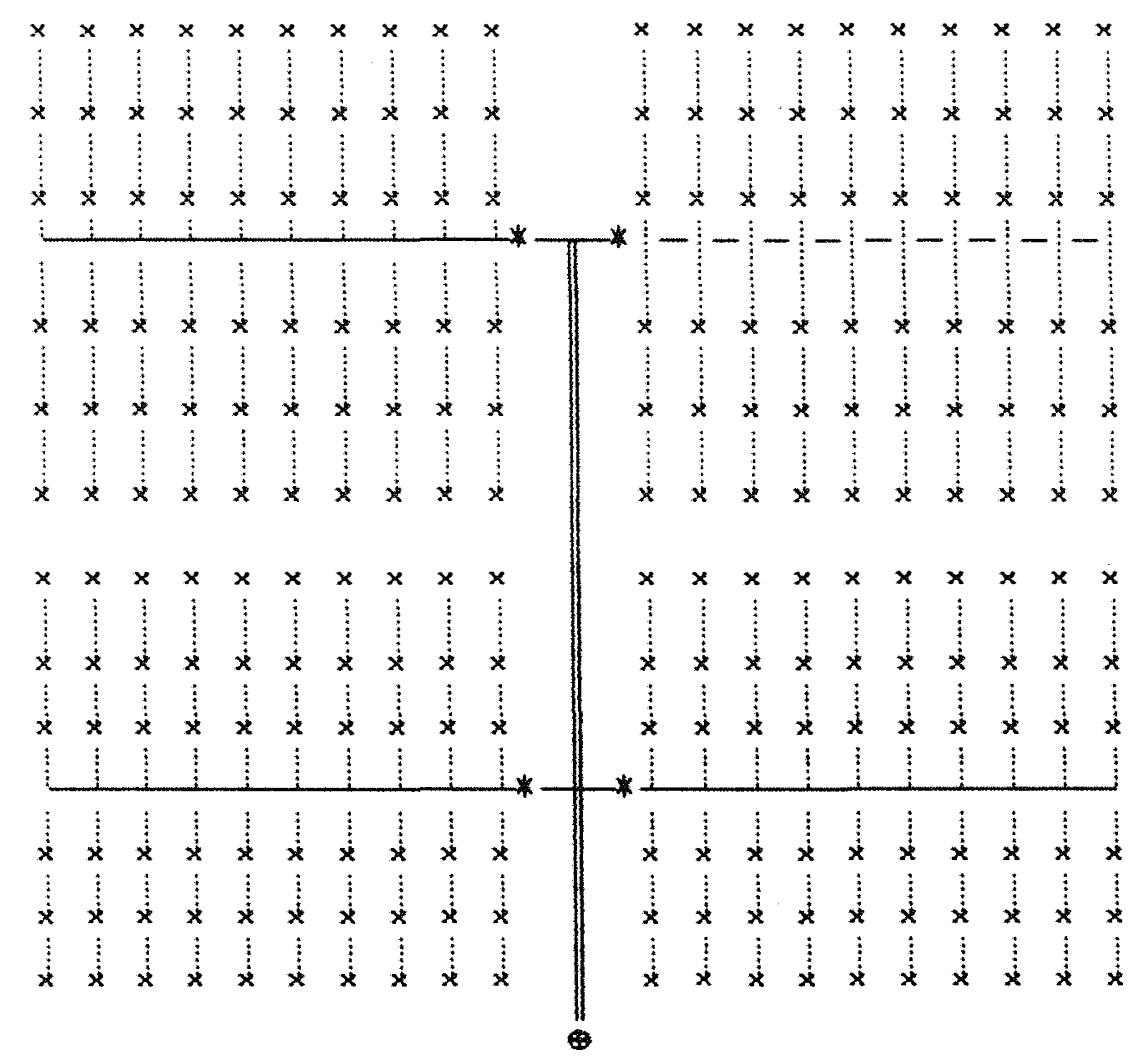

\footnotetext{
* estaçóes de bombeamento e de controle

* regulador de pressão ou de vazão

.......... linha lateral com microaspersores

- linha de derivaçăo

= linha secundária
}
Figura 3 - Exemplo de configuraçăo com quatro unidades operacionais e uma linha secundária.


3.2. Formulaçăo matematica do problema de maximizaçăo na programaçăo năo-1i near

o problema de maximização na programação não-linear apresenta o seguinte formato geral:

$\begin{array}{ll}\text { Maximizar } & \phi=B\left(x_{1}, x_{2}, \ldots, X_{v}\right) \\ \text { sujeita a } & G^{t}\left(x_{1}, x_{2}, \ldots, x_{v}\right) \leq R_{t} \\ & C o m \quad t=1,2, \ldots, u \\ \text { e } & x_{j} \geq 0 \quad(j=1,2, \ldots, v)\end{array}$

sendo que

$\phi$ - Simbolo geral para o maximizando ( o que vai ser $\operatorname{maximizadol}$;

Xj - variáveis de decisão;

Ri - constantes;

$B\left(x_{j}\right)$ - funçßes diferenciáveis;

$G^{t}\left(X_{j}\right)$ - funçð̋s diferenciáveis.

Um problema de programação não-linear é composto por uma funçăo-objetivo (eq. 1), um conjunto de "u" restriçశes (eq. 2) e um conjunto de condiçశes de năo-negatividade (eq. 3) para as "v" variáveis de decisão. o modelo desenvolvido neste trabaliho apresenta 67 linhas e 59 colunas, com 216 valores não nulos. O número de variáveis de decisão é igual a 59. 


\subsection{Função-objetivo}

A função-objetivo do modelo consiste na maximização da receita liquida anual (FO), dada por:

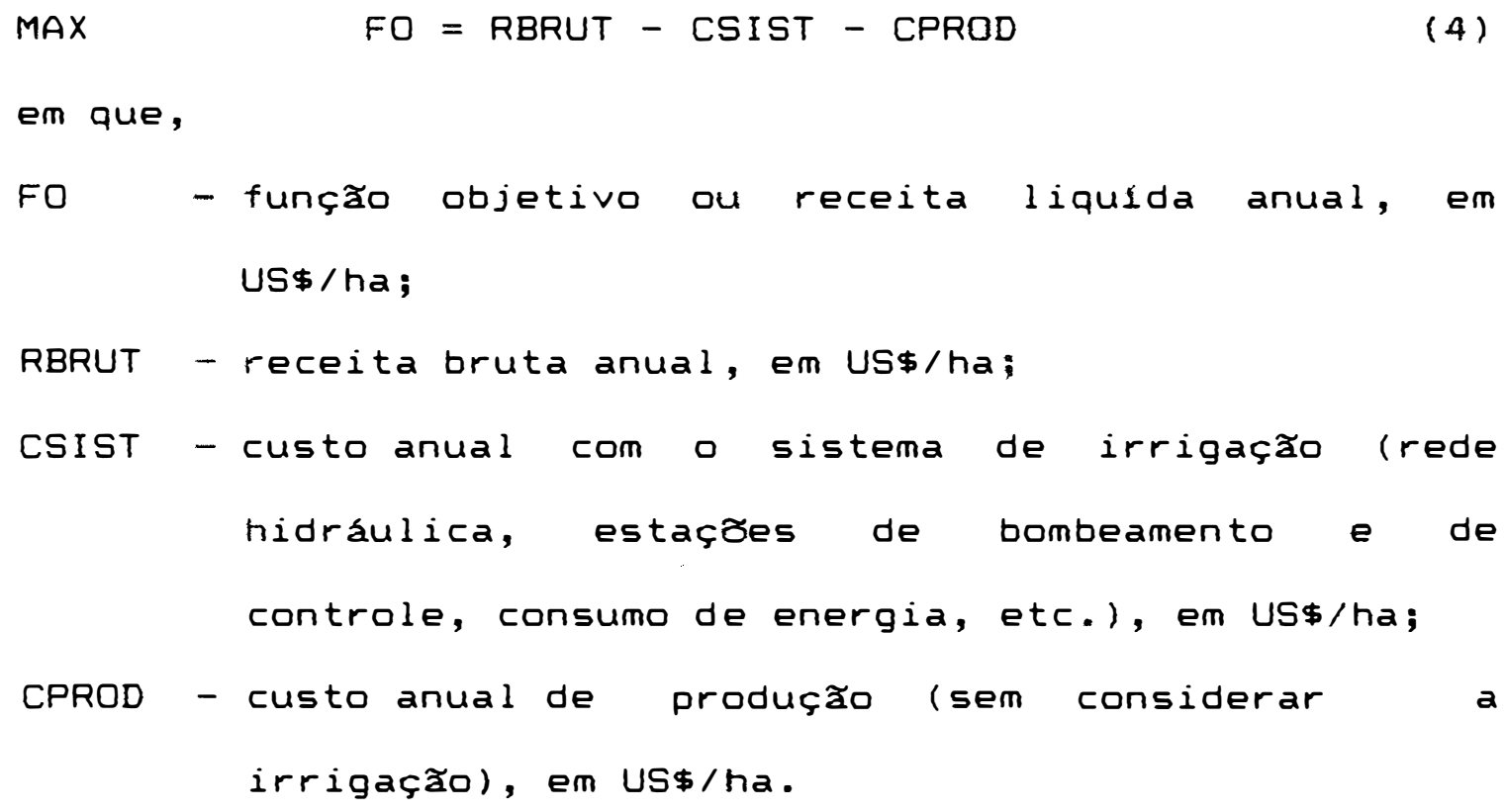

3.3.1. Receita bruta

A receita bruta anual (RBRUT) é dada por:

RBRUT $=C X L \cdot P M A X \cdot N P E \cdot P R E L$

sendo,

CXL - preço da caixa de laranja, em US\$;

PMAX - máxima produção de laranja irrigada (caixa por árvore) ;

NPE - número de árvores por ha;

PREL - produção relativa, em valor decimal. E a relaçăo entre a produção real (PREAL) e a produção máxima (PMAX) 
A relação entre a diminuiçăo da produçăo relativa e o déficit de evapotranspiraçăo relativa é dada pelo fator de efeito sobre o rendimento (Ky), obtido empiricamente (DOORENBOS \& KASSAM, 1979). Desta forma:

$$
1-(P R E A L / P M A X)=K y \cdot[1-(E T a / E T M A X)]
$$

em que,

ETa - evapotranspiração real (atual), em $\mathrm{m} / \mathrm{ciclo}$;

ETMAX - evapotranspiração máxima (potencial), em m/ciclo.

Para estes autores, o valor de Ky para os citros varia de 0,8 a 1,1. Neste estudo utilizou-se Ky igual a 1,1090 :

$$
(\text { PREAL/PMAX })=(E T A / E T M A X)=\text { PREL }
$$

Supondo que a área sombreada corresponda à área disponível para cada árvore (EE.EL), o volume de água requerido durante o ciclo será dado por:

$$
V_{r}=(E T a \cdot E E \cdot E L) / U E
$$

sendo,

Vr - volume de água requerido por árvore durante o ciclo, em $m^{3}$;

EE - espaçamento entre emissores ou grupo de emissores na linha lateral (espaçamento entre árvores), em m ;

EL - espaçamento entre linhas laterais ou entre fileiras de árvores, en $m$; 
UE - uniformidade de emissão, em valor decimal.

Por sua vez, o volume de água aplicado por árvore durante o ciclo é dado por:

$$
V a=3600 .(N E \cdot Q E \cdot I \cdot D I) / T
$$

em que,

Va - volume de água aplicado por árvore durante o ciclo, em $m^{3}$;

NE - número de emissores por árvore;

QE - vazão do emissor correspondente à carga hidráulica média (ou de operação) na unidade operacional, em $m^{3} / 5$;

I - número de horas de irrigação por conjunto de unidades operacionais atuando simultaneamente, em um turno de irrigação;

DI - número de dias com irrigação durante o ciclo;

T - número de dias que compaem o turno de irrigação.

I gualando $\mathrm{Vr}$ com Va, tem-se:

$E T a=3600 .(U E \cdot N E \cdot Q E \cdot I \cdot D I) /(T \cdot E E \cdot E L)$

A eq. (7) com ETa expresso pela eq. (10), ao ser substituida na eq. (5), resulta em: RBRUTA $=C X L \cdot$ PMAX. NPE. $[3600 .(U E \cdot N E \cdot Q E \cdot I \cdot D I) /$ (ETMAX - T . EE - EL)] 
28.

\subsubsection{Custo de produção da laranja}

- custo anual de produção da laranja por hectare (CPROD), sem considerar a irrigação, é dado por:

$$
\text { CPROD }=(20000 \cdot \mathrm{CP} \cdot \mathrm{NUO} \cdot \mathrm{NGE} \cdot \mathrm{NLL}) / \mathrm{A}
$$

sendo,

CP - custo anual de produção da laranja, em US\$/árvore;

NUO - número total de unidades operacionais na área ;

NGE - número de emissores ou grupos de emissores na linha lateral (número de saldas);

NLL - número de saldas na linha de derivaçăo. Corresponde à metade do número de linhas laterais conectadas na linha de derivaçăo ;

A - área a ser irrigada, em $\mathrm{m}^{2}$.

\section{3. 3. Custo do sistema de irrigação}

o sistema de irrigação por microaspersão a ser dimensionado, é composto por:

- estação de captação e de bombeamento;

- estação de controle;

- linha principal;

- linha secundária;

- linha de derivação;

- linha lateral;

- microaspersores;

- acessorios. 
o custo do sistema de irrigação por hectare (CSIST) écalculado por:

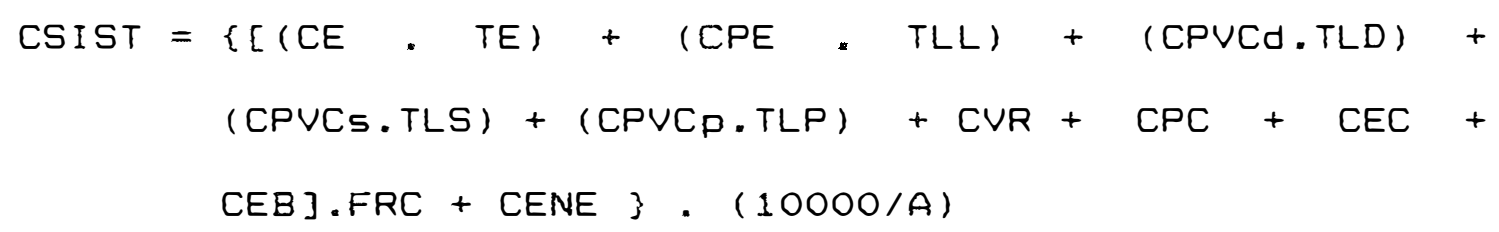

em que,

CE - custo unitário do emissor, US\$;

TE - número total de emissores;

CPE - custo do tubo de polietileno (US\$/m), en função do diåmetro (m);

TLL - extensão total de linhas laterais no sistema, em m;

CPVCd - custo da tubulação de PVC utilizada nas linhas de derivação, em US\$/m, em função do diâmetro (m);

CPVCs - custo da tubulação de PVC da linha secundária (US\$/m), em função do diâmetro $(m)$;

CPVCp - custo da tubulação de PVC da linha principal (US\$/m), em função do diåmetro $(m)$;

TLD - extensão total de linhas de derivação, em m;

TLS - extensão total de linha secundária, em m ;

TLP - extensão total de linha principal, em m;

CVR - custo das válvulas e registros (US\$) em função do número total de unidades operacionais ;

CPC - custo do painel de controle (US\$) em função do número de unidades operacionais ; 
CEC - custo da estação de controle (US\$) em função da vazão atual;

CEB - custo da estação de bombeamento (US\$) em função da potencia bruta requerida (cV);

FRC - fator de recuperação do capital, em valor decimal; CENE - custo da energia eletrica (US\$) em função do consumo (kWh);

3.3.3.1. Relaçres custo do componente $x$ dimensăo característica

o custo das válvulas e registros (CVR) é dado por:

$$
\text { CVR }=\mathrm{C} 1 \cdot \mathrm{NUO}
$$

sendo,

C1 - coeficiente da regressão.

o custo do painel de controle (CPC) é dado

por :

$$
C P C=C 2 \cdot(N U O)^{C 3}
$$

em que,

C2 e C3 - coeficientes da regressão.

o custo da estação de controle (CEC) é dado por:

$$
C E C=C 4+(C 5 . Q T)
$$

sendo, C4 e C5 - coeficientes da regressão; 
- vazão atual do sistema de irrigação, em $\mathrm{m}^{3} / \mathrm{s}$. Dada por:

$$
Q T=2 \cdot Q E \cdot N E \cdot N G E \cdot N L L \cdot N U O S
$$

em que,

NuOS

$$
\text { - número de unidades operacionais }
$$
simul taneamente.

0 custo da estação de bombeamento (CEB) é dado por:

$$
C E B=C 6 \cdot[(2000 \cdot Q E \cdot N E \cdot N G E \cdot N L L \cdot N U O S) \cdot(H M+H T) /(75 \cdot N B M)]^{C 7}
$$

sendo,

C6 e C7 - coeficientes da regressão;

$H M$

- carga hidráulica média do emissor, em m.c.a. ;

HT

- perdas de carga hidráulica no sistema (m.c.a.): perda de carga na rede hidráulica mais o desnivel geométrico ;

NBM

- rendimento do conjunto motobomba, em \%.

$$
\text { o fator de recuperação do capital (FRC) é }
$$

dado por:

$$
F R C=\left[r \cdot(1+r)^{n}\right] /\left[(1+r)^{n}-1\right]
$$

em que,

$r \quad$ taxa de juros anual, em valor decimal ;
$n \quad$ número de anos de vida útil do sistema de
$\quad$ irrigação;


- custo anual com energia (CENE) é calculado

por:

$$
\begin{aligned}
& \text { CENE = CKWH. (2 .QE . NE .NGE. NLL . NUOS }) .9,80665 . \\
& I \cdot D I \cdot N U O(H M+H T) /(N B M \cdot T \cdot N U O S)
\end{aligned}
$$

sendo,

CKWH - custo do kWh, em US\$.

3.3.3.2. Equaçช̃es de totalização dos componentes do sistema

o número total de emissores (TE) é dado por:

$T E=(A \cdot N E) /(E E \cdot E L)$

A extensão total das linhas laterais (TLL), ou seja, a soma dos comprimentos de todas as laterais existentes no sistema, é dada por:

$$
T L L=(A / E L)-[A /(2 . N G E . E L)]
$$

A soma dos comprimentos das linhas de derivação (TLD) do sistema de irrigação por microaspersăo, é dada por:

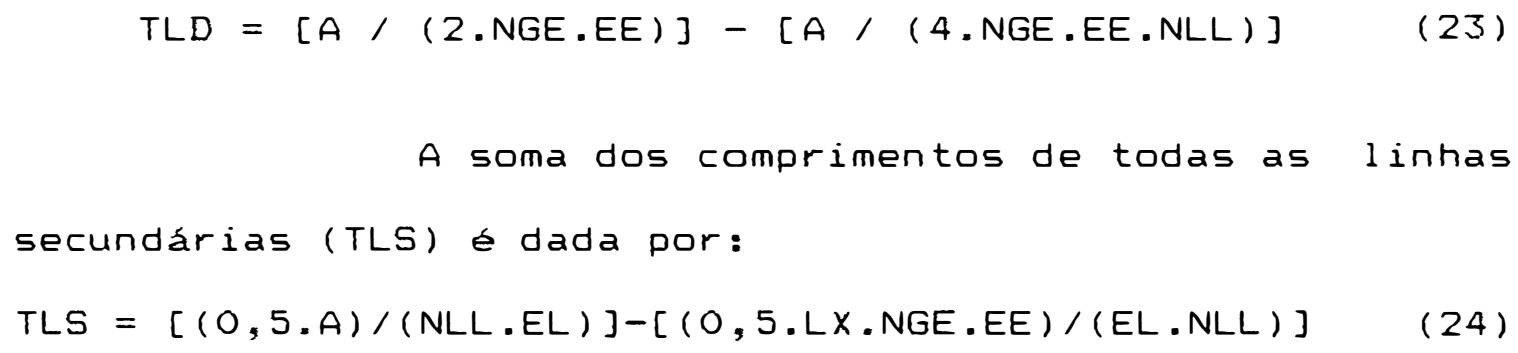


em que,

Lx - comprimento do campo na direção x, em m.

A extensão total de linha principal (TLP) é calculada por:$$
T L P=L X-(2 . N L L . E L)
$$ \\ o número de saldas na linha lateral (NGE) é
}

dado por:

$$
N G E=(L L / E E)+0,5
$$

sendo,

LL - comprimento da linha lateral, em $\mathrm{m}$.

o número de saidas na linha de derivação

(NLL) é calculado por:

$$
N L L=(L D / E L)+0,5
$$

em que,

LD - comprimento da linha de derivaçăo, em $m$.

- número total de unidades operacionais (NUO) é dado por:

$$
\begin{aligned}
& \text { NUO = A / (2.NGE.NLL.EE.EL) (28) } \\
& 0 \text { número de linhas secundárias (NLS) }
\end{aligned}
$$$$
\text { existentes na área é calculado por: }
$$

$$
N L S=T L S,[L Y-(N G E . E E)]
$$

existentes na area e calculado por: 
sendo,

LY - comprimento na direção y, em $\mathrm{m}$.

- número de saidas na linha secundária (NSS)

é dado por:

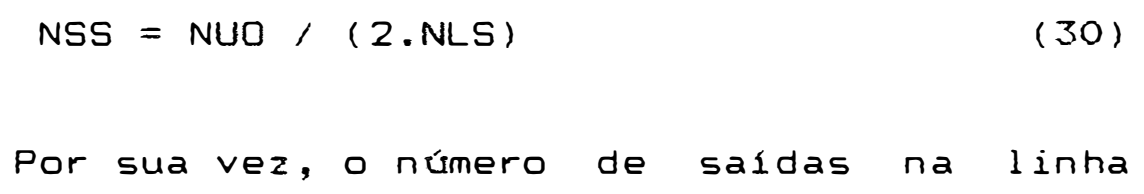

Por sua vez, o número de saidas na linha principal (NSP) é calculado por:

$$
N S P=N L S / 2
$$

\section{4. Equaçð̃es de perda de carga}

A perda de carga hidráulica total no sistema (HT) é calculada por:

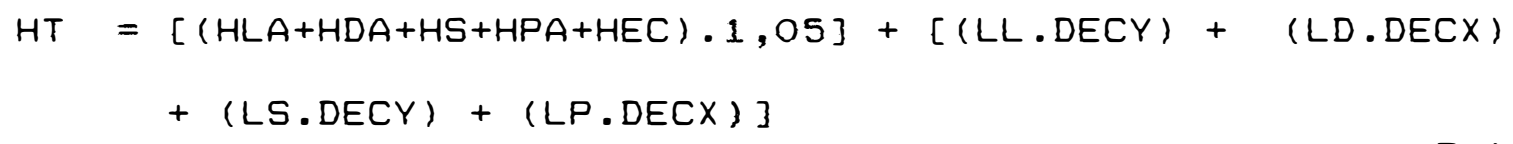

em que,

HLA - perda de carga na linha lateral em aclive, em m.c.a.;

HDA - perda de carga na linha de derivação em aclive, em m.c.a.;

HS - perda de carga na linha secundaria, em m.c.a.;

HPA - perda de carga na linha principal em aclive, em m.c.a.; 
35.

DECX - declividade na direção x (longitudinal) da área a ser irrigada, em $\mathrm{m} / \mathrm{m}$;

DECY - declividade na direção y (transversal) da área a ser irrigada, em $\mathrm{m} / \mathrm{m}$.

0 primeiro termo entre colchetes na eq. (32) representa a perda de carga na rede hidráulica, enquanto o segundo termo indica a perda decorrente do desnivel geométrico. O fator 1,05 é utilizado para compensar as perdas localizadas, estimadas em $5 \%$ da perda total.

Para estimar a perda de carga na tubulaçăo utilizou-se a fórmula de Darcy-Weisbach (Equação Universal de Perda de Cargal, dada por:

$$
H f=\left(B \cdot f \cdot Q^{2} \cdot L\right),\left(\pi^{2} \cdot g \cdot D^{5}\right)
$$

em que,

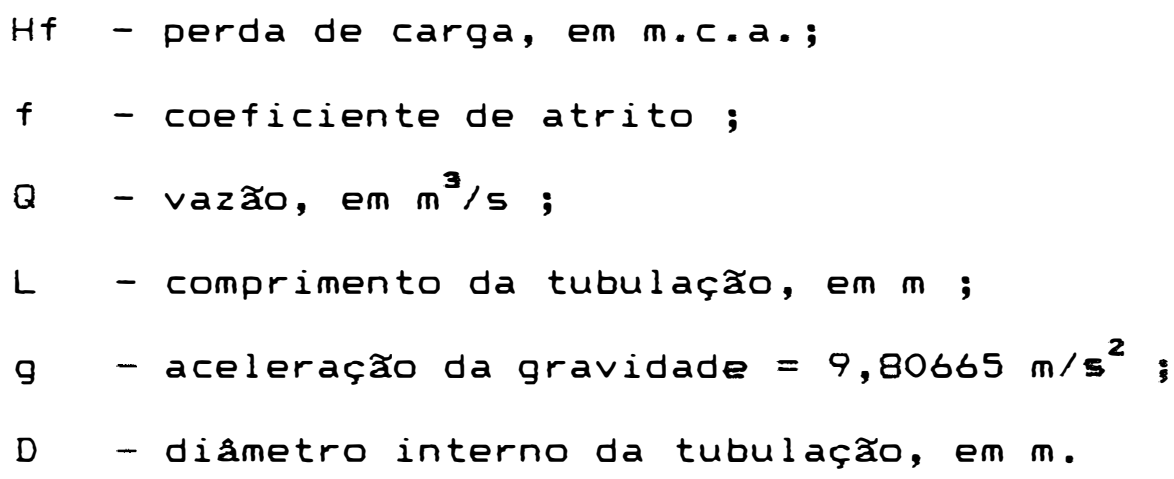

Segundo KELLER \& BLIESNER (1990), para tubos plásticos com diåmetro interno inferior a $125 \mathrm{~mm}$, pode-se 
utilizar a equação de Blasius para estimativa de do fator $f:$

$$
\begin{aligned}
& f=0,316 \cdot R e^{-0,25} \\
& \text { para } 2000 \leq R e \leq 10^{5}
\end{aligned}
$$

sendo,

Re - número de Reynolds, cujo valor para a água a $20 \circ \mathrm{C}$ é dado por:

$$
\operatorname{Re}=1,26 \cdot 10^{\circ} \cdot(Q / D)
$$

Substituindo-se as eqs.(34) e (35) na eq. (33), obtém-se:

$$
H f=0,0007794 \cdot Q^{1,75} \cdot L \cdot D^{-4,75}
$$

No caso de tubulaçơes com múltiplas derivaçסes, deve-se multiplicar a eq.(36) por um fator de correção $F$.

SCALOPPI (1986) desenvolveu um fator Fa de aplicação geral (qualquer distância entre a primeira saida e o ponto de derivação de águal, cuja equação é:

$$
F_{a}=[(N . F)+r x-1] /(N+r x-1)
$$

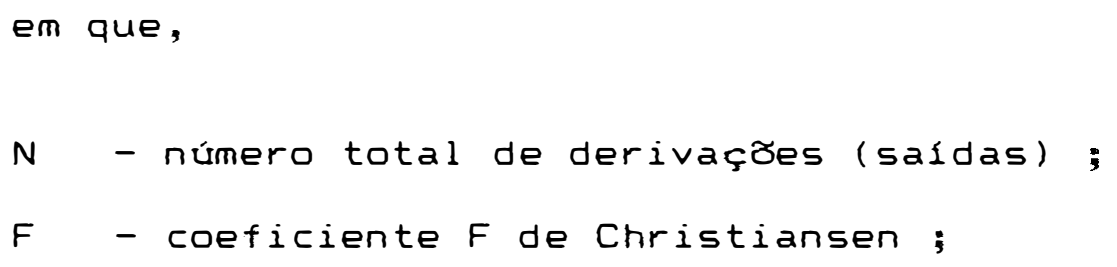




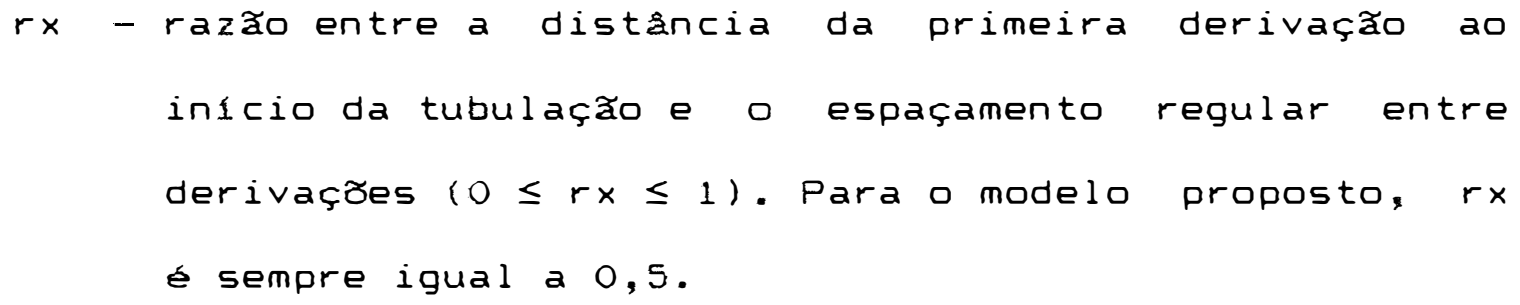
inicio da tubulaçăo e o espaçamento regular entre derivações ( $0 \leq r x \leq 1)$. Para o modelo proposto, $r x$ é sempre igual a 0,5 .

o fator $F$ de Christiansen (CHRISTIANSEN, 1942) é dado por:

$$
F=[1 /(m+1)]+[1 /(2 . N)]+\left[(m-1)^{0.5} /\left(6 . N^{2}\right)\right]
$$

sendo,
m - expoente da velocidade na fórmula empregada para o cálculo da perda de carga (neste caso: m $=1,75$ ).

\subsubsection{Perda de carga nas linhas laterais}

O modelo contempla áreas com declividade uniforme nas direçðes $x$ e $y$. Desta forma, existirăo linhas laterais em aclive e em declive.

3.4.1.1. Perda de carga na linha lateral em aclive (HLA)

A perda de carga na linha lateral em aclive (HLA) é dada por:

$$
H L A=0,0007794 \cdot L L \cdot Q L^{1,75} \cdot D L A^{-4,75} \cdot F L \cdot 1,03
$$


38.

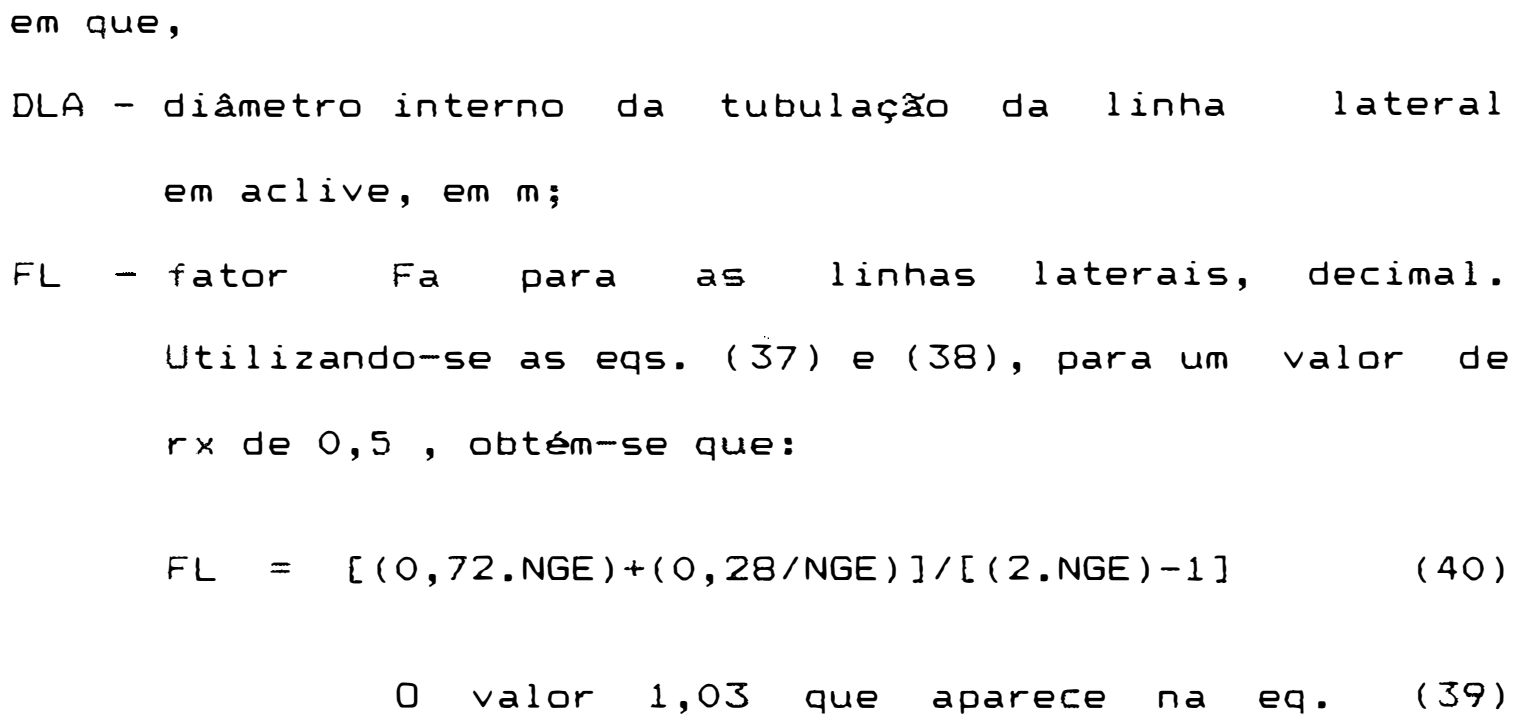

corresponde às perdas localizadas decorrentes da inserçăo do microaspersor na linha lateral.

o comprimento da linha lateral (LL), em $m$, é

calculado por:

$$
L L=L Y-L S-(0,5 . E E)
$$

A vazăo na linha lateral (QL), em $\mathrm{m}^{3} / \mathrm{s}$,

dada por:

$$
Q L=N G E \cdot Q E
$$

3.4.1.2. Perda de carga na linha lateral em decli ve (HLD)

E dada por:

$$
H L D=0,0007794 \cdot L L \cdot Q^{1,75} \cdot D L D^{-4,75} \cdot F L \cdot 1,03
$$
sendo,

HLD - perda de carga na linha lateral em declive, em m.c.a.;

DLD - diâmetro da linha lateral em declive, em $m$. 


\section{4.2. Perda de carga na linha de derivação}

A perda de carga na linha de derivação tem as mesmas características que na linha lateral, ou seja, condiçăo de aclive e declive, e tubulação com múltiplas derivaçశ̃es.

3.4.2.1. Perda de carga na linha de deri vação em aclive (HDA)

A perda de carga na linha de derivação em aclive (em m.c.a.), é dada por:

$$
H D A=0,0007794 \cdot L D \cdot Q D^{1,75} \cdot D D A^{-4,75} \cdot F D
$$

em que,

DDA - diåmetro interno da linha de derivação em aclive, em m ;

FD - fator Fa para a linha de derivaçăo, em valor decimal. Sua equação para $r \times$ igual a 0,5 é:

$$
F D=[(0,72 . N L L)+(0,28 / N L L)] /[(2 . N L L)-1]
$$

- comprimento da linha de derivação (LD), em m, é dado por:

$$
L D=[L X-(2 . L P)-E L] / 2
$$


A vazão na linha de derivação $(Q D)$, em $\mathrm{m}^{3} / \mathrm{s}$, é calculada por:

$$
Q D=2 \cdot N L L \cdot Q L
$$

3.4.2.2. Perda de carga na linha de deri vação em declive (HDD)

Por sua vez, a perda de carga na linha de derivação em declive (mca), é calculada por:

$$
H D D=0,0007794 \cdot L D \cdot Q D^{1,75} \cdot D D D^{-4,75} \cdot F D
$$

sendo,

DDD - diâmetro da linha de derivaçăo em declive, em $m$.

\section{4. 3. Perda de carga na li nha secundária (HS)}

A perda de carga na linha secundária é estimada por:

$$
H S=0,0007794 \cdot L S \cdot Q S^{1,75} \cdot D S^{-4,75} \cdot F S
$$

em que,

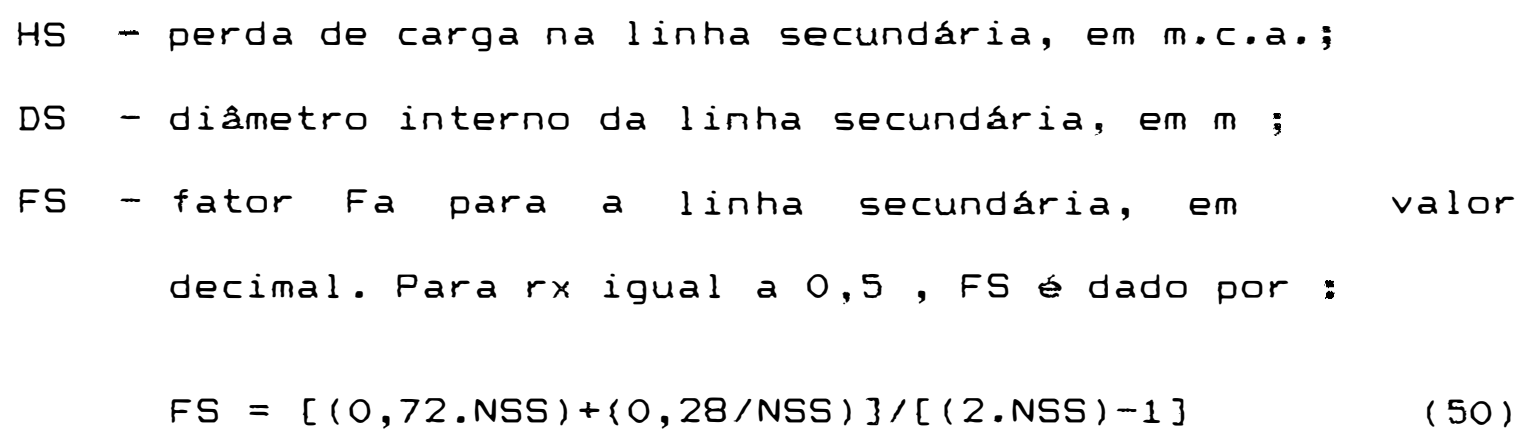


- comprimento da linha secundaria (LS), em m, é calculado por:

$$
\begin{aligned}
& \text { LS }=\text { LY - (NGE.EE) } \\
& \text { A vazão da linha secundária (QS), em } \mathrm{m}^{3} / 5 \text {, e }
\end{aligned}
$$

dada por:

$$
Q S=2 \cdot Q E \cdot N E \cdot N U O S \cdot N L L \cdot N G E / N L S
$$

\subsection{Perda de carga na linha principal}

A linha principal divide-se em dois trechos: aclive e declive.

3.4.4.1. Perda de carga na linha principal em aclive (HPA)

A perda de carga na linha principal em aclive (HPA) é estimada por:

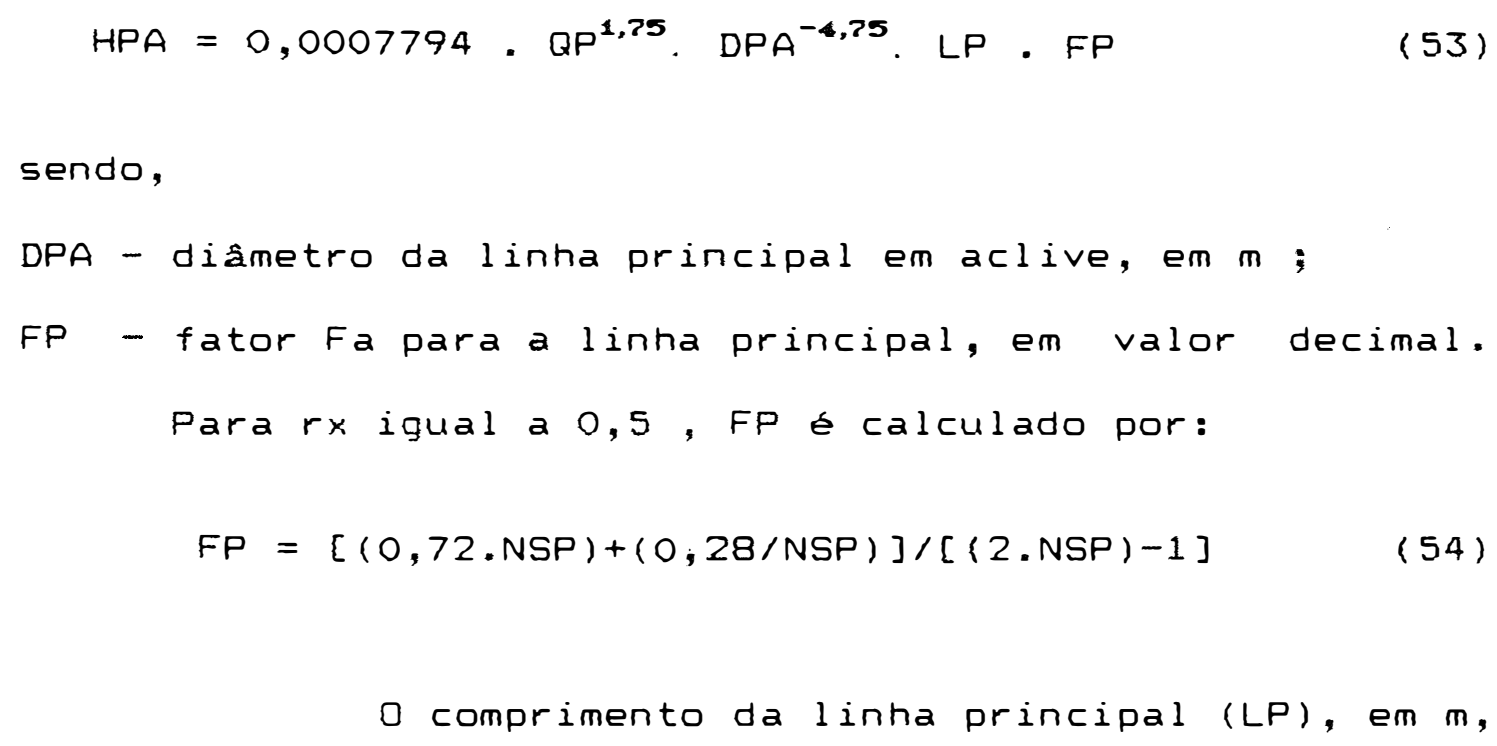


é dado por:

$L P=T L P / 2$

A vazão na linha principal (QP), em $\mathrm{m}^{3} / 5$, é calculada por:

$$
Q P=N U O S \cdot Q E \cdot N E \cdot N L L \cdot N G E
$$

3.4.4.2. Perda de carga na linha principal em declive (HPD)

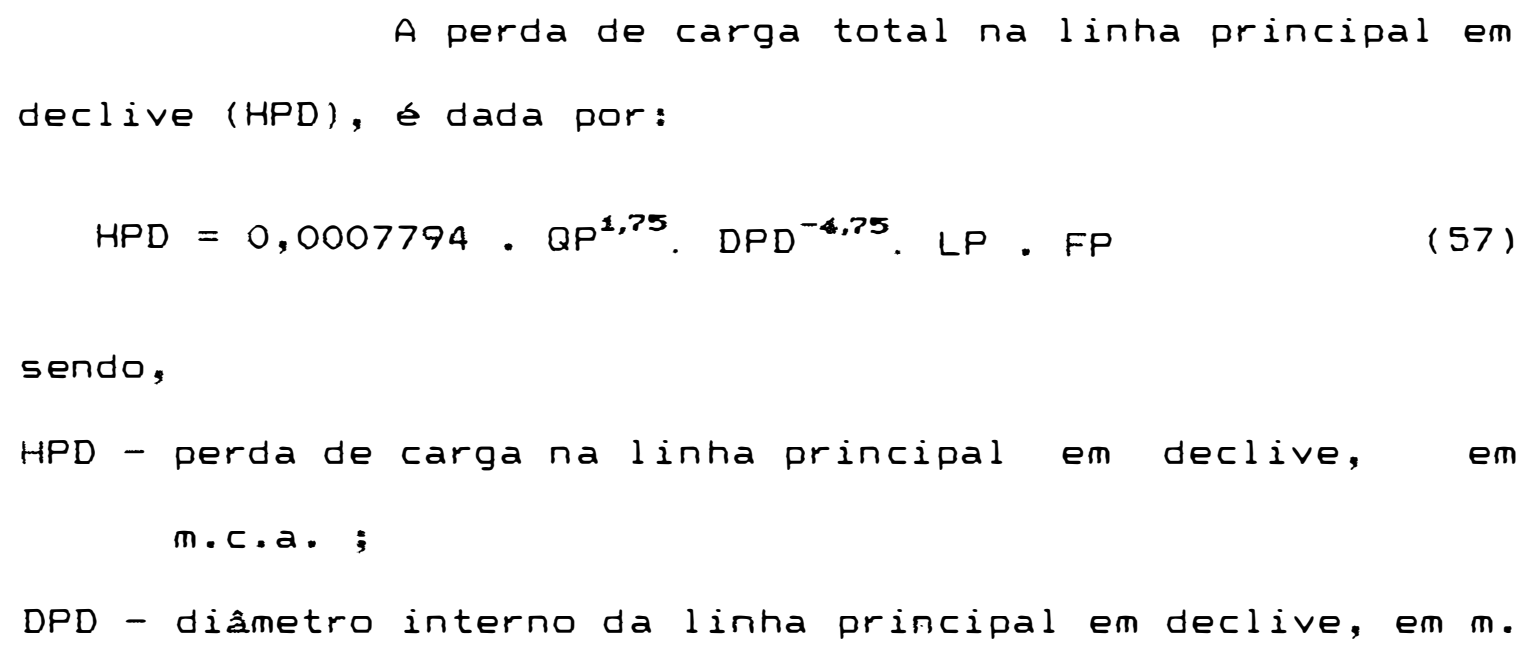

3.4.5. Balanço de perdas e ganhos de carga hidráulica nas linhas em aclive e declive

As linhas em aclive perdem carga hidráulica em função do desnivel geométrico e da própria perda de carga na tubulação. Por sua vez, as linhas em declive 
também perdem carga por atrito na tubulação, porém ganham carga em função da topografia. Desta forma, para que se assegure que a carga hidrálica consumida na linha em aclive seja igual àquela dissipada na linha em declive, săo necessárias as seguintes equações:

$$
\begin{aligned}
& H L A+(L L . D E C Y)=H L D-(L L . D E C Y) \\
& H D A+(L D . D E C X)=H D D-(L D . D E C X) \\
& H P A+(L P . D E C X)=H P D-(L P . D E C X)
\end{aligned}
$$

3.5. Equaçỡes referentes aos critérios hidráulicos de di mensionamento

As linhas laterais e de derivação que compơem a unidade operacional serăo dimensionadas em função da uniformidade de emissão. Por sua vez, as linhas secundárias e principal serão definidas com base na velocidade.

3.5.1. Dimensionamento das linhas laterais e de derivação com base na uniformidade de emissão

A variação permissivel de carga hidráulica na unidade operacional (DHUO) é dada por:

$$
\text { DHUO }=\text { HMAX }- \text { HMIN }=M \cdot(H M-H M I N)
$$




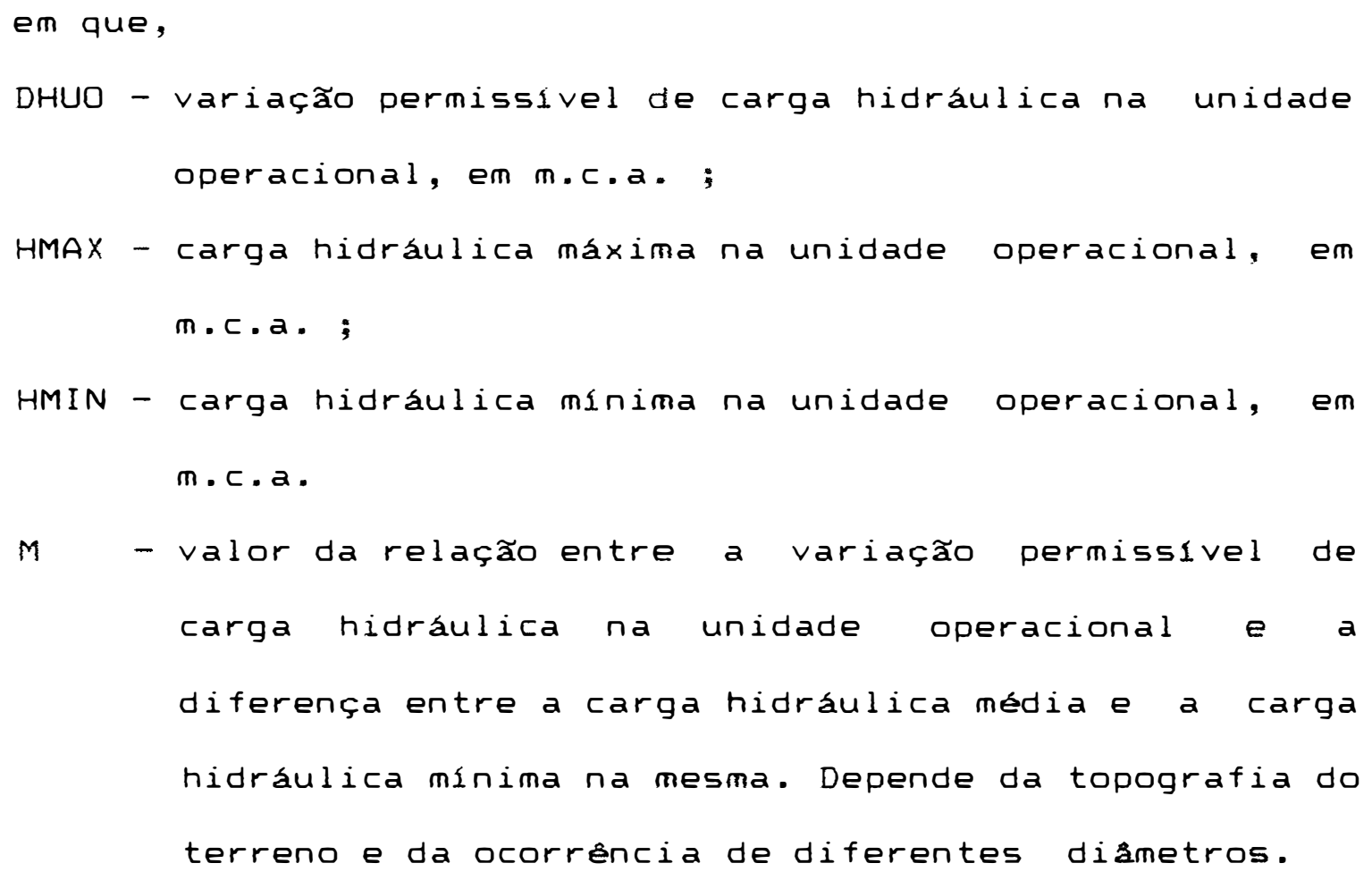

Segundo HERNANDEZ ABREU et al. (1987), para que se tentia uma uniformidade de distribuição de água em niveis satisfatórios, o fator M deve variar de 2 a $4,5$.

Para fins de projeto, ESTADOS UNIDOS (1983)

e KELLER \& BLIESNER (1990) recomendam que se utilize M igual a 2,5 .

o coeficiente de uniformidade de emissão (UE) écalculado por:

$$
U E=\left[1-\left(1,27 \cdot C V F \cdot N E^{-0,5}\right)\right] \cdot(Q M I N / Q E)
$$

sendo,

UE - uniformidade de emissăo, decimal;

CVF - coeficiente de variação de fabricação do emissor, decimal ; 
QMIN - vazăo correspondente à carga hidráulica mínima na unidade operacional, em $\mathrm{m}^{3} / \mathrm{s}$;

A conversao da vazao mínima em carga hidráulica minima e vice-versa éfeita por meio da relação vazão - pressão do microaspersor, que é expressa por:

$$
\text { QMIN }=k \cdot H M I N^{x}
$$

sendo

$k, x$ - coeficientes empiricos.

Desta forma, as equaçžs que definem o dimensionamento das lintias laterais e de derivaçăo em funçăo da uniformidade de emissăo, săo:

$$
\begin{aligned}
& \text { DHUO }=2,5 .(H M-H M I N) \\
& H L A+(L L . D E C Y) \geq 0,4 \cdot \text { DHUO } \\
& H L A+(L L . D E C Y) \leq 0,6 \cdot \text { DHUO } \\
& \text { HDA + (LD.DECX } \geq 0,4 \cdot \text { DHUO } \\
& \text { HDA + (LD.DECX } \leq 0,6 \cdot \text { DHUO } \\
& \text { DHUO = HLA + HDA + (LL.DECY + (LD.DECX) }
\end{aligned}
$$

A eq. (64) fornece a variaçăo permissivel de carga hidráulica na unidade operacional. Esta variaçăo será 
dividida entre as linhas laterais e de derivação, sendo que cada uma consumirá de 40 a 60\% de DHUO (eqs.65 a 68), porém de tal forma que a a soma seja igual a 100\%, ou seja, igual a DHUO (eq. 69).

3.5.2. Dimensionamento das linhas secundária e principal com base na relocidade

A velocidade na linha secundária, na linha principal em aclive e na linha principal em declive é calculada, respectivamente, por:

$$
\begin{aligned}
& V S=1,27324 \cdot\left(Q S / D S^{2}\right) \\
& V P A=1,27324 \cdot\left(Q P / D P A^{2}\right) \\
& V P D=1,27324 \cdot\left(Q P / D P D^{2}\right)
\end{aligned}
$$

em que,

vS - velocidade na linha secundária, em m/s ;

VPA - velocidade na linha principal em aclive, em $\mathrm{m} / \mathrm{s}$;

VPD - velocidade na linha principal em declive, em $\mathrm{m} / \mathrm{s}$.

Segundo LABYE et al. (1988), a velocidade deve estar entre $0,2 \mathrm{~m} / \mathrm{s}$ e $2,0 \mathrm{~m} / \mathrm{s}$ para tubulaç̧es com diametro de até $0,3 m$. Desta forma, as equaçớs que definem - dimensionamento das linhas secundária e principal em função da velocidade são:

$$
\begin{aligned}
& v S \geq 0,2 \\
& v S \leq 2,0
\end{aligned}
$$


47.

$$
\begin{aligned}
& V P A \geq 0,2 \\
& V P A \leq 2,0 \\
& V P D \geq 0,2 \\
& V P D \leq 2,0
\end{aligned}
$$

\subsection{Restriçžes}

Além da função objetivo e das equaçres referentes aos aspectos hidráulicos, o modelo apresenta uma série de restriçôes referentes à operação do sistema e geometria da área irrigada.

\subsubsection{Restrição referente ao turno de irrigação}

o turno de irrigação (T), dado em dias, deve ser menor que um determinado valor, denominado turno máximo (TX), dado por:

$$
T X=(0,5 . P(N) / E T M D
$$

sendo,

TX - número máximo de dias que pode ter um turno de irrigação ;

PW - área molhada pelo emissor em relação à área efetivamente ocupada pela árvore, em \% ;

ETMD - evapotranspiração máxima diária no periodo de pico, em mm/dia.

Desta forma, a restrição é expressa por:

$$
T \leq T X
$$


3.6.2. Restrição referente ao tempo diário disponivel para irrigação

Em função da tarifa de energia e da possibilidade do irrigante, tem-se um número de horas por dia disponivel para irrigação (TD). Desta forma:

$$
[(N \cup O \cdot I) /(N U O S \cdot T)] \leq T D
$$

\subsection{Restrição quanto à vazão disponi vel}

A vazå requerida pelo sistema de irrigaçăo deve ser menor ou igual à vazão disponivel na fonte de água. Logo:

(2. QE - NE - NGE - NLL - NUOS ) / UE $\leq$ QDISP

em que,

QDISP - vazăo disponivel na fonte de água, em $\mathrm{m}^{3} / \mathrm{s}$.

3.6.4. Restrição que assegura pelo menos uma unidade operacional em funcionamento na linha secundária

Uma das hipóteses básicas do modelo consiste em que se tentia toda e qualquer linha secundaria sempre em operação. Para assegurar isto, tem-se a seguinte restrição: NUOS $\geq N L S$ 
3.6.5. Restriçăo referente à ocupaçăo total da área disponi vel

A restrição que assegura que o sistema de irrigação por microaspersão irá cobrir toda a área disponível está caracterizada na eq. (28).

3.6.6. Restrição referente à produção relativa

A produção relativa (PREL), definida
anteriormente, tem valor máximo igual a 1. Para assegurar
que este limite seja respeitado, tem-se a seguinte
restrição:

(3600.UE.NE.QE.I.DI)/(ETMAX.T.EE.EL) $\leq 1$

\subsection{Dados de entrada}

Para que o modelo possa efetuar a otimização do sistema de irrigação por microaspersão faz-se necessário - fornecimento de paråmetros básicos, que caracterizam a cultura a ser irrigada e as condiçóes operacionais do sistema e geométricas da área. A relação destes parámetros encontra-se na Tabela 1. 
50.

Tabela 1 - Dados de entrada do modelo de Programação Nao-linear para dimensionamento de sistemas de irrigação por microaspersão na cultura da laranja

\begin{tabular}{|c|c|}
\hline PAR AMME TRO & DESCR I ÇAO \\
\hline CXL & Preço da caixa $(40,8 \mathrm{Kg})$ de laranja, US\$ \\
\hline PMAX & Produção máxima com irrigação, cx/árvore \\
\hline NPE & Número de arvores por hectare \\
\hline NE & Número de emissores por árvore \\
\hline DI & Número de dias de irrigação durante o ciclo \\
\hline ETMAX & $\begin{array}{l}\text { Evapotranspiração máxima para um determinado } \\
\text { nivel de probabilidade de ocorrancia, em } \\
\text { m/ciclo }\end{array}$ \\
\hline ETMD & $\begin{array}{l}\text { Evapotranspiração máxima diária no periodo de } \\
\text { pico, para um determinado nivel de } \\
\text { probalibilidade de ocorrencia, em } \mathrm{mm} / \mathrm{dia}\end{array}$ \\
\hline EE & $\begin{array}{l}\text { Espaçamento entre emissores ou grupos de } \\
\text { emissores na lintia lateral, em } m\end{array}$ \\
\hline EL & Espaçamento entre linhas laterais, em $\mathrm{m}$ \\
\hline$C P$ & Custo de produção da laranja, em US\$/arvore \\
\hline CE & Custo unitário do microaspersor, em US\$ \\
\hline$H M$ & $\begin{array}{l}\text { Carga hidráulica média ou de operação do } \\
\text { microaspersor, em m.c.a. }\end{array}$ \\
\hline NBM & Rendimento do conjunto motobomba, em $\%$ \\
\hline CKWH & Custo do kwh de energia eletrica, em US\$ \\
\hline DECX & Declividade da área irrigada na direção $x, \mathrm{~m} / \mathrm{m}$ \\
\hline DECY & Declividade da área irrigada na direção $y, \mathrm{~m} / \mathrm{m}$ \\
\hline FRC & Fator de recuperação do capital \\
\hline
\end{tabular}


Tabela 1 - Dados de entrada do modelo de Programaçăo Não-linear para dimensionamento de sistemas de irrigação por microaspersão na cultura da laranja

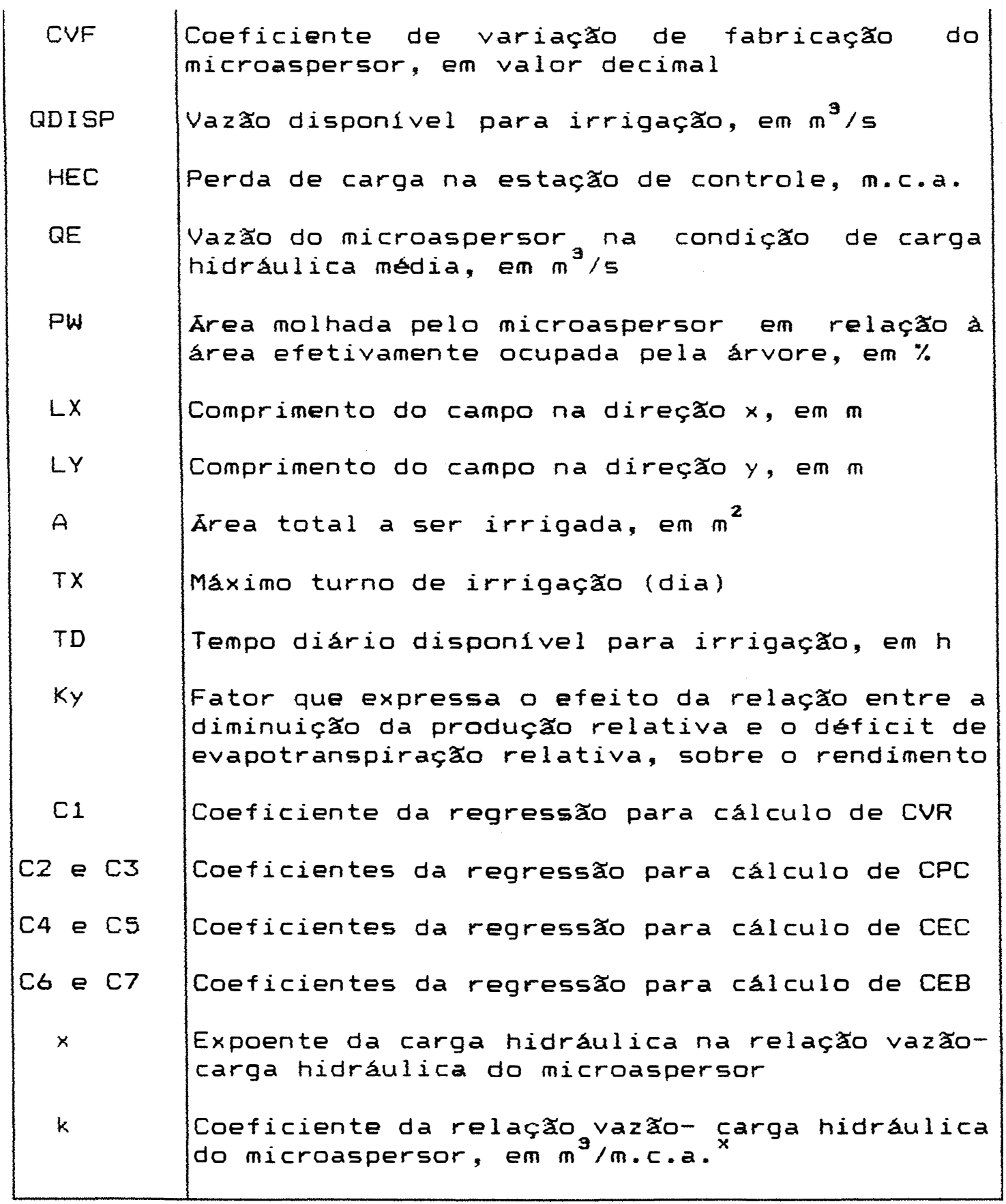


3.8. Dados de saída

Os dados de salda sao as variáveis de decisăo que geraram a maximizaçăo da receita liquida. Na Tabela 2 estăo listadas estas variáveis e seus respectivos limites inferior e superior. A definiça destes extremos é de fundamental importancia para que se obtentia éxito na busca da solução ótima. Há necessidade, também, de se estabelecer um valor inicial as variáveis do modelo, visando facilitar o processo de otimização.

Tabela 2 - Relação das variáveis de decisão do modelo (dados de salda) e seus respectivos limites inferior e superior

\begin{tabular}{|c|c|c|c|}
\hline VAR I AVEL & UNIDADE & LIMITE INFERIOR & LIMITE SUPERIOR \\
\hline FO & US\$/ha.ano & $-\infty$ & $+\infty$ \\
\hline CSIST & US\$/ha.ano & 1 & $+\infty$ \\
\hline RBRUTA & US\$/tia.ano & 1 & $+\infty$ \\
\hline CPROD & US\$/ha.ano & 1 & $+\infty$ \\
\hline CENE & US\$/ano & 1 & $+\infty$ \\
\hline CEB & US\$ & 1 & $+\infty$ \\
\hline CUR & US $\$$ & 1 & $+\infty$ \\
\hline CPC & US\$ & 1 & $+\infty$ \\
\hline CEC & US\$ & 1 & $+\infty$ \\
\hline LL & $m$ & $4,5 . E E$ & LY/2 \\
\hline LD & $m$ & $2,5 . E L$ & $L x / 2$ \\
\hline LS & $m$ & $L Y / 2$ & LY \\
\hline LP & $m$ & 0 & $L x / 2$ \\
\hline TLL & $m$ & $9 . E E$ & $A / E L$ \\
\hline TLD & $m$ & $2,5 . E L$ & $A /(10 . E E)$ \\
\hline TLS & $m$ & $L Y / 2$ & $(0,5 . A) / 3 . E L$ \\
\hline TLP & m & 0 & $L X-(6 . E L)$ \\
\hline HLA & $m$ & 0,01 & 10 \\
\hline HLD & $m \cdot c \cdot a$. & 0,01 & 10 \\
\hline HDA & m.c.a. & 0,01 & 10 \\
\hline HDD & $m \cdot c \cdot a$. & 0,01 & 10 \\
\hline HS & m.c.a. & 0,01 & 10 \\
\hline HPA & $m \cdot c \cdot a$. & 0,01 & 10 \\
\hline HPD & m.c. a. & 0,01 & 10 \\
\hline
\end{tabular}


Tabela 2 - Relação das variáveis de decisão do modelo (dados de saida) e seus respectivos limites inferior e superior

\begin{tabular}{|c|c|c|c|}
\hline$H T$ & m.c.a. & 10 & 80 \\
\hline$D L A$ & $m$ & 0,010 & 0,022 \\
\hline DLD & $m$ & 0,010 & 0,022 \\
\hline$D D A$ & $m$ & 0,035 & 0,144 \\
\hline DDD & m & 0,035 & 0,144 \\
\hline DS & $m$ & 0,035 & 0,310 \\
\hline DPA & $m$ & 0,035 & 0,310 \\
\hline$D P D$ & $m$ & 0,035 & 0,310 \\
\hline NUO & - & 1 & $A /(30 . E E . E L)$ \\
\hline NUOS & - & 1 & $A /(30 . E E . E L)$ \\
\hline NGE & - & 5 & $L Y /(2 . E E)$ \\
\hline NLL & - & 3 & $L X /(2 . E L)$ \\
\hline NLS & - & 1 & $A /(6 O . E E . E L)$ \\
\hline NSS & - & 1 & $A /(60 . E E . E L)$ \\
\hline NSP & 3 & 0 & $A /(120 . E E . E L)$ \\
\hline$Q L$ & $m^{3} / 5$ & 5. QE & $(L Y, Q E) /(2 . E E)$ \\
\hline QD & " & 30. QE & $(A \cdot Q E) /(2 . E L \cdot E E)$ \\
\hline QS & $"$ & 3O. QE & $(A \cdot Q E) /(E E . E L)$ \\
\hline QP & $"$ & $30 . Q E$ & $(A . Q E) /(2 . E L . E E)$ \\
\hline$Q T$ & $"$ & 30. QE & $(A . Q E) /(E E . E L)$ \\
\hline FL & - & 0,36 & 1 \\
\hline$F \bar{D}$ & - & 0,36 & 1 \\
\hline FS & - & 0,36 & 1 \\
\hline FP & - & 0,36 & 4 \\
\hline DHUO & m.c.a. & 0,01 & 20 \\
\hline VS & $\mathrm{m} / \mathrm{s}$ & 0,2 & 2,0 \\
\hline VPA & $m / s$ & 0,2 & 2,0 \\
\hline VPD & $\mathrm{m} / \mathrm{s}$ & 0,2 & 2,0 \\
\hline TE & - & 0 & $+\infty$ \\
\hline UE & - & 0,7 & 1 \\
\hline HMIN & $m \cdot c \cdot a$. & 8 & 15 \\
\hline$I$ & $h$ & 1 & 21 \\
\hline$T$ & $d i a$ & 1 & $T X$ \\
\hline
\end{tabular}

3.9. Valores dos dados de entrada utilizados

A citricultura desenvolvida na regiå de Limeira, SP, foi escolnida para aplicação do modelo proposto. 
Os dados de entrada utilizados neste trabalho encontram-se na Tabela 3.

Tabela 3 - Dados de entrada referentes a microaspersão e à citricultura desenvolvida em Limeira, SP

\begin{tabular}{|c|c|c|}
\hline PARAMETRO & UNIDADE & VALOR \\
\hline $\begin{array}{l}\text { CXL } \\
\text { PMAX } \\
\text { EE } \\
\text { EL } \\
\text { NPE } \\
\text { NE } \\
\text { DI } \\
\text { ETMAX } \\
\text { ETMD } \\
\text { CP } \\
\text { CE } \\
\text { HM } \\
\text { NBM } \\
\text { CKWH } \\
\text { FRC } \\
\text { CVF } \\
\text { QDISP } \\
\text { HEC } \\
\text { PW } \\
\text { FX } \\
\text { TD }\end{array}$ & $\begin{array}{c}\text { US\$/cx } \\
\text { cx/árvore } \\
m \\
m \\
\text { árvore } \\
\text { emissor/árvore } \\
\text { dia } \\
m / c i c l o \\
m m / d i a \\
\text { US\$/arvore } \\
\text { US\$/emissor } \\
m . c . a . \\
- \\
\text { uS\$/kwh } \\
- \\
m / s \\
m . c . a . \\
\% \\
d i a \\
h / d i a\end{array}$ & $\begin{array}{c}2,28 \\
6,5 \\
4 \\
8 \\
312 \\
1 \\
120 \\
0,487 \\
4,7 \\
4,34 \\
2,11 \\
15 \\
0,65 \\
0,05064 \\
0,13587 \\
0,05 \\
0,2 \\
15 \\
50 \\
5,32 \\
21\end{array}$ \\
\hline
\end{tabular}

O preço da caixa de laranja (CXL) utilizado corresponde à media de 10 anos, referentes à safras de $80 / 81$ a $90 / 91$, segundo NEVES ${ }^{1}$ (1993).

Os dados referentes cultura da laranja irrigada são reais e foram obtidos junto a fazenda

${ }^{1}$ NEVES, E.M. (Escola Superior de Agricultura "Luiz de Queiroz"/USP, Piracicaba, SP) Comunicaçăo pessoal, 1993. 
Amazonas, situada em Leme, SP. A copa é Valência e o porta-enxerto é o limão cravo. o espaçamento entre árvores (EE) é de $4 m$ e entre ruas de árvores (EL) é de $8 m$, totalizando 312 plantas por hectare (NPE). A produção máxima de caixas de laranja por árvore (PMAX) adotada neste trabalho corresponde ao valor médio gerado pelo pomar em um periodo de 10 anos (de 1980 a 1989), sob regime de irrigação.

Com base no trabalino de SEQUEIRA SAMPAIO (1990), verifica-se que um solo tipico desta região é o Latossolo de textura média (Vermelho-amarelo e Vermelho escuro) distrófico. Adotou-se, então, este solo como exemplo, tendo como caracteristicas: $100 \mathrm{~mm}$ de água disponível e $50 \mathrm{~mm}$ de água facilmente disponivel, com profundidade do sistema radicular de $1 \mathrm{~m}$. Com estes dados foi possivel definir o valor da porcentagem de área molhada (PW). Deste mesmo estudo, obteve-se as valores de ETMAX, ETMD e DI, para o nivel de probabilidade de ocorrência de $70 \%$, sendo que o autor trabalhou com dados provenientes da Estação Meteorológica de Cordeirópolis, SP (a mais próxima de Limeira, SP).

o custo de produção por caixa de laranja (CP), para um espaçamento de $8 \mathrm{~m} \times 4 \mathrm{~m}$, foi obtido junto à Associação dos Citricultores do Estado de São Paulo ( ACIESP).

o custo na energia foi obtido junto à CPFL, 
enquanto o fator de recuperação do capital (FRC) foi calculado para taxa de juros anual de $6 \%$ e vida útil de 10 anos.

Para estabelecer as relações custo-dimensão caracteristica, do tipo custo por metro linear versus diâmetro interno da tubulação, foram levantados os dados técnicos e de custo de todos as componentes do sistema de irrigação, desde a moto-bomba até o microaspersor. .

As relações custo-dimensăo caracteristica encontram-se na Tabela 4, e foram obtidas utilizando o programa computacional para ajuste de equações em dados experimentais, desenvolvido por ZULLO JUNIOR \& ARRUDA (1987).

Tabela 4 - Ajuste das relaçzes custo-dimensionais Utilizadas no modelo proposto.

\begin{tabular}{|c|c|c|c|c|}
\hline ITEM & COEF ICIENTE & & DOMINIO & $R^{2}$ \\
\hline CUR & $C_{1}=403,43$ & 0 a & $0,025 m^{3} / 5$ & 1,00 \\
\hline CPC & $C 2=683,90$ e $C 3=0,52$ & $0 \leq$ & NUO $\leq 40$ & 0,89 \\
\hline CEC & $C 4=1812,12$ e $C 5=0,10$ & $0 \leq$ & $Q T \leq 0,042$ & 0,94 \\
\hline CEB & $C_{6}=834,22$ e $C 7=0,47$ & 0 & $50 \mathrm{CV}$ & 0,99 \\
\hline
\end{tabular}

A relação custo-dimensional para tubos de polietileno utilizados nas lintias laterais é dada por:

$$
C P E=[9,03 .(D L A+D L D)]-0,0090
$$

com $R^{2}=0,94$ e válida para diámetros entre $0,01 \mathrm{~m}$ e $0,022 \mathrm{~m}$ 
Para tubos de PVC adotados nas linhas de derivação, a relação é:

$$
\text { CPVCd }=91,41 \cdot\left(D D A^{1,51}+D D^{1,51}\right)
$$

com $R^{2}=0,99$ e válida para diâmetros entre $0,035 m$ e 0,144m

Para tubos de PVC utilizados nas linhas secundária e principal, as equaçơes são:

$$
\text { CPVCs }=380,45 \cdot \mathrm{DS}^{1,78}
$$

com $R^{2}=0,99$ e válida para diâmetros entre $0,035 m$ e 0,310m

$$
C P \cup C P=190,23 \cdot\left(D P A^{1,78}+D P D^{1,78}\right)
$$

com $R^{2}=0,99$ e válida para diâmetros entre 0,035m e 0,310m

\subsection{Parámetros de entrada utilizados na análise de sensibilidade da função objetivo}

Além dos dados de entrada descritos no item anterior, existem outros cujo efeito no valor da função objetivo é alvo deste trabalino. Estes parâmetros de entrada são: tamantio e formato da área, modelo de microaspersor (vazão) e declividade nas direçăes $x$ e $y$.

Os tamanhos de área analisados foram $82944 \mathrm{~m}^{2}$ e $230400 m^{2}$.

Os formatos avaliados foram aqueles de relação LX/LY igual a: $0,25,0,44,1,2,25$ e 4 .

Os tres microaspersores analisados apresentam, na carga hidraulica média de 15m.c.a., vazós 
58.

de $9,72.10^{-6} \mathrm{~m}^{3} / 5(351 / \mathrm{h}), 1,55.10^{-5} \mathrm{~m}^{3} / \mathrm{s}(561 / \mathrm{h}) \mathrm{e}$ $2,41 \cdot 10^{-5} \mathrm{~m}^{3} / 5(87 \mathrm{l} / \mathrm{h})$. As relações vazão - carga hidráulica para estes microaspersores encontram-se na Tabela 5 .

Tabela 5 - Relaçăo vazão-pressăo para os microaspersores \begin{tabular}{|c|c|c|c|}
\hline EMISSOR & $\begin{array}{c}\text { VAZZO NA CARGA } \\
\text { HIDRAULICA DE } \\
\text { OPERAÇZO }(15 \mathrm{~m} . \mathrm{C.2.})\end{array}$ & $\begin{array}{c}\text { RELAÇZO } \\
\text { VAZZL - CARGA } \\
\text { HIDRAULICA }\end{array}$ & $R^{2}$ \\
\hline 1 & $9,72.10^{-6} \mathrm{~m}^{3} / \mathrm{s}$ & $Q=2,42 \cdot 10^{-6} \cdot H^{0,51}$ & 0,99 \\
2 & $1,55.10^{-5} \mathrm{~m}^{3} / \mathrm{s}$ & $Q=3,73 \cdot 10^{-6} \cdot H^{0,52}$ & 0,99 \\
3 & $2,41.10^{-5} \mathrm{~m}^{3} / \mathrm{s}$ & $Q=6,53 \cdot 10^{-6} \cdot H^{0,48}$ & 0,99 \\
\hline
\end{tabular}

$Q=$ vazao do microaspersor, em $\mathrm{m}^{3} / \mathrm{s}$;

$H=$ carga hidráulica no microaspersor, em m.c.a.

As declividades na direções $x$ e y foram adotadas como sendo identicas, porém com valores iquais a o (em nivel\}, $1 \%, 3 \%$ e $5 \%$.

A combinação destes paråmetros e seus diferentes valores resultou em 120 configuraçzes.

\subsection{Sol ução do modelo}

Para solucionar o modelo nãolinear de otimização de sistemas de irrigação por microaspersão aplicado ao caso da citricultura em Limeira, SP, utilizou-se o modulo MINOS do "software" GAMS ("General 
59.

Algebric Modeling System"), que permite a resolução de sistemas de equaçōes não-lineares.

Os algoritmos básicos utilizados pelo GAMS/MINOS são: a método de Newton, o método do Gradiente Reduzido e o método de Lagrange. As caracteristicas e aplicaçర̃es do programa GAMS são encontradas em BROOKS et a1. (1988).

0 modulo GAMS/MINOS resolve problemas que apresentam equaçơes não-lineares na funçăo objetivo e nas restrições, porém não admite variáveis inteiras กสัo-1 ineares.

O modelo proposto apresenta muitas variáveis não-lineares que só tem significado real se forem inteiras, como é o caso do número de unidades operacionais (NuO).

Para adequar as limitações do programa às necessidades do modelo, algumas exigencias foram estabelecidas e adotadas como hipóteses básicas do modelo proposto, as quais foram descritas no item número 3.1 . Criou-se, ainda, um procedimento para se obter a solução ótima com variáveis inteiras não-lineares, que consiste em:

$$
\text { - selecionar valores iniciais confiáveis }
$$
para as variáveis de decisão (Tabela 2), caso contrário, o programa GAMS irá adotar o valor 0 , que para muitas funçōes não é recomendado pois a derivada também será o ;

- rodar o modelo e anotar os valores das variáveis NUOS e NLS que otimizam a funçăo objetivo. Na 
maioria das vezes, estas variáveis apresentam-se como não inteiras;

- a partir das variáveis NUOS e NLS obtidas na primeira solução, identificar os valores inteiros mais próximos (tanto inferior como superior) e compor as pares NUOS - NLS que atendam a exigência descrita nas hipóteses básicas (NUOS/NLS = número inteiro);

- rodar estas combinaçனes (NUOS e NLS pré-estabelecidos) visando obter o valor de NUO (que continua como variávell para cada uma delas. Muito provavelmente, o valor de NUO obtido seja não inteiro. Portanto, deve-se considerar os valores inteiros de NUO mais próximos e compor com os pares NUOS - NLS, as combinaçơses que atendam as hipóteses básicas (NUO iqual ou múltiplo de NUOS, NUO/NLS igual a um número par e NUOS/NLS igual a um número inteirol;

- rodar as combinaçzes compostas por valores inteiros de NUO, NUOS e NLS. Dentre as combinaçひes que resultem em valores inteiros de NGE e NLL, escolher aquela que fornece o maior valor na função objetivo (maior receita liquida). Ela é a solução ótima local.

As hipóteses básicas e a adoção do procedimento descrito acima permitem que se obtenha uma solução ótima composta por variáveis inteiras não-lineares.

A solução encontrada pelo programa GAMS é um otimo local, ou seja, pode ou não ser o ótimo global. 


\section{RESULTADOS E DISCUSSÃO}

A combinação dos diferentes paråmetros de entrada utilizados na análise de sensibilidade, resultou em 120 diferentes situaçőes de projeto. Para ilustrar como o modelo é expresso na linguagem GaMs para ser solucionado pelo "solver" MINOS, encontra-se no Apêndice 1 a descrição de uma destas situações.

o tempo necessário para que o programa GAMS/MINOS resolva o modelo de maximização desenvolvido é de, aproximadamente, 60 segundos.

\subsection{Resultados}

Os resultados para as 120 combinaçơes estudadas estão no Apêndice 2 - Tabela 1. Constatou-se que os valores das variáveis, obtidos para cada uma das 120 situaçỡes, foram consistentes com os limites estabelecidos e com as equaçơes năo-lineares que compơem o modelo, o que demonstra a precisão do programa utilizado. Notou-se, também, que as configuraçós produzidas pelo modelo proposto não diferiram das conformaçơes definidas pelas hipóteses básicas. Isto evidencia a eficácia das equaçớs năo-lineares em gerar conformaçơes previstas pelo modelo. 
Na maioria das situaçơs, o modelo năo adotou linhas principais. Porém, nas configuraçōes 89 e 90 (Apêndice 2 - Tabela 1), ocorreram tais linhas e o sistema de equaçóes não-lineares apresentou resultados consistentes.

A coerencia entre os resultados obtidos e as hipóteses do modelo desenvolvido ocorreu, também, em relação aos critérios hidráulicos e operacionais.

A uniformidade de emissão não esteve acima de $90 \%$ em nenthuma das soluções apresentadas, indicando que - ótimo em termos de distribuiçăo de água nem sempre resulta em maior receita liquida.

Não foi possivel encontrar a solução ótima em 12 casos, ou seja, não se identificou um conjunto de valores que atendesse às restriçơs do modelo, dentro dos limites estabelecidos para as variáveis.

Os diâmetros das linhas da rede hidráulica, fornecidos como solução otima pelo modelo, năo são mecessariamente valores disponiveis no mercado, posto que o programa Gams năo trabaliha com variáveis não-lineares inteiras (não utiliza variáveis discretas). Os diâmetros das linhas são variáveis continuas e podem ser interpretados como diámetros equivalentes. 0 trecho composto por um diâmetro equivalente pode ser desdobrado em duas partes, constituldas por diåmetros comerciais sucessivos. Esta conversão pode ser realizada de forma 
otimizada utilizando-se a Programação Linear.

4.z. Configuração de maior receița liquida anual versus configuração de menor receita liquida anual

A configuração que resultou em maior valor de receita liquida anual (US\$2939/ha) é aquela de 23,04 ha, com 480m x 480m, em nivel e com emissor de $351 / h$. Por sua vez, a de menor valor de receita liquida anual (US\$2402/ha) apresenta $L X=144 \mathrm{~m}$ e LY $=576 \mathrm{~m}$ (área de 8,294 ha com LX/LY $=0,25$ ), declividade de $5 \%$ nas duas direções e vazão do microaspersor de $561 / \mathrm{h}$.

Os resultados para estas duas situações encontram-se na Tabela 6. Nota-se que a situação mais rentável apresentou maior receita bruta anual e menor custo anual do sistema em relação à outra configuração.

A declividade contribuiu para a diferença de desempentio das duas situações analisadas. Na configuração de maior receita a declividade é igual a o (em nível), o que possibilitou dividir a área de 23,04 ha em 4 unidades operacionais com uniformidade de emissão de $82 \%$. Na conformação de menor rentabilidade, o desnivel é de $5 \%$ e a uniformidade de emissão de $81 \%$, porém a área foi subdividida em 8 unidades, gerando uma maior custo anual do sistema de irrigação. Portanto, a maior receita liquida foi obtida em uma área de forma quadrangular, em nível e com o microaspersor de menor vazăo (35 l/h). 
Tabela 6 - Comparação entre a configuração de maior e a de menor receita İquida anual.

\begin{tabular}{|c|c|c|}
\hline VARLAVEIS & CONFGUAACAO & CONFGURACEO \\
\hline & MAIS AENTAVEL | & MENOS RENTAVEL \\
\hline A(he) & 23.04 & 8.294 \\
\hline$L \times(m)$ & 480 & 144 \\
\hline$L Y(m)$ & 460 & 576 \\
\hline OE (M) & 35 & 56 \\
\hline DECX(\%) & 0 & 5 \\
\hline DECY $\{\%\}$ & 0 & 5 \\
\hline FO (USsmaeno) & 2939 & 2402 \\
\hline CSIST US\$ma.anol & 329 & 483 \\
\hline RBRUTA IUS\& me enol & 4624 & 4241 \\
\hline CPROD NS\&he enol & 1356 & 1356 \\
\hline NUO & 4 & 8 \\
\hline NUOS & 9 & 9 \\
\hline NLS & 1 & 1 \\
\hline$L(m)$ & - & - \\
\hline$U(m)$ & 118 & 70 \\
\hline$L D(m)$ & 236 & 68 \\
\hline $\operatorname{LS}(\mathrm{m})$ & 360 & 504 \\
\hline CENE (USS/ano) & 1284 & 631 \\
\hline CEB(USS) & 3050 & 2042 \\
\hline CVR(USS) & 1614 & 3227 \\
\hline CPCUSA) & 1406 & 2017 \\
\hline CECNS\$ & 8112 & 3627 \\
\hline$\pi(m)$ & 28320 & 10080 \\
\hline$\pi \times(m)$ & - & - \\
\hline$\pi 0(m)$ & 944 & 544 \\
\hline$\pi s(m)$ & 360 & 504 \\
\hline HT (mca) & 28.94 & 50 \\
\hline HDA (mca) & 3.78 & 0.091 \\
\hline HOD (mcs) & 3.78 & 6.89 \\
\hline HLA(mca) & 453 & 0,94 \\
\hline HLO (mos) & 4.53 & 7.94 \\
\hline$D P A(m)$ & - & - \\
\hline$D F D(m)$ & - & - \\
\hline$D L D(m)$ & 0,018 & 0,014 \\
\hline DDA $(m)$ & 0.096 & 0.104 \\
\hline DDD (m) & 0.096 & 0.042 \\
\hline NGE & 30 & 18 \\
\hline NLL & 30 & 9 \\
\hline NSS & 2 & 4 \\
\hline$Q L(m)$ & 1050 & 1008 \\
\hline $00(\mathrm{~m})$ & 63000 & 18144 \\
\hline HS (mca) & 4.26 & 1.01 \\
\hline as (Wn) & 63000 & 16144 \\
\hline HPA (mca) & - & - \\
\hline OP (Wh & - & - \\
\hline OT (Mn) & 63000 & 18144 \\
\hline NSP & - & - \\
\hline HPD (mca) & - & - \\
\hline DHUO (mcal & 8.31 & 7.93 \\
\hline VPA $(m / s)$ & - & - \\
\hline VPO (m/s) & - & - \\
\hline$V s(\mathrm{~m} / \mathrm{s})$ & 1.66 & 0.64 \\
\hline TE & 7200 & 2592 \\
\hline$D S(m)$ & 0.116 & 0.101 \\
\hline DLA(m) & 0.018 & 0.022 \\
\hline UE & 0.82 & 0,81 \\
\hline HMIN (mcal & 11.68 & 11.83 \\
\hline $\lim$ & 13,67 & 10,49 \\
\hline$T$ (dia) & 3 & 4 \\
\hline
\end{tabular}


4. 3. Efeito do tamanho e formato da área na receita 1 iquida anual

No Apêndice 3 - Fiquras de 1 a 12 , tem-se a receita liquida anual em função do tamanto e do formato da área, para os diferentes microaspersores e declividades utilizados nesta análise de sensibilidade.

Verificou-se que, tanto para a declividade de $1 \%$ como para o terreno em nivel, a área de 23,04ha resultou em maior receita liquida anual em comparação com a de $8,294 h a$, para todos os formatos (LX/LY) e microaspersores avaliados. Nas declividades $3 \%$ e $5 \%$, não se constatou esta mesma predominåncia pois, com o aumento do valor de LX/LY, a área de 8,294ha apresentou, na maioria dos casos, maior receita liquida que aquela de 23,04 ha. Estas tendências podem ser notadas nas figuras 4 e 5 , onde se tem a vazão do microaspersor de $351 / \mathrm{h}$ na condiçăo em nivel e na situação com declividade de $5 \%$.

A variação do custo anual do sistema de irrigação por microaspersão em função do formato da área, tem relação com as constataçóes realizadas anteriormente. Nas Figuras o e 7 tem-se esta relação para a vazão do microaspersor de $35 \mathrm{l} / \mathrm{h}$, nas condiçäes em nivel e de $5 \%$ de declividade. Em nivel, a área de 8,294 ha apresentou maior custo anual do sistema que a área de 23,04ha, para todos os formatos. Por sua vez, na condição de $5 \%$ de declividade, a área de 23,04ha apresentou maior custo anual do sistema, 
YAZÃO $=351 / \mathrm{h}$ DECLMDADE: ON0

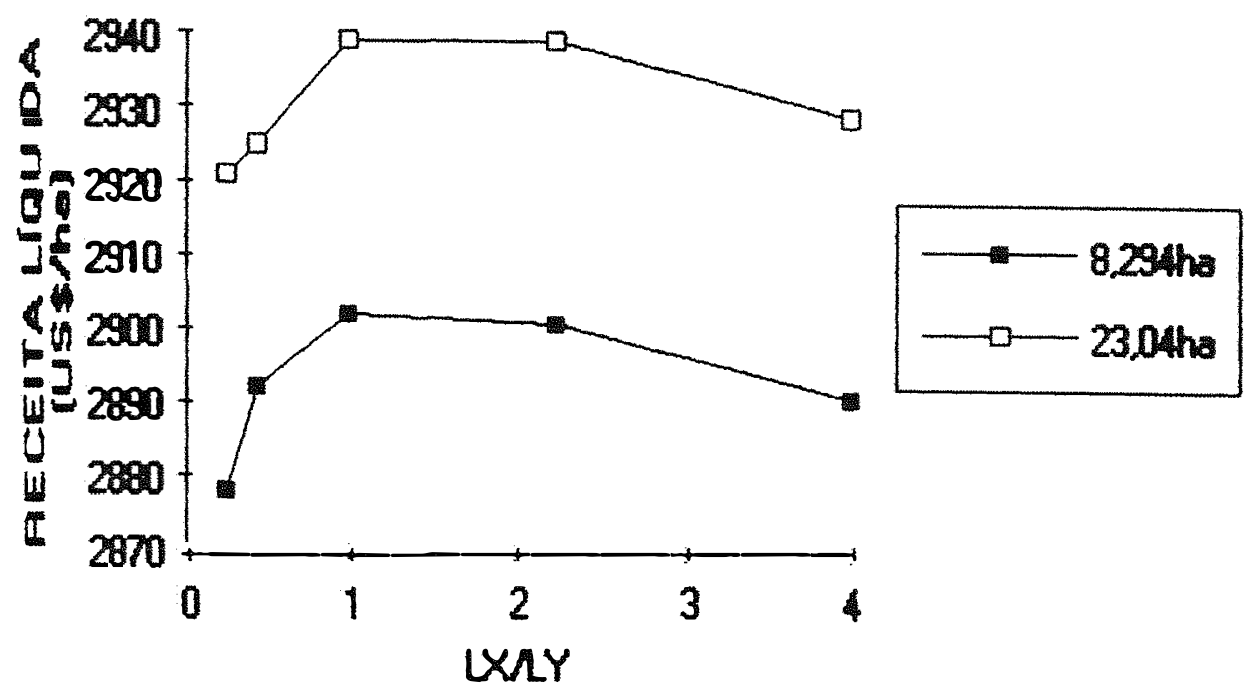

Figna 4 - Receida liquida anual em funcão do tamanho e do formato da área.

para a vazăo de $35 \mathrm{l} / \mathrm{h}$ e declividade 0 .

VAZAO $=35 \mathrm{lh}$ DECLMDADE: $5 \% \times 5 \%$
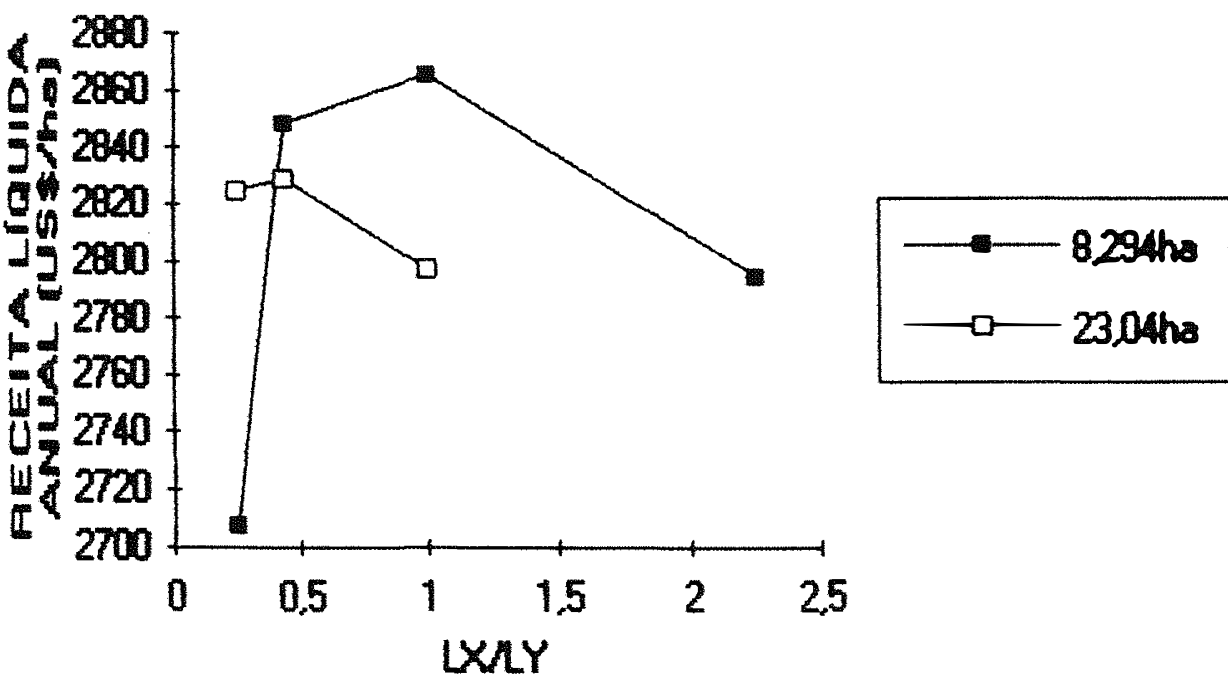

Figesa 5 - Receita liquida anual en fungảo do lamanho e do lormoto da áres. para a yerco de 35 th e decFividede de $5 \%$. 


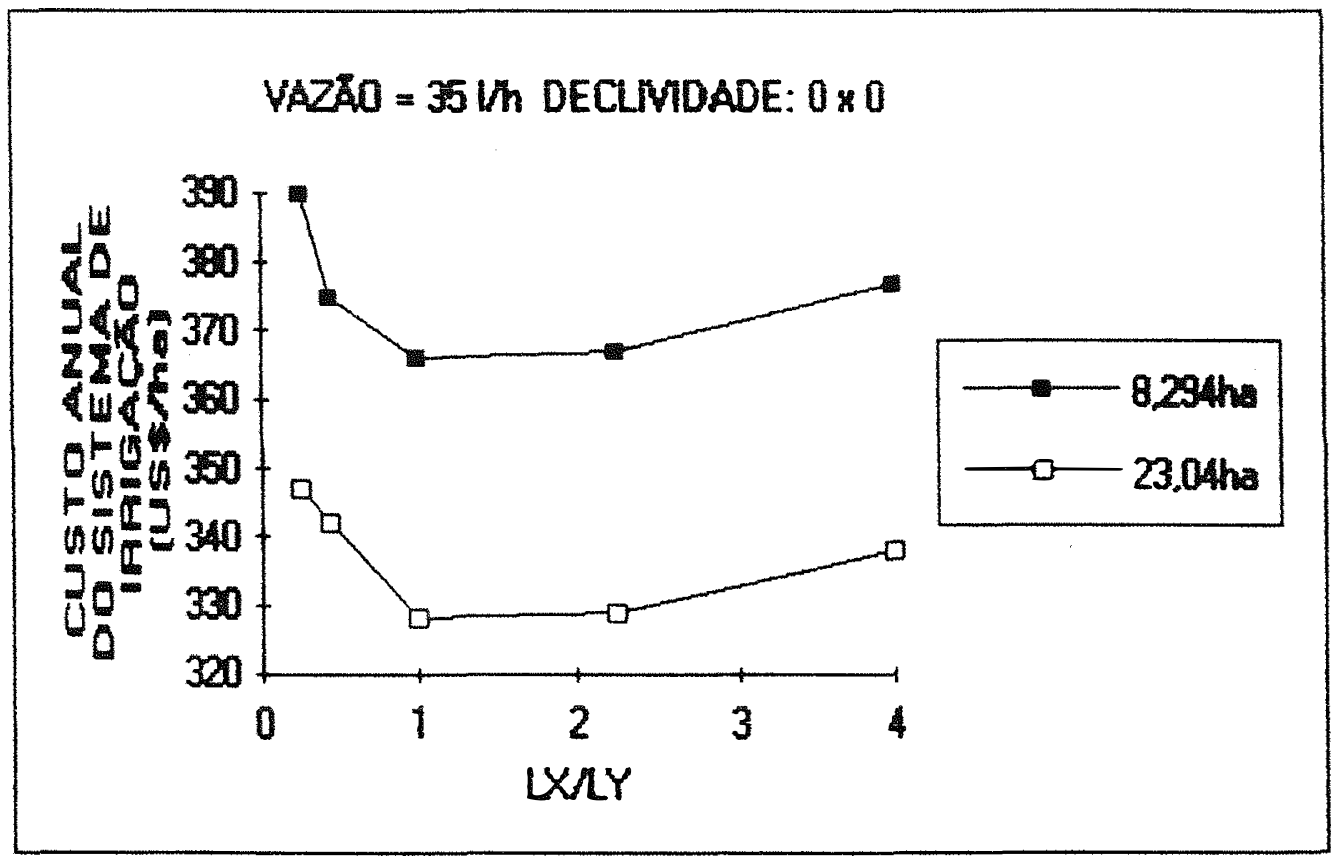

Figua 6 - Custo anual do sisterna de irigacâo em funcáo do lamantio e do fomato da área, pała a vazão de $35 \mathrm{lth}$ e decividade 0

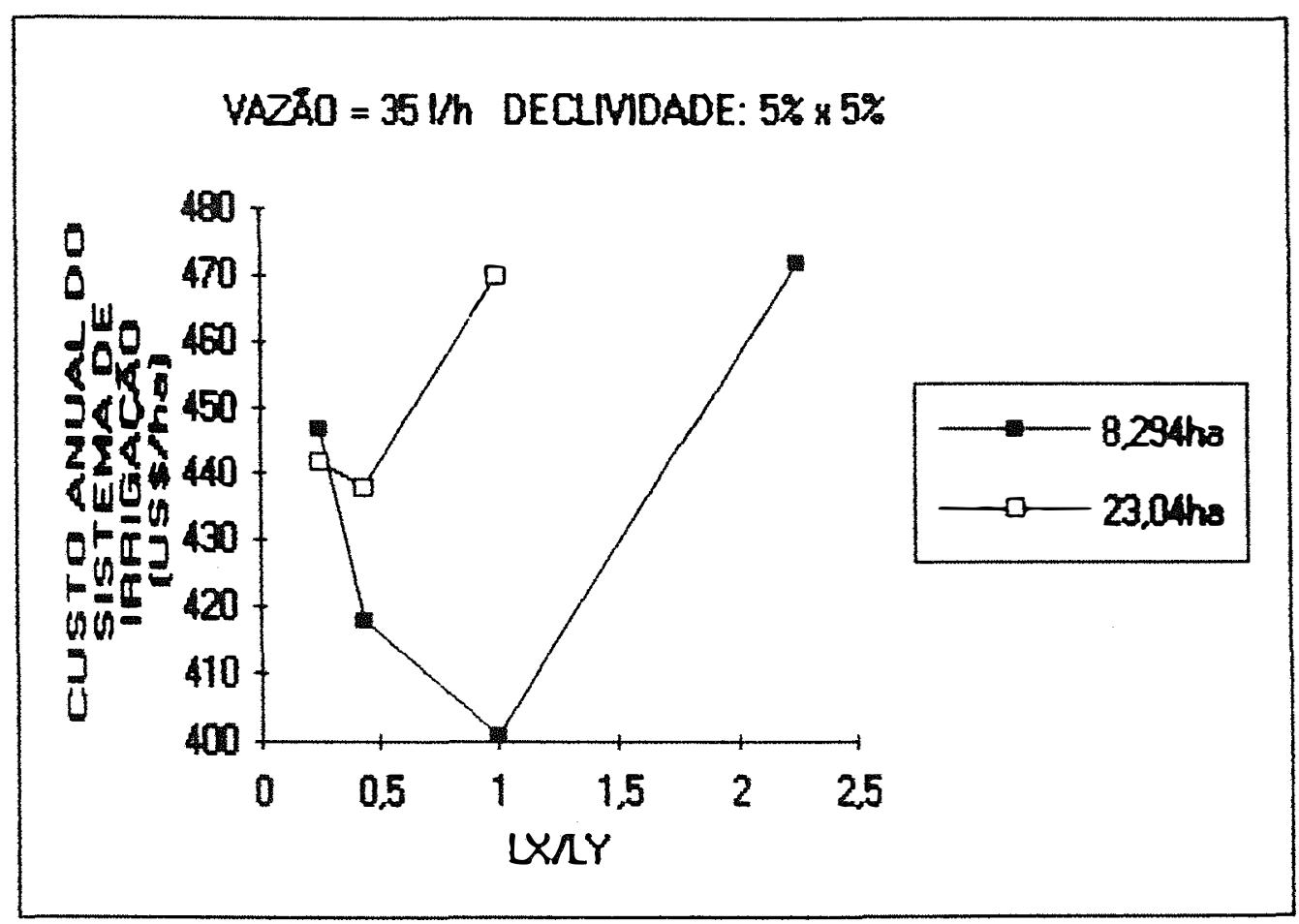

Figura 7 - Custo anual do sistema de ingaçäo em função do lamantro e do formato da àea, para a vazõo de 35 th e declividade $5 \%$ 
68.

na maioria dos formatos.

No Apêndice 2 - Tabela 1, verifica-se que o custo de produção é fixo para as 120 configuraçర̃es, enquanto a receita bruta é praticamente constante e de valor máximo. Desta forma, o custo anual do sistema é o principal fator que determina a variação da receita líquida anual nas situaçăes analisadas neste trabalho.

o formato que resultou em maior receita liquida anual para a área de 8,294 ha foi o quadrangular ( $L X / L Y=1)$, para todos os microaspersores e declividades analisados (Apéndice 3 - Figuras 1 a 12). No caso da área de 23,04ha, o valor de LX/LY que resultou em maior receita liquida anual variou entre 0,44 e 1 . Para o microaspersor de vazão igual a 35 l/h, utilizado em declividades de até $3 \%$, o formato quadrangular foi mais rentável. O valor LX/LY igual a 0,44 resultou em maior receita para o microaspersor de 87 l/h combinado com todas as declividades e, também, para os emissores de vazóes 35 l/he 56 l/h associados à declividade de $5 \%$.

Portanto, para areas de 8,294ha o formato mais rentável é o quadrangular, enquanto que para áreas de 23, O4ha este formato prevalece para declividades de ate $3 \%$, associadas a microaspersores de vazăo inferior ou igual a 56 l/h. Para declividade de 5\% ou microaspersor de 87 l/h, - valor LX/LY igual a 0,44 resulta em maior lucro. 
4. 4. Efeito da vazão do microaspersor na receita 1 iquida anual

Para realizar esta análise considerou-se apenas o formato quadrangular, uma vez que ele resulta, na maioria dos casos, na configuração mais rentável. Nas Figuras 8, 9, 10 e 11 eståo os gráficos referentes à receita liquida em função do microaspersor utilizado, para cada uma das declividades analisadas.

$$
\text { Observa-se que, para todas as declividades, }
$$

a receita liquida diminui com o uso de microaspersores de maior vazăo, tanto na área de 8,294ha como na de $23,04 h a$. Nota-se, ainda, que a área de 8,294ha resultou em maior receita liquida nas declividades $0,1 \%$ e $3 \%$, sendo que no valor 5\% prevaleceu a área de $23,04 h a$, o que está coerente com a descrito no item anterior.

A Figura 12 apresenta o custo anual do sistema de irrigação em função do microaspersor, para a condição em nível. Nota-se que o custo do sistema aumenta com o uso de microaspersores de maior vazão, dal o decréscimo na receita liquida correspondente. Uma vez que o microaspersor de vazăo $351 /$ h atende às restriçžes técnicas do modelo (tempo diário disponivel para irrigação e máximo turno de irrigaçãol, ele é a solução mais economica posto que o uso de emissores de maior vazão resultará em maior custo do sistema. 


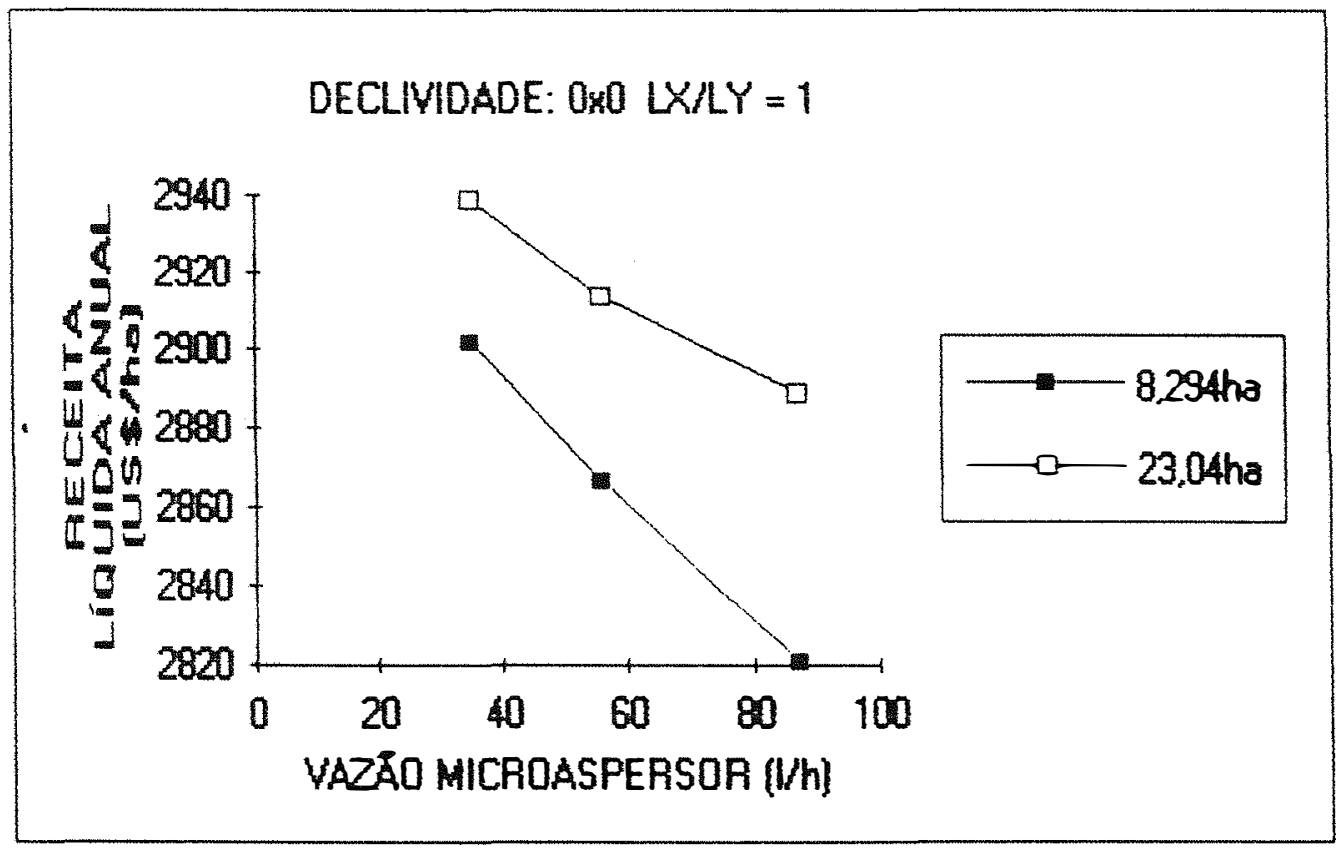

Figura 8 - Receda líquida anual em funcão da yazð̃o do microaspersor. para $L X \Lambda Y=1$ e declividade 0.

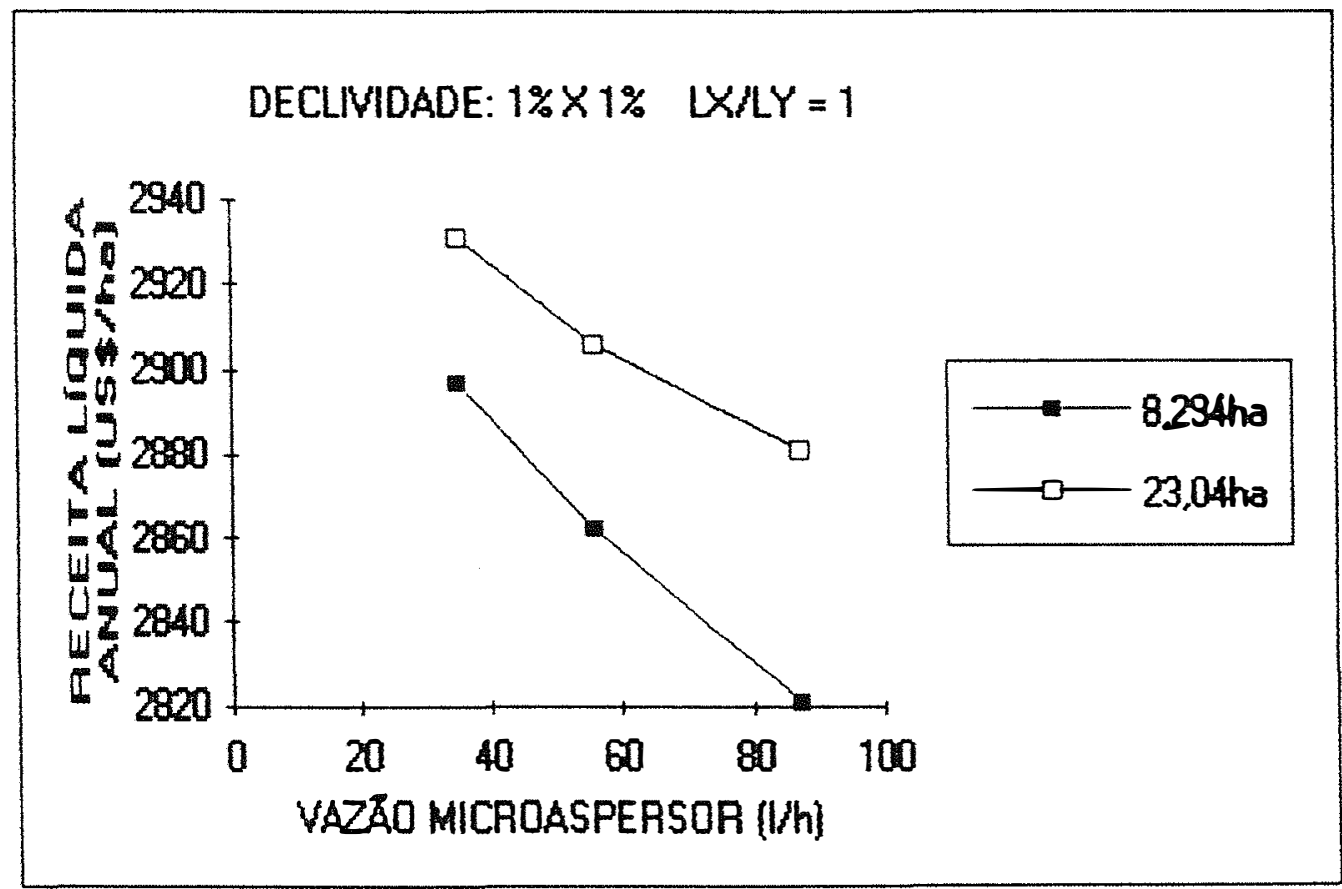

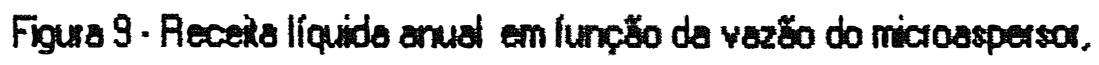
para $L X \wedge Y=1$ e dectividade $1 \%$. 


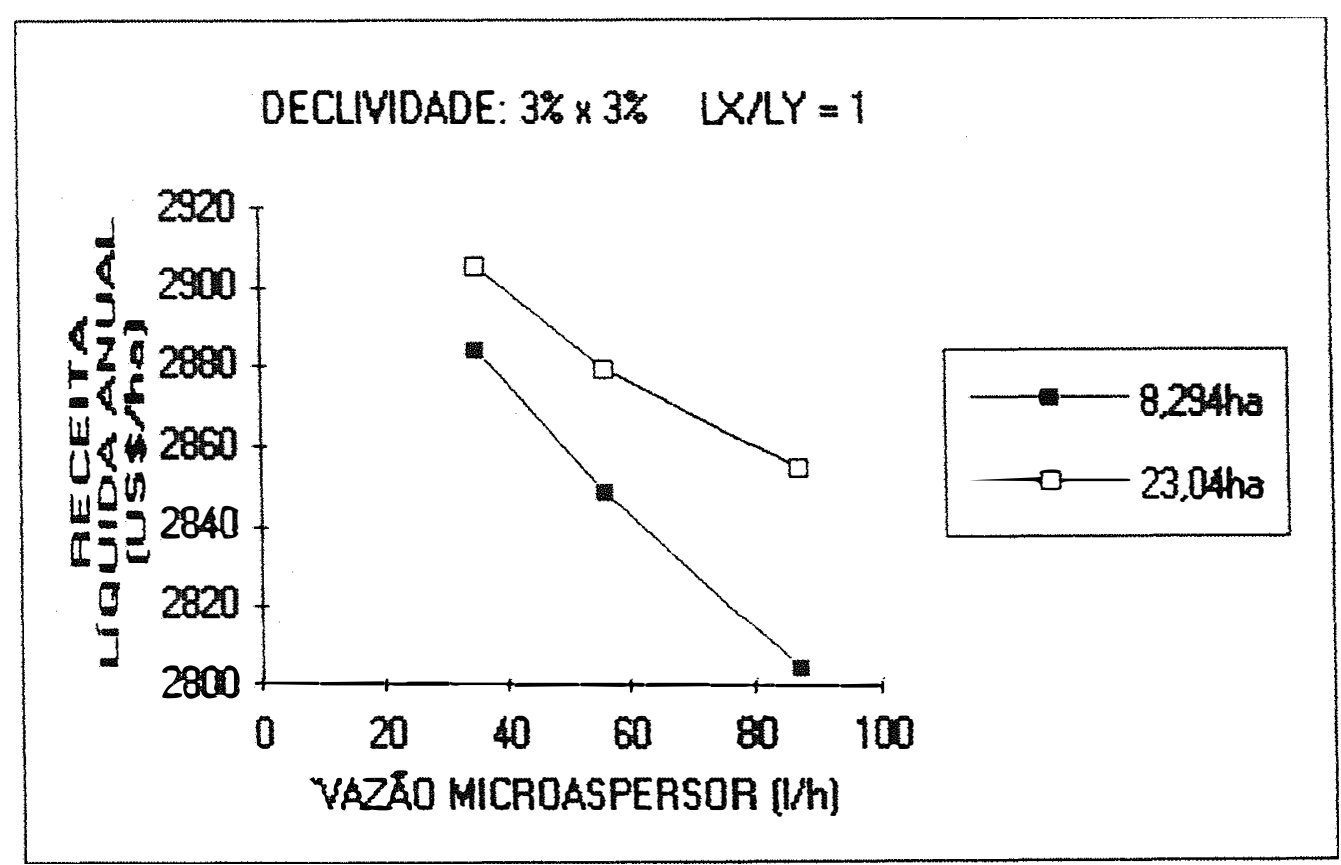

Figura 10 - Receita liquida anual en luncão da vazão do microaspersor. para $L$ K $Y Y=1$ e dectividade $3 \%$.

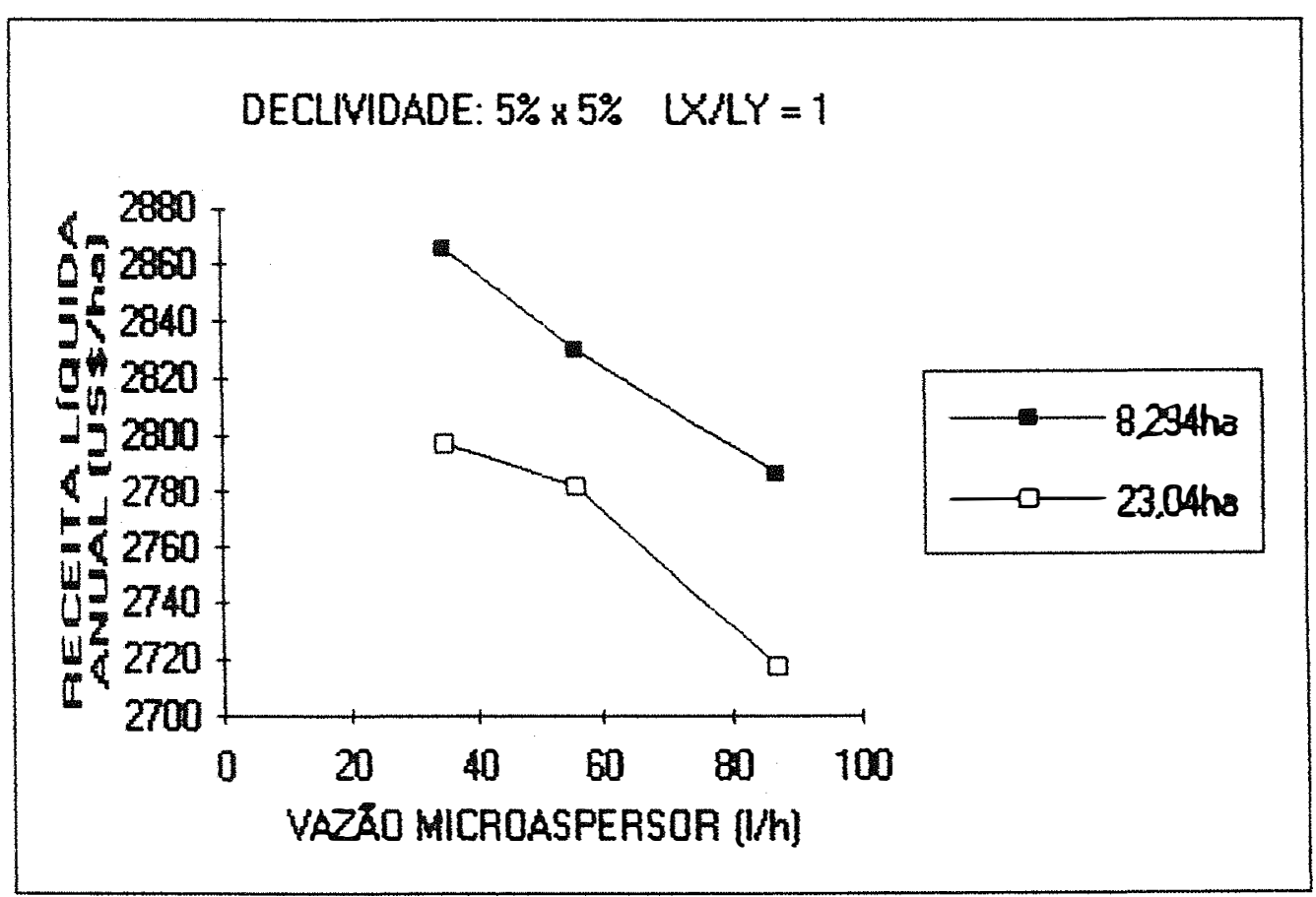

Figua 11 - Receita líquida anual em função da vazấo do microaspersox, para $L \times \wedge Y=1$ e dectividade de $5 \%$. 


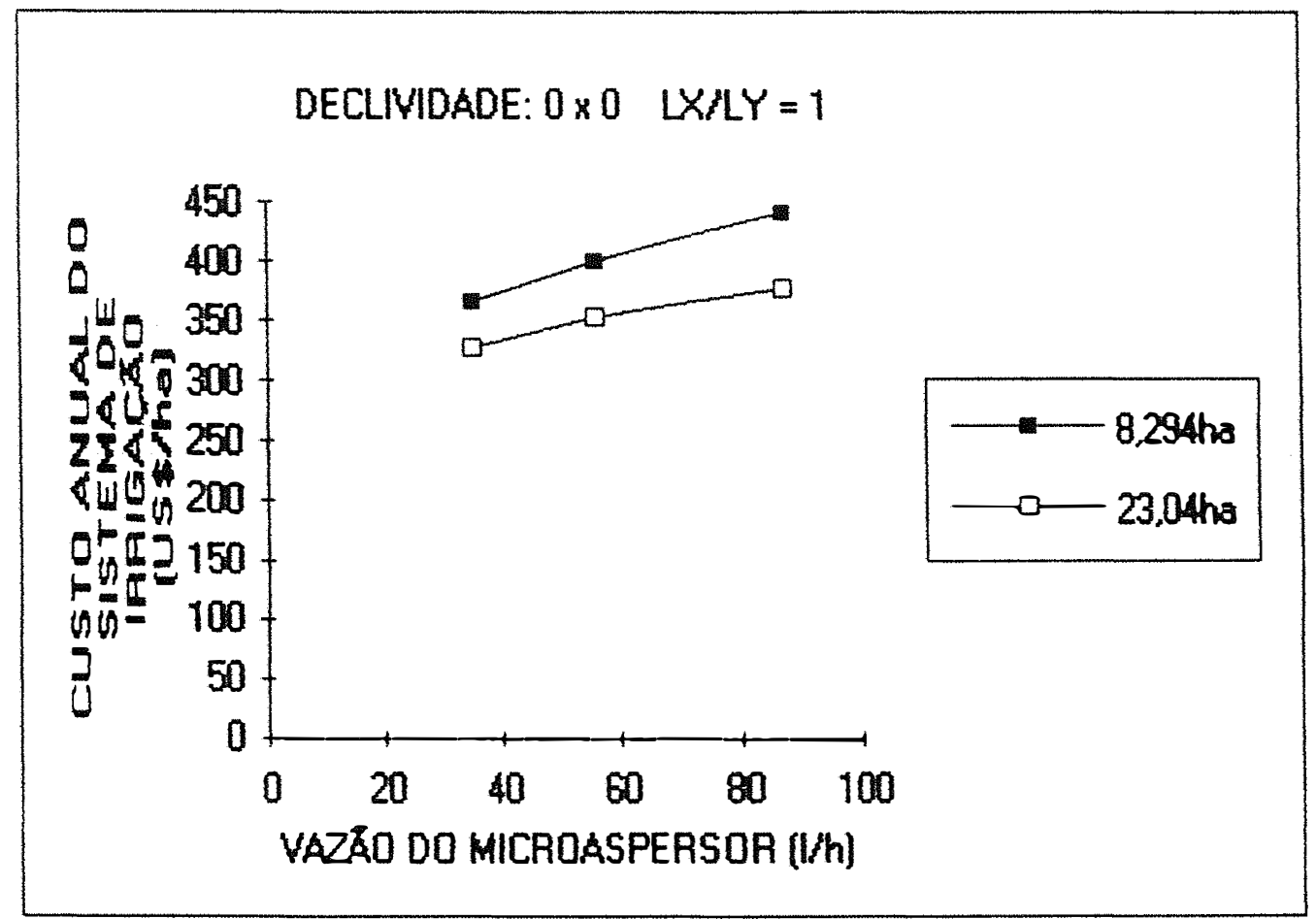

Figua 12 - Custo anuat do sistema de irigação em função da yazão do microaspersor, para dectividade 0 e $L \times \Omega Y=1$. 


\title{
4.5. Efeito da declividade na receita liquida anual
}

\author{
o sentido da declividade na direção $x$ é da \\ esquerda para a direita, enquanto que na direção y é de \\ cima para baixo.
}

$$
\text { Os valores de declividade utilizados na }
$$
análise de sensibilidade foram $0,1,3$ e $5 \%$. Adotou-se, sempre, o mesmo valor para as direçठ̃es $x$ e $y$.

Nas Figuras 13,14 e 15 estão representadas as relaçōes entre a receita liquida anual e a declividade nas duas direçōes, para os dois tamanhos de área no formato quadrangular e para os trés microaspersores em estudo. Verifica-se que a receita liquida anual decresce com o aumento da declividade, nos trés microaspersores avaliados. Observa-se, ainda, que até a declividade $3 \%$ a área de 23,04ha resulta em maior receita liquida anual, sendo que para valores acima de 3\% prevalece a área 8,294ha.

o custo anual do sistema de irrigação é que determina esta inversão de tendencia, conforme pode ser observado na figura 16, para o microaspersor de vazão 35 $1 / h$. 


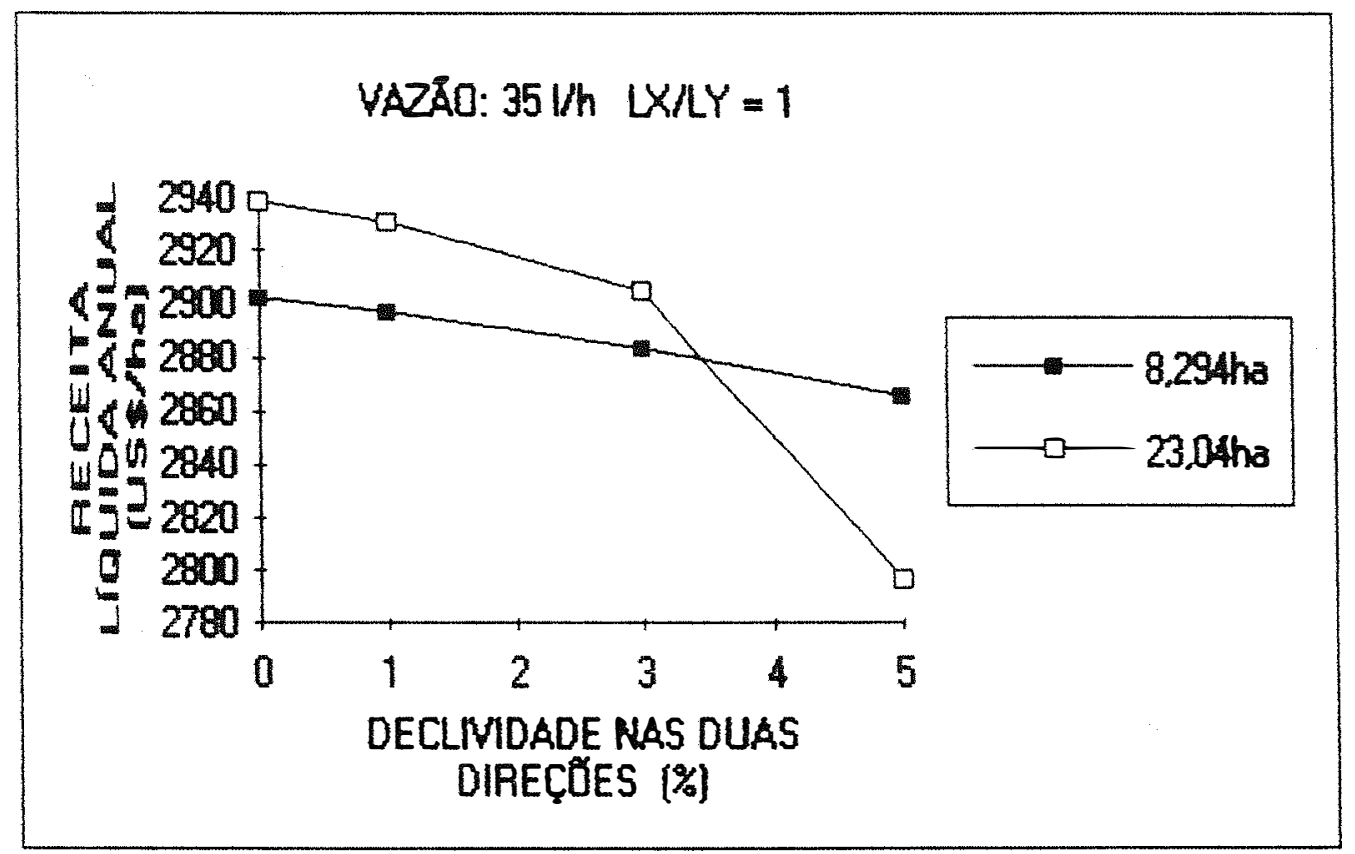

Figura 13 - Receila liquida anual em funçäo da dectividade na dua dinecóes. para a yazão de 3 th e $L X / Y=1$.

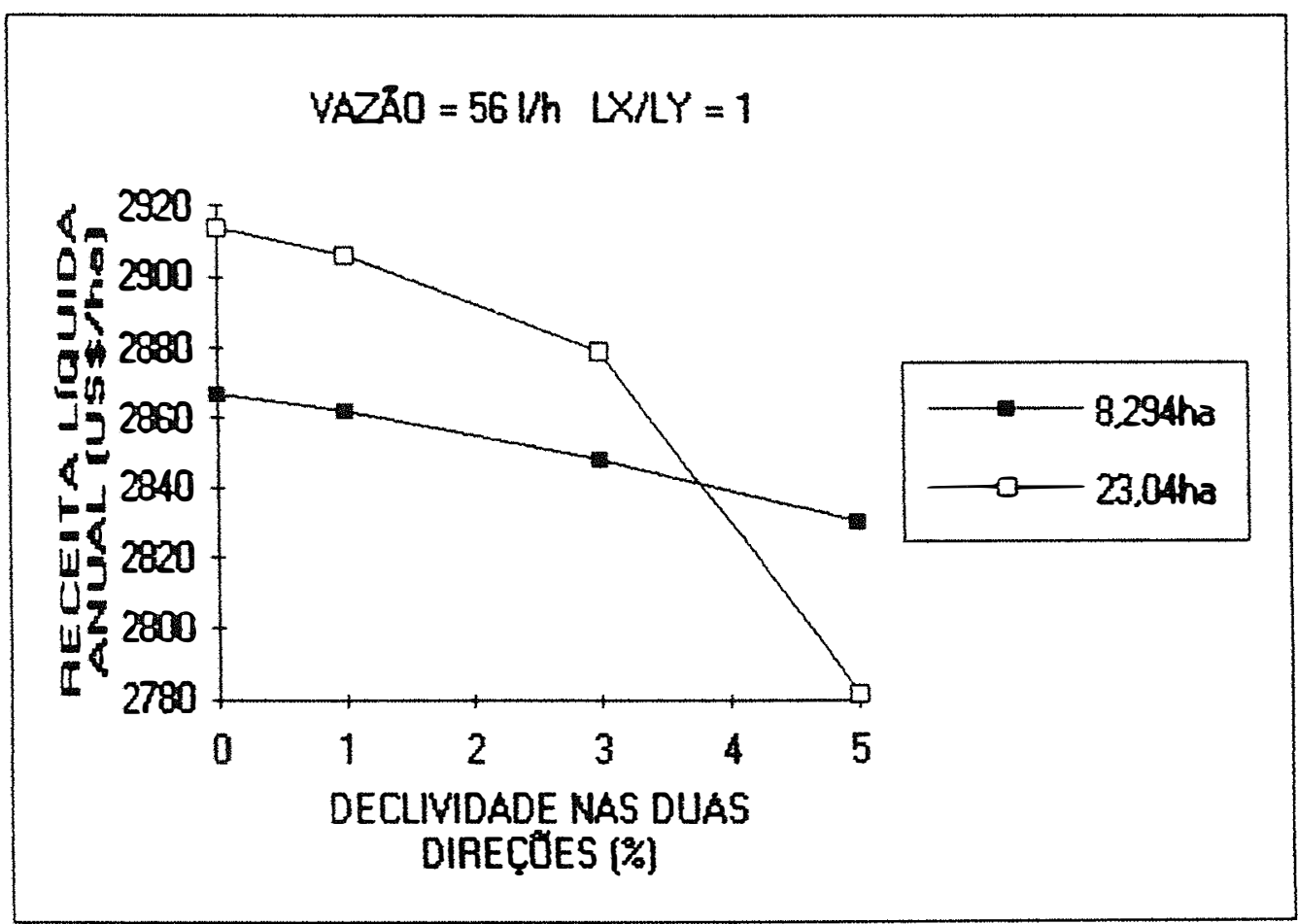

Figua 14 - Receita líquida amuat em funcäo da declividade nas duas dreçôs. para a vazão de 56 th e LX 


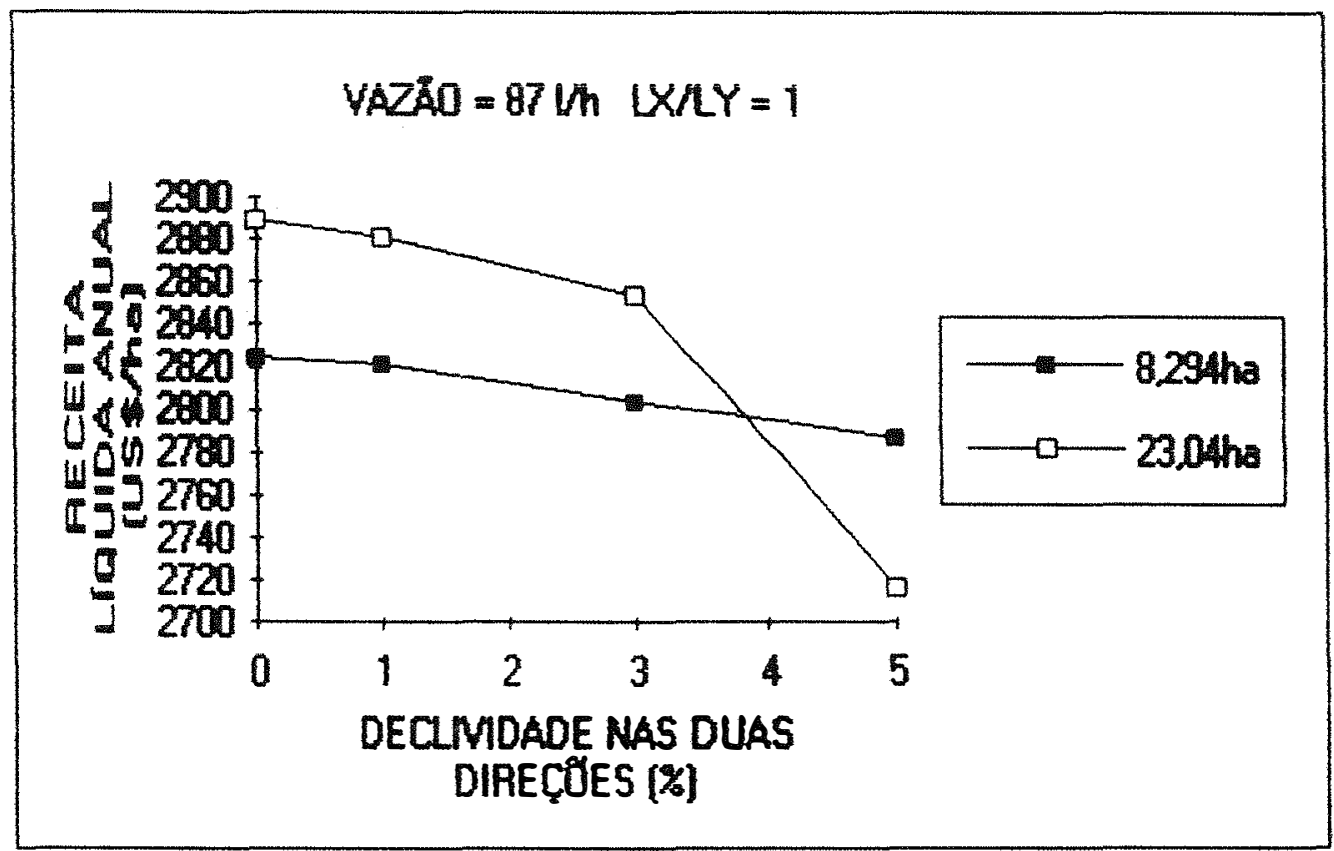

Figura 15 - Receita líquida anual en função da declividade nas duss frecöes. para a yazấo de 87 the LXNY $=1$.

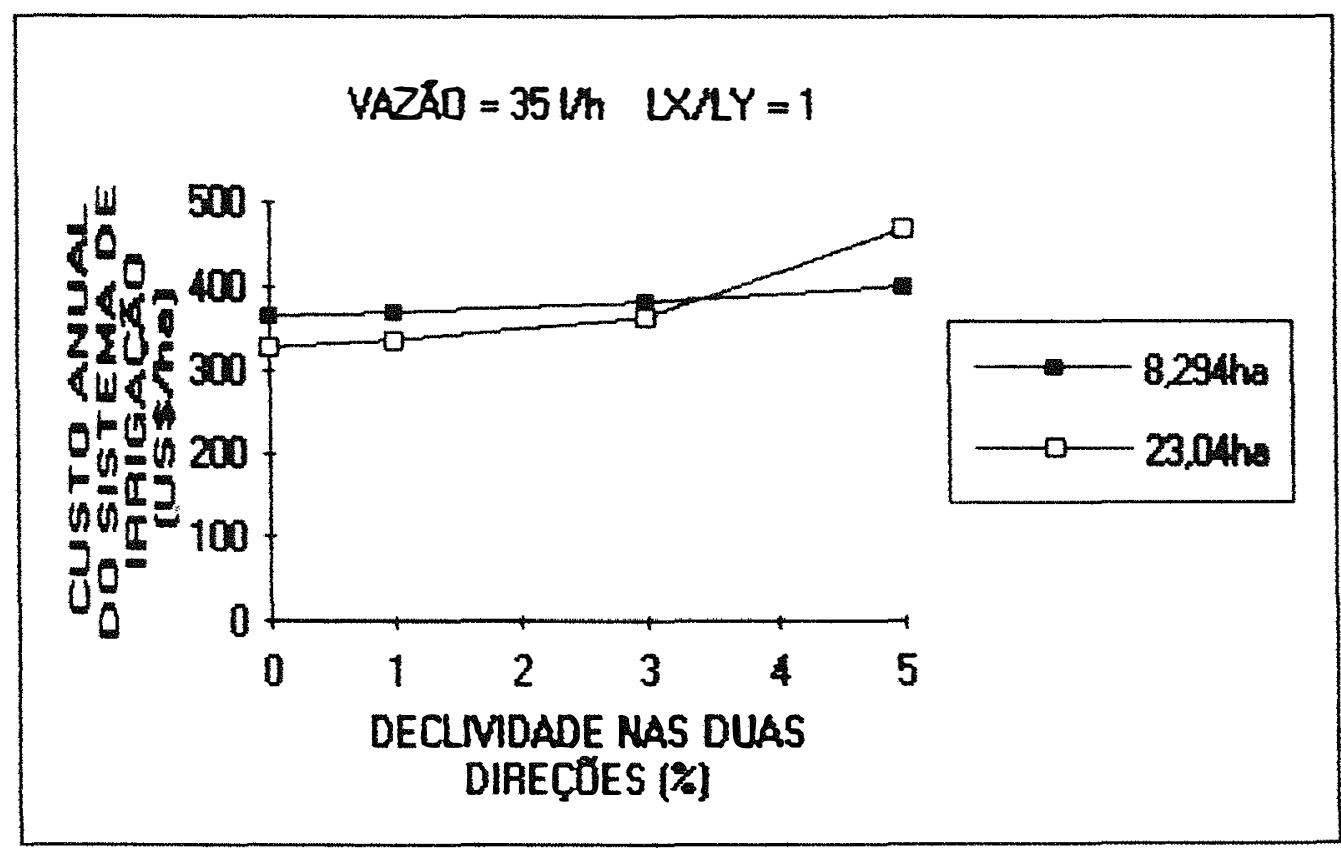

Figura 16 - Custo anual do sistema de irigacão en função da dectridade nas duas deçöes, para a yazõo de 35 the $L X \wedge Y=1$. 
76.

4.6. Relação da uniformidade de emissão (UE) com o formato e com a declividade

A relação entre a uniformidade de emissão e - formato da área, para o microaspersor de vazão igual a 351/h, na condição em nivel e na situação com declividade de $3 \%$, está descrita nas figuras 17 e 18 . Observa-se que para a área de 23,04ha a uniformidade de emissão decresce com o aumento da relação LX/LY. Por sua vez, na área de 8,294ha, a variação da UE com o formato foi muito pequena. Os valores de UE da área de 8,294ha estiveram, na maioria dos valores LX/LY, acima dos correspondentes para a área de 23, o4ha.

As Figuras 19 e 20 revelam que a uniformidade de emissão decresce com o aumento da declividade. Isto ocorre porque o aumento da declividade provoca maiores variaçães na distribuição de carga hidráulica na unidade operacional, que é a base do conceito de uniformidade de emissão. Desta forma, como o tamanho e o formato da área năo foram alterados, maiores variaçăes na carga hidráulica da unidade significam menores valores de uniformidade de emissão. 


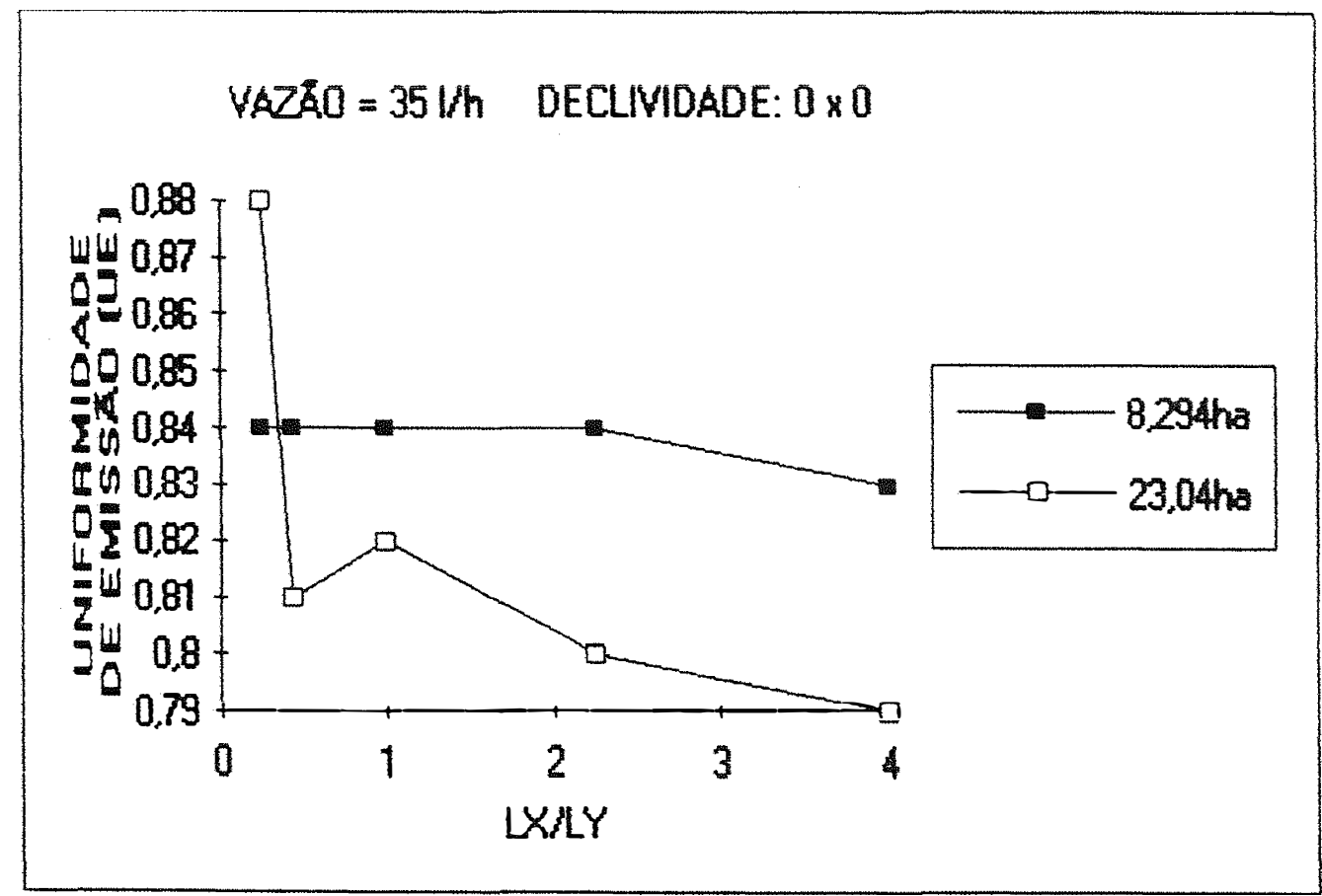

Figura 17 - Unifornidade de enisas̃o em funç̃ó do tamanho e do formato da área. para a yazăo de 35 the declividade 0.

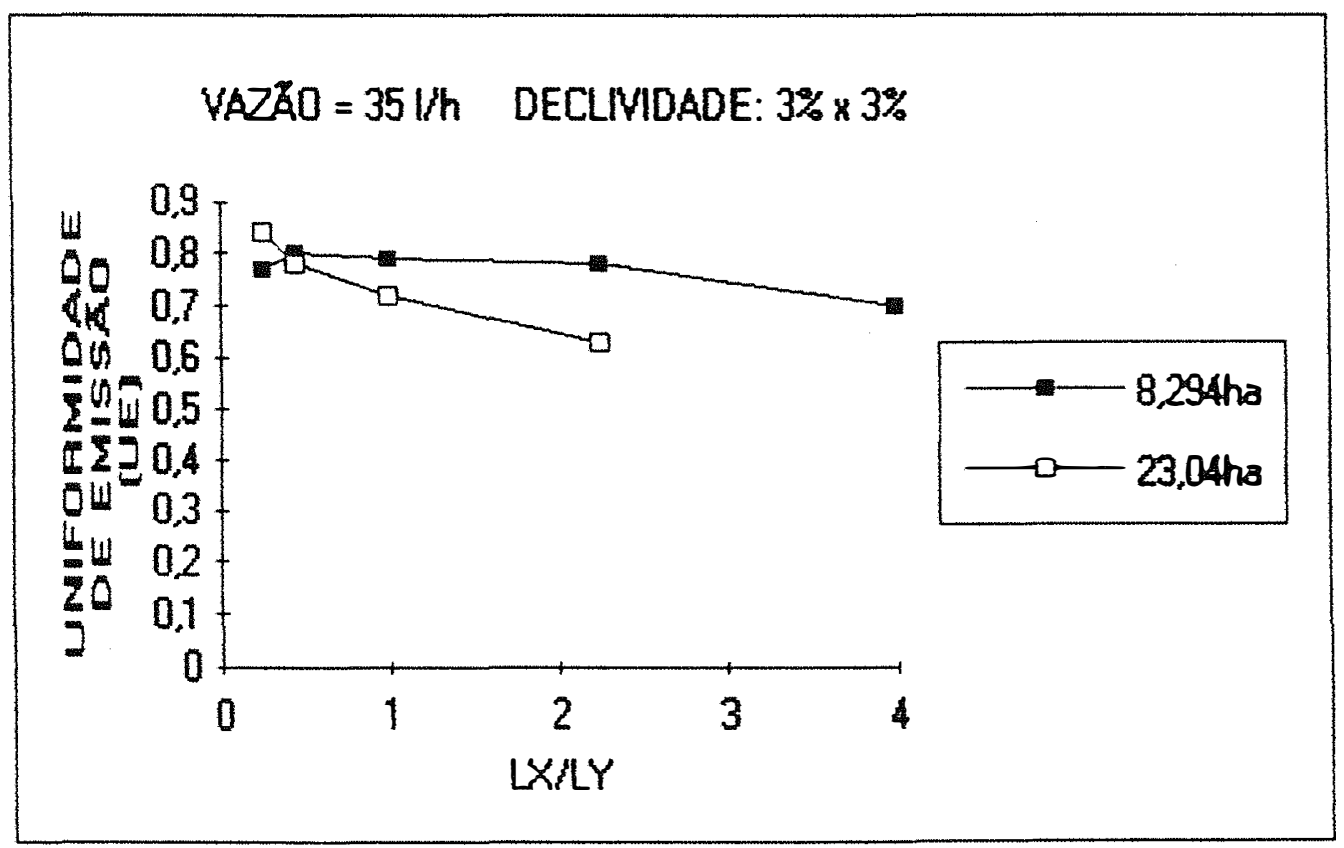

Figua 18 - Uniformidade de encesão em fungăo do lamanho e do formato da área, para a yazẫo de 35 the declividade de $3 \%$. 


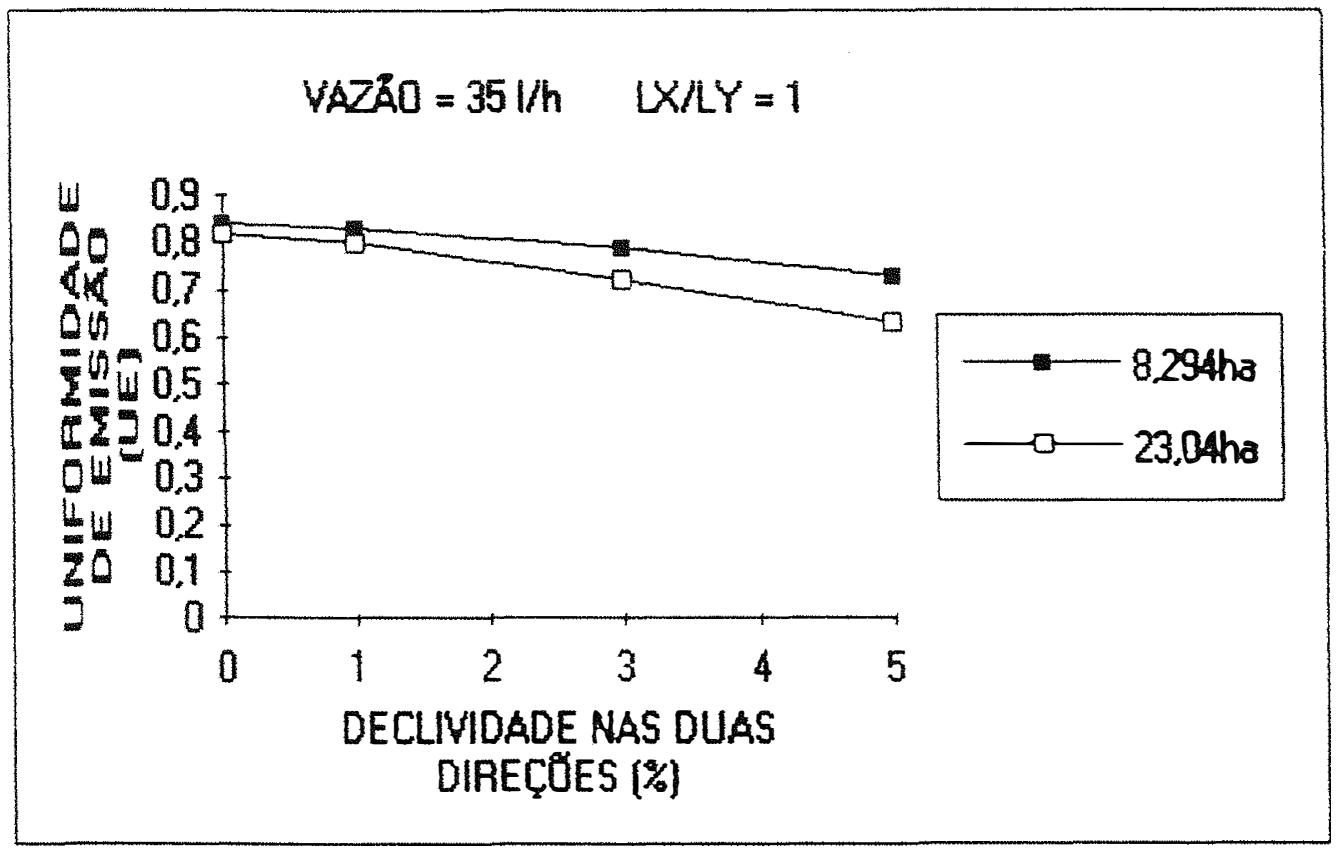

Figura 19 - Unifornidade de enisajo en funça da declividade nas duas dineçöes. para a vazão de 35 the $\operatorname{LX}$ LY igual a 1.

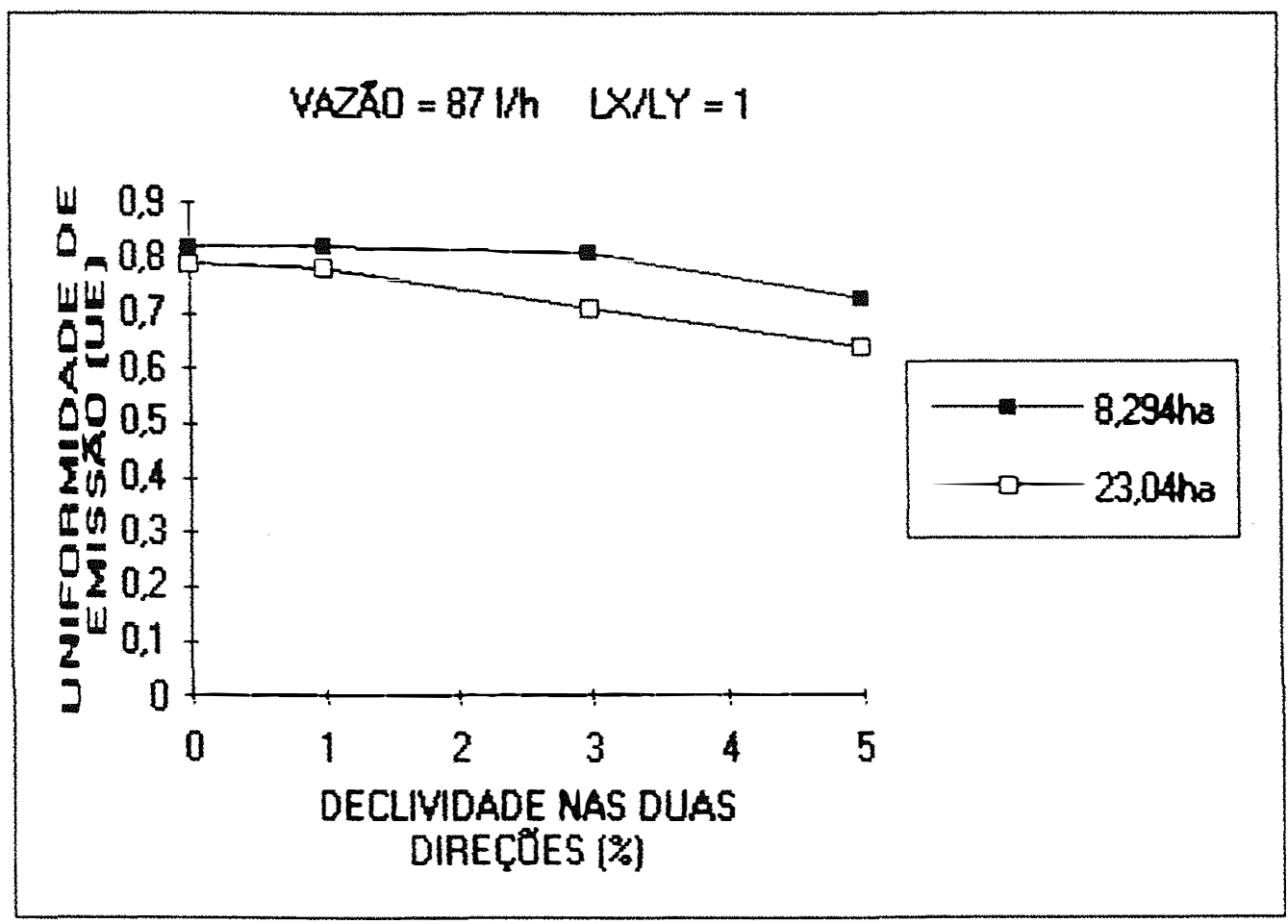

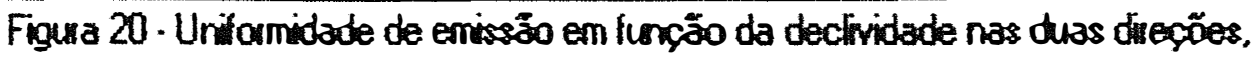
para a vazăo de 87 th e LXAY igual a 1. 
79.

4.7. Relação entre o número total de unidades operacionais CNUOD e o tamanho e formato da área

A relação entre o número total de unidades operacionais (NUO) e o tamanho e formato da área, para o microaspersor de vazão 35 l/h associado às declividades 0 e $3 \%$ está caracterizada nas figuras 21 e 22, respectivamente. Observa-se que na condição en nivel, NUO permaneceu constante (igual a 4) para a área de 8,294ha, enquanto que para a área de 23,04 ha apresentou um pico inicial ( em LX/Ly $=0,25$ ) de 10 unidades operacionais, decrescendo, em seguida, para o valor 4, onde permaneceu. As tendencias das curvas são as mesmas apresentadas na relação UE $\times$ formato da área (Figura 17). Para a área de 23,04ha, a relação LX/LY igual a 0,25 resultou em um número elevado de unidades operacionais e alto indice de uniformidade de emissão. Porém, esta configuração acarretou elevado custo anual do sistema de irrigação (Figura b), e menor receita liquida anual (Figura 1) em relação aos demais formatos.

Na declividade de $3 \%$ verifica-se a mesma tendéncia encontrada na situação em nivel, porém com número menor de unidades operacionais nas maiores relações LX/LY (acima de 2,25). 
VAZAO $=35 \mathrm{kh}$ DECLMIDADE: ONO

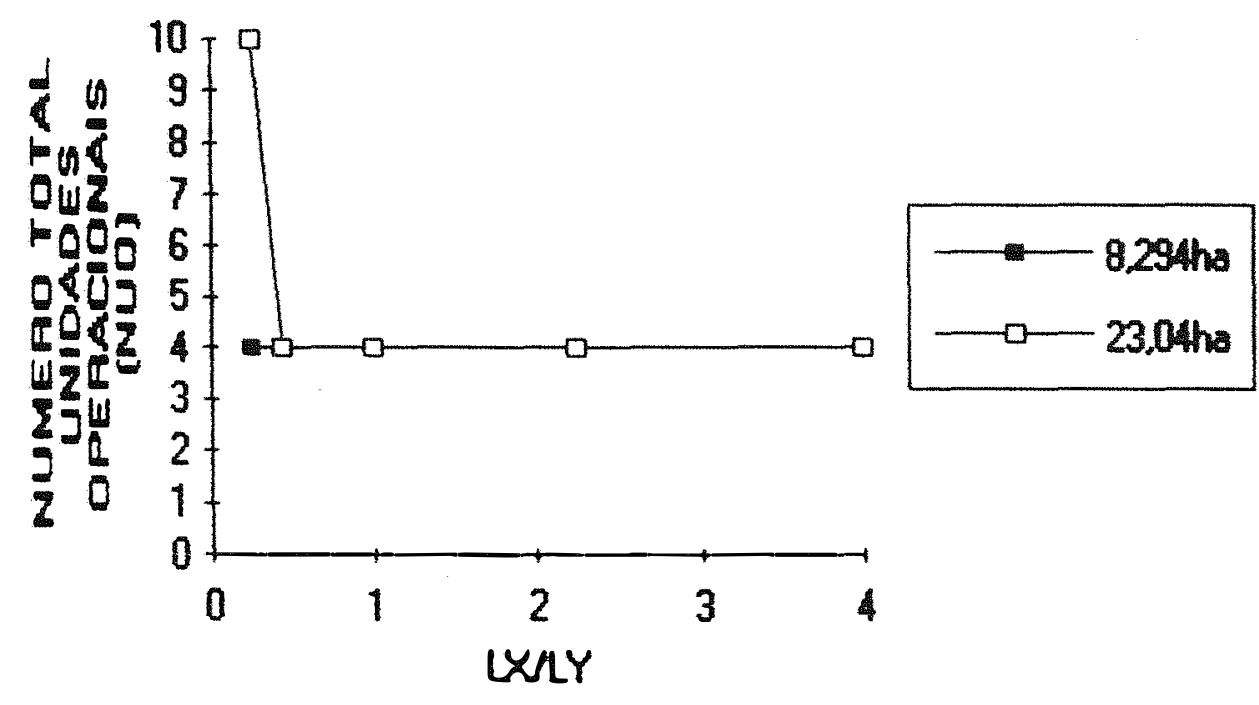

Figura 21 - Número lotal de unidades operacionais (NUO) em funçâo do tamanho e do formato da área, para a vazž́o de 35 the decividade 0.

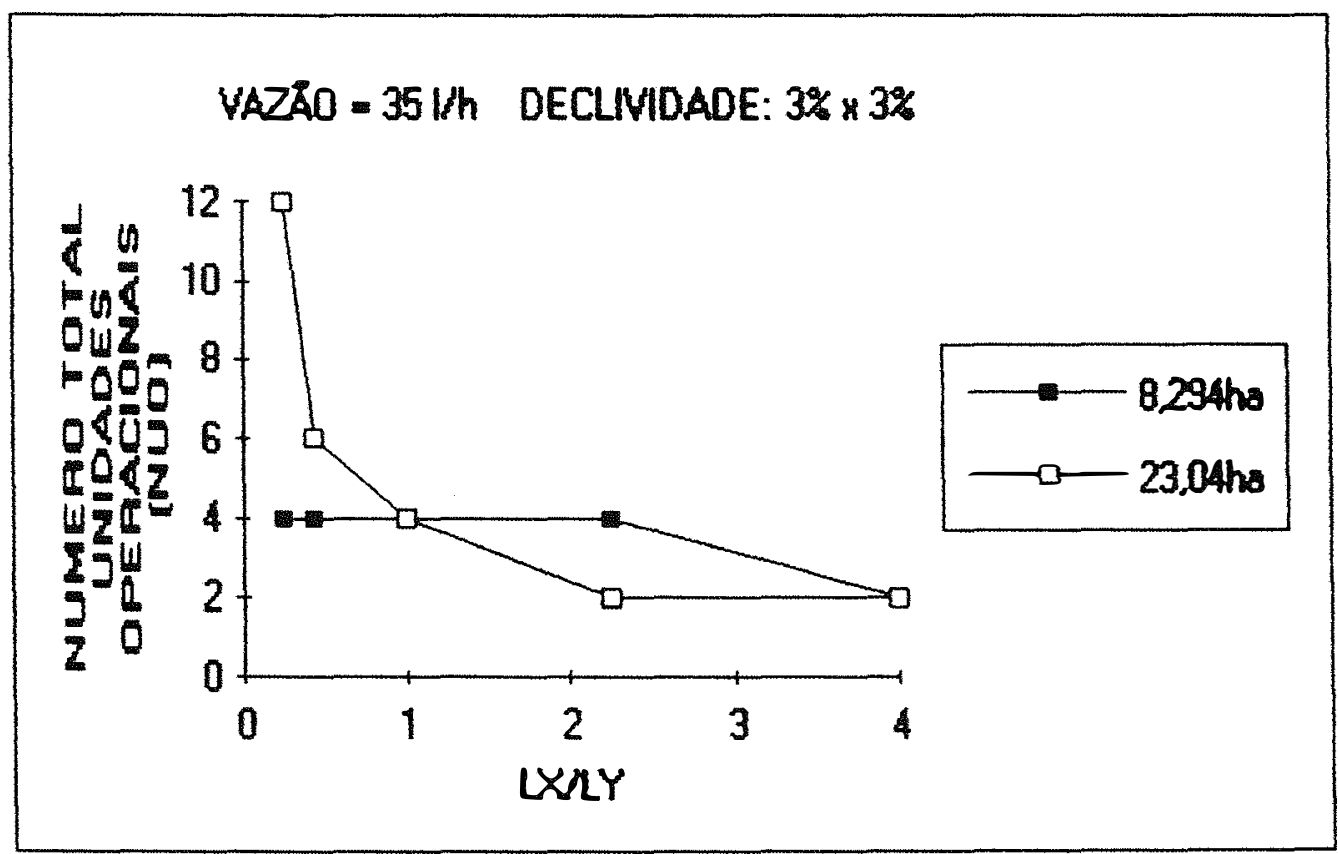

Figua 22 - Nimexo lokd de unidade operacionas (NUO) en funçäo do lamanho e do formato da ádea, para a yazỗo de 35 the decividade de $3 \%$. 
81.

4.8. Situaçช̃es em que o modelo não encontrou uma solução ótima

As situaçơs que não geraram solução ótima aparecem em branco no Apêndice 2 - Tabela 1, e correspondem a combinaçơes envolvendo o extremo superior dos parâmetros de entrada avaliados, ou seja, relaçós LX/Ly de valor 2,25 e 4, declividades de 3 e $5 \%$ e microaspersores de 56 e 87 1/h. O que se verificou E que estas configuraçర̃es năo convergiam para uma soluçăo ótima, pois não atendiam às restriçós do modelo e os limites estabelecidos para as variáveis. Um exemplo disto, é o caso onde a área é de 8,294ha, com LX igual a 57bme LY igual a $144 \mathrm{~m}$ (LX/LY igual a 4), com declividade de $5 \%$ nas duas direçoses. Esta situação geométrica associada com um microaspersor de 35 l/h, não forneceu solução ótima. Mudando os limites de UE, obteve-se um resultado ótimo para uniformidade de emissão de 52\%, o qual está muito abaixo do convencionalmente aceito (acima de $85 \%$ ).

Estes casos não resolvidos constituem-se num indicador de confiabilidade do modelo e do programa computacional utilizado, uma vez que os critérios e limites estabalecidos foram respeitados a ponto de nã se identificar uma solução ótima, por ocasião do não atendimento destas condiç̧̌s. 


\subsection{Sugestzes para continuidade}

$$
\text { Para dar continuidade à linha de pesquisa }
$$

iniciada por este trabalho, faz-se as seguintes sugestros:

$$
\text { - pesquisar ou desenvolver um programa }
$$

computacional que resolva problemas com variáveis inteiras não-lineares ;

- desenvolver um modelo que compense o efeito da declividade por meio de diferentes comprimentos da linha, mantendo-se constante o diametro;

$$
\text { - tornar mais amigável o processo de }
$$
simulação utilizando o programa computacional GAMS/MINOS;

- ampliar a aplicação do modelo a outros sistemas de irrigação pressurizada e outras condiçães geometricas e operacionais. 
83.

5. CONCLUSOES

Considerando os resultados obtidos neste trabalho para a região de Limeira, SP, estabeleceram-se as seguintes conclusões:

a) Os resultados obtidos nas 120 situaçơs analisadas demonstraram que o modelo proposto foi eficaz na geração de configuraçס̄es segundo a conformação estabelecida nas hipóteses básicas ;

b) Das componentes da receita liquida anual, o custo anual do sistema de irrigação foi a que mais variou, em função da análise de sensibilidade realizada ;

c) A configuração que resultou em maior receita liquida anual (US\$2939/ha) apresenta formato quadrangular, área de 23,04ha, terreno em nivel e microaspersor de $351 / \mathrm{h}$. Por sua vez, a de menor receita liquida (US\$2402/ha) corresponde a uma área de 8,294ha, com formato retangular $\{L X=144 m$ e $L Y=576 m)$, declividade de $5 \%$ nas duas direções e microaspersor de vazão igual a 56 l/h; 
d) Para áreas de 8,294ha o formato que resultou em maior receita liquida anual, em todas as combinaçzes envolvendo microaspersor (vazão) e declividade do terreno, foi o quadrangular. Para áreas de 23,04ha o formato quadrangular prevaleceu para declividades de até $3 \%$, associadas a microaspersores de vazão igual ou inferior a 56 l/h. Declividade de $5 \%$ ou emissor de $87 \mathrm{l} / \mathrm{h}$ de vazão apresentaram maior rentabilidade com LX/LY igual a 0,44 ;

e) A receita liquida anual diminuiu com o uso de microaspersores de maior vazão, sendo que a maior rentabilidade foi obtida com emissores de 35 l/h;

f) A receita liquida anual decresceu com o aumento da declividade do terreno. Até a declividade de $3 \%$ a area de 23,04 ha apresentou maior rentabilidade que a de 8,294 ha. Porém, para a declividade de $5 \%$ verificou-se uma inversão nesta predominância, sendo a de 8,294ha a mais rentável. 


\section{REFERENCI AS BIBLIOGRAFICAS}

ALLEN, R.G. \& BROCKWAY, E. Concepts for energy-efficient irrigation system design. Journal of Irrigation and Drainage Engineering, New York, $110(2): 99-106,1984$.

BENAMI, A. \& OFEN, A. Irrigation engineering. Haifa, IESP, 1984. 257p.

BERNARDO, S. Manual de irrigaçăo. 4.ed. Viçosa, UFV' Imprensa Universitária, 1986. 488p.

BHAVE, P.R. Selecting pipe sizes in network optimization by LP. Journal of the Hydraulics Division, New York, $105(7): 1019-25,1978$.

BROOKS, A. ; KENDRICK, D. ; MEERAUS, A. GAMS: a user's guide. Redwood City, The Scientific Press, 1988. 289 p.

BUCKS, D.A.; NAKAYAMA, F.S.; WARRICK, A.W. Principles, practices, and potentialities of trickle (drip) irrigation. In: HILLEL, D., ed., Advances in irrigation. New York, Academic Press, 1982. v.1. P.219-98. 
86.

Bustos, D. Modelo de optimización para riego por goteo. Chillán, 1988. 63̉p. (Graduacion - Universidad de (oncepcion).

CASE, K.E. \& WHITE, 3.A. A linear programming formulation of a water supply problem. Transactions of the American Institute of Industrial Engineers, $4(2): 85-91,1972$.

CHIANG, A.C. Matematica para economistas. São Paulo, McGraw-Hill, 1982. 684p.

CHRISTIANSEN, J.E. Irrigation by sprinklers. Davis, University of California, 1942. 65p. (Bulletin, 670).

DOORENBOS, J. \& KASSAM, A.H. Efectos del agua sobre el rendimento de los cultivos. Roma, FAO, 1979. 212p. (FAO. Irrigation and Drainage Paper, 24).

ESTADOS UNIDOS. Department of Agriculture. Trickle irrigation. Washington, USDA/SOil Conservation Service, s.d. 129p. (National Engineering Handbook. Section 15: Irrigation, 7).

GIL, P.E. ; MURRAY, W. ; WRIGHT, M.H. Practical optimization. New York. Academic Press, 1981. $401 \mathrm{p}$.

GOEHRING, L.D. Optimization of trickle irrigation system design. Fort Collins, 1976. 90p. (M.S. - Colorado State University). 
GUPTA, I. ; HASSAN, M.Z . ; COOK, J. Linear programming analysis of a water supply system with multiple supply points. Transactions of the American Institute of Industrial Engineers, 4(3):200-4, 1972.

HERNANDEZ ABREU, J.M.; RODRIGO LOPEZ, A. ; PEREZ REgalado, A. ; Gonzalez heRnANDEZ, J.F. El riego localizado. Madrid, Instituto Nacional de Investigaciones Agrarias, 1987. 317p.

HOLZAPFEL, E.A. ; MARIAO, M.A.; VALENZUELA, A. Drip irrigation nonlinear optimization model. Journal of Irrigation and Drainage Engineering. New York, $116(4): 479-96,1990$

KARMELI, D. \& ORON, G. Analysis of closed conduit irrigation system and its subdivision. Journal of the Irrigation and Drainage Division, New York, $105(2): 187-96,1979$.

KARMELI, D. ; GADISH, Y. ; MEYERS, S. Design of optimal water distribution networks. Journal of the Pipeline Division, New York, 94(1):1-10, 1968.

KELLER, J. Selection of economical pipe sizes for sprinkler irrigation systems. Transactions of the ASAE, St. Josept, 8(2):186-90,93. 1965. 
88 .

KELLER, J. \& BLIESNER, R.D. Sprinkle and trickle irrigation. New York, AVI Book, 1990. 652p.

LABIE, $Y . ;$ OLSON, M.A.; GALAND, A.; TSIOURTIS, N. Design and optimization of irrigation distribution networks. Rome, FAO, 1988. 247p. (FAO. Irrigation and Drainage Paper, 44).

LANZER, E.A. Programação linear; conceitos e aplicaçöes. 2.ed. Rio de Janeiro, IPEA/INPES, 1988. $270 \mathrm{p}$.

ORON, G. Technical and economic considerations in the design of closed conduit irrigation systems: a case study. Agricultural Water Management, Amsterdam, $5(1): 15-27,1982$.

ORON, G. \& KARMELI, D. Procedure for the economical evaluation of water networks parameters. Water Resources Bulletin, Urbana, 15(4):1050-60, 1979.

ORON, G. \& KARMELI, D. Solid set irrigation system design using linear programming. Water Resources Bulletin, Urbana, 17(4):565-70, 1981.

ORON, G. \& WALKER, W.R. Optimal design and operation of permanent irrigation systems. Water resources Research, Washington, 17(1):11-7, 1981. 
PLEBAN, S. \& AMIR, I. An interactive computerized aid for the design of branching irrigating networks. Transactions of the ASAE, St. Joseph, 24(2):358-61, 1981.

SCALOPPI, E.J. Coeficiente para cálculo da perda de carga de pressão em tubulações com múltiplas derivações. In: CONGRESSO NACIONAL DE IRRIGAÇZO E DRENAGEM, 7., Brasilia, 1986. Anais. Brasilia, ABID, 1986. v.3, p. $1037-48$.

SEQUEIRA SAMPAIO, E.L. Probabilidade de atendimento natural das necessidades hidricas dos citros no Estado de Săo Paulo. Piracicaba, 1990. 147p. (Mestrado Escola Superior de Agricultura "Luiz de Queiroz"/USP). 
90.

APENDICE 1 


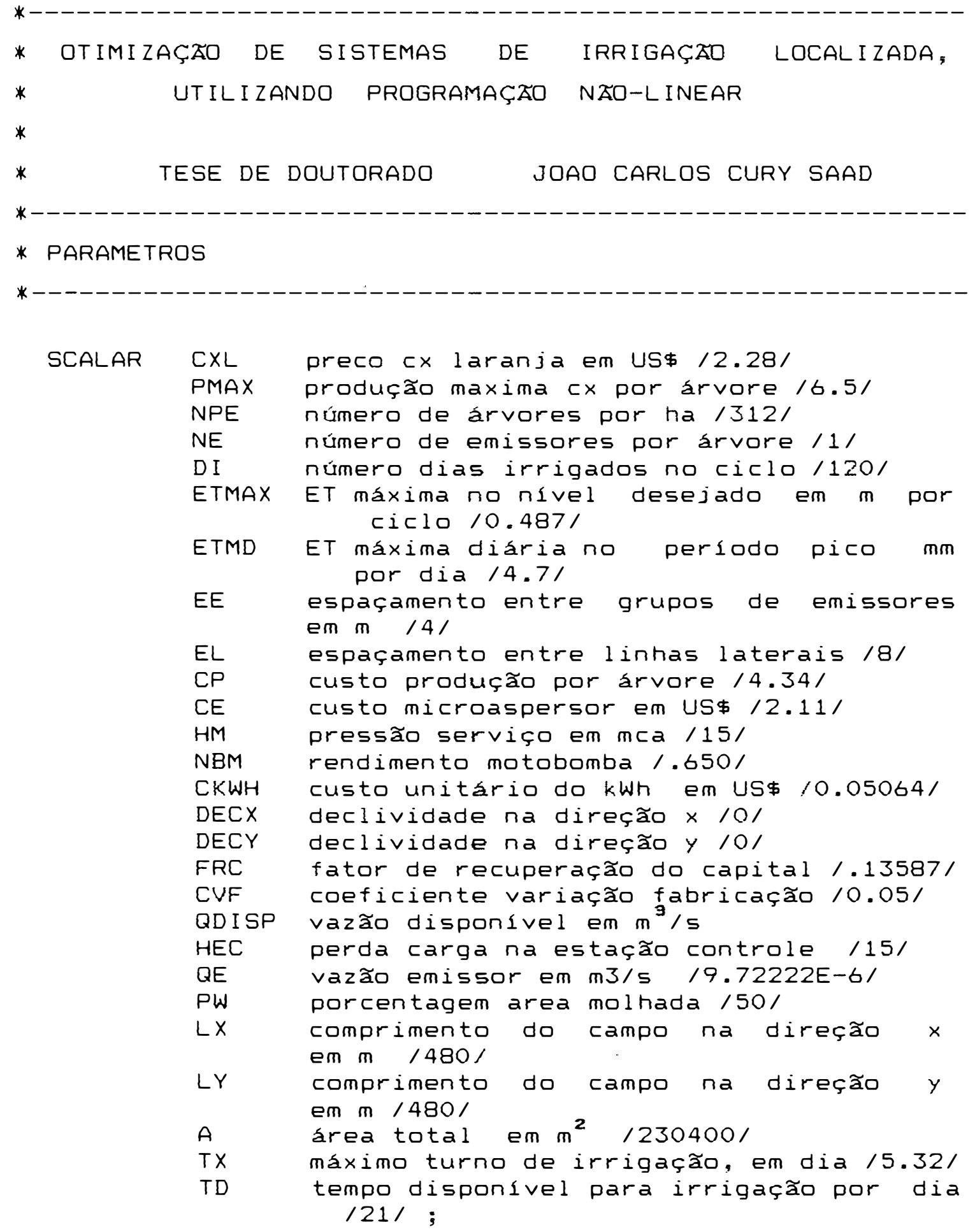




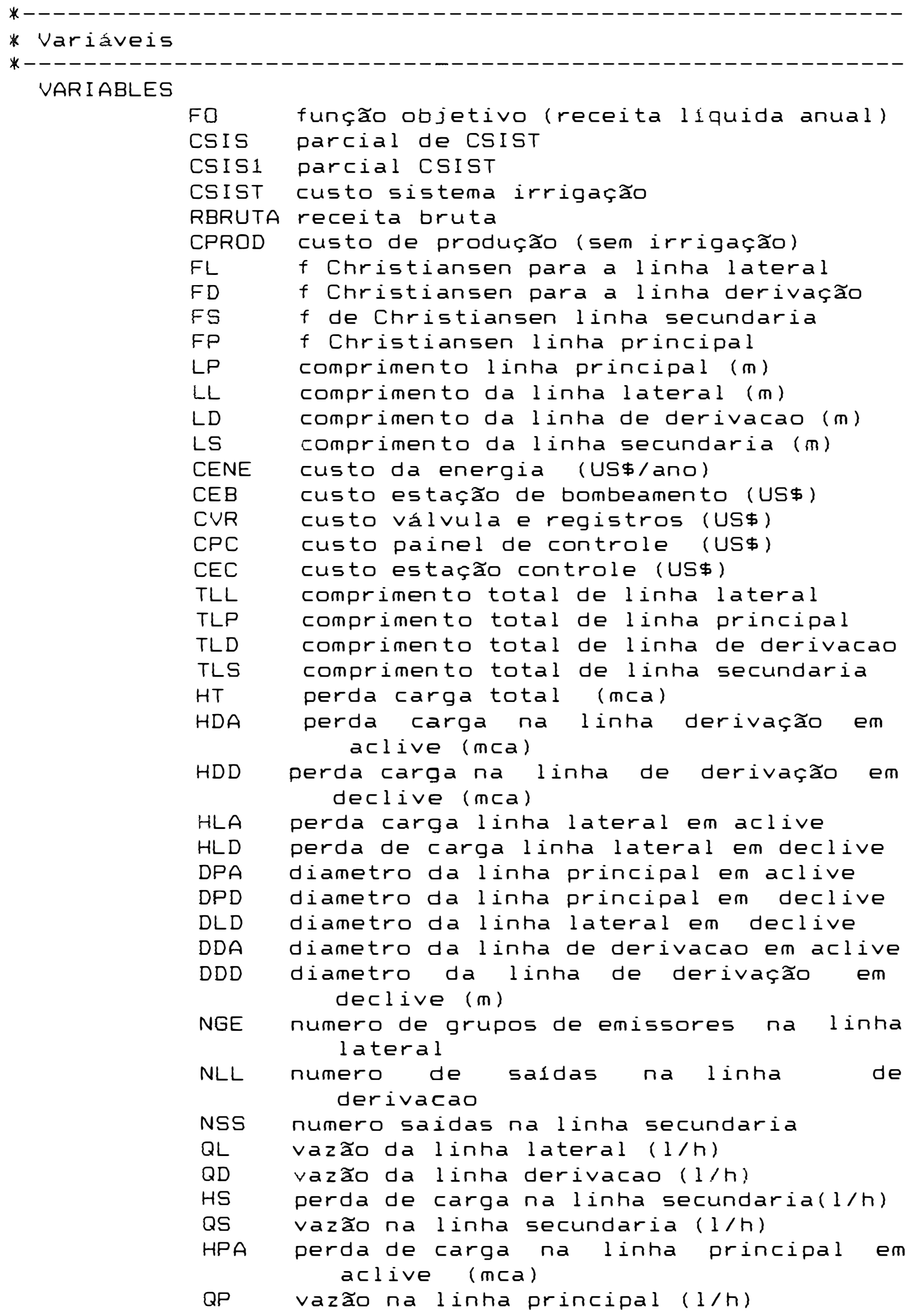




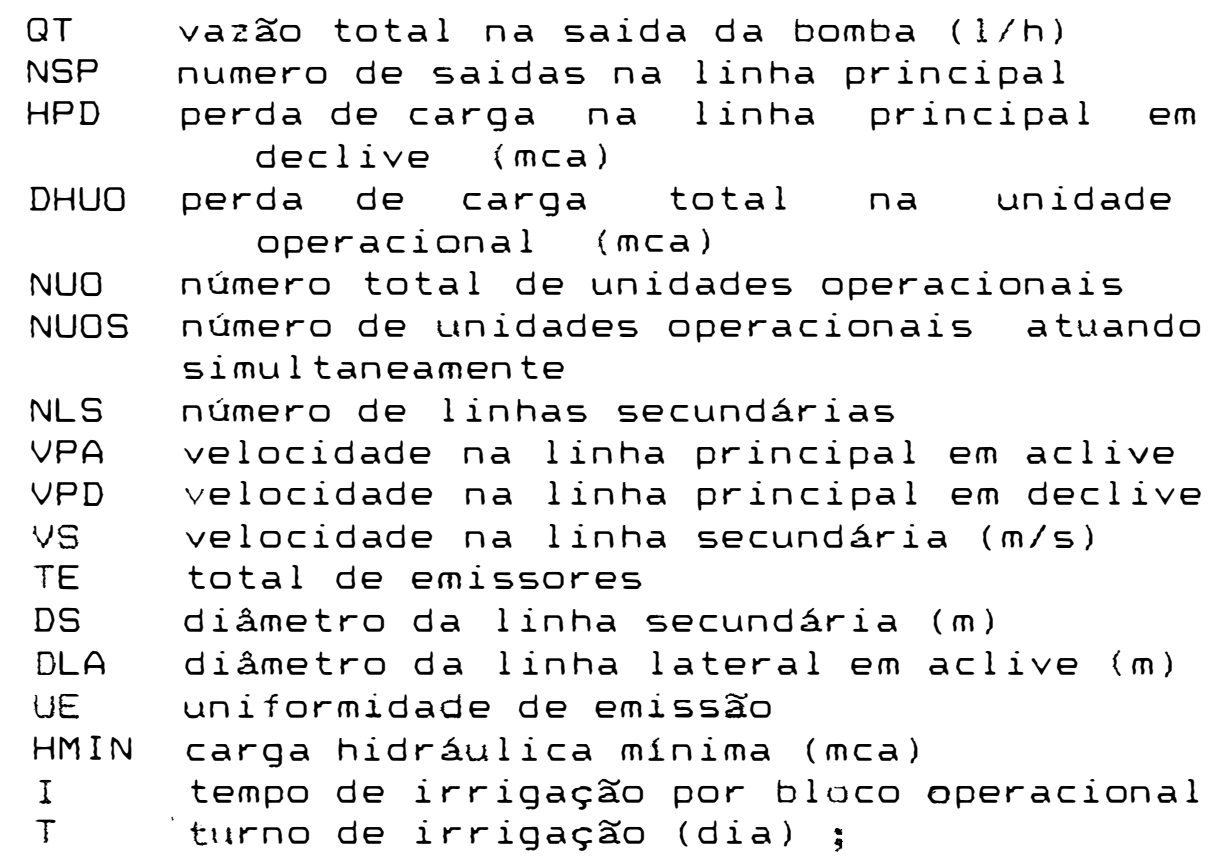

FREE VARIABLES FO;

POSITIVE VARIABLES RBRUTA, CSIS, CSIS1, CSIST, CPROD, FL, FD, FS, FP, CENE, CEB, CVR, CPC, CEC, TLL, TLP, TLD, TLS, HT, HDD, HLA, HLD, NUO, NUOS, NLS, I, T, NGE, NSS, $H S, Q S, H P A, Q P$, NSP, HPD, DHUO, UPA, UPD, US, TE, QL, QD, DPA, DPD, HDA, DLD, DDD, DLA, DDA, LL, LD, LS, LP, NLL, DS, QT, UE, HMIN;

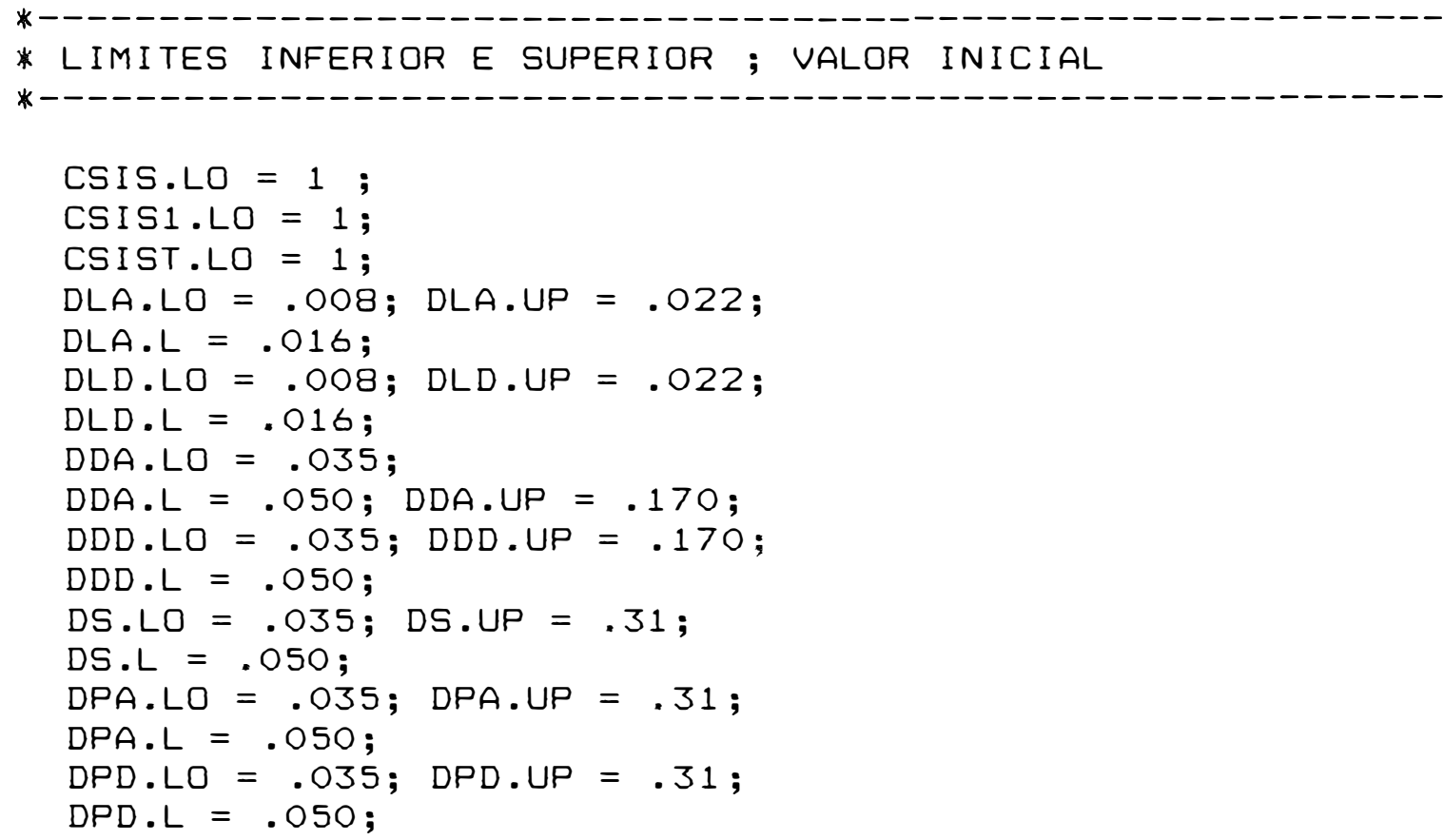




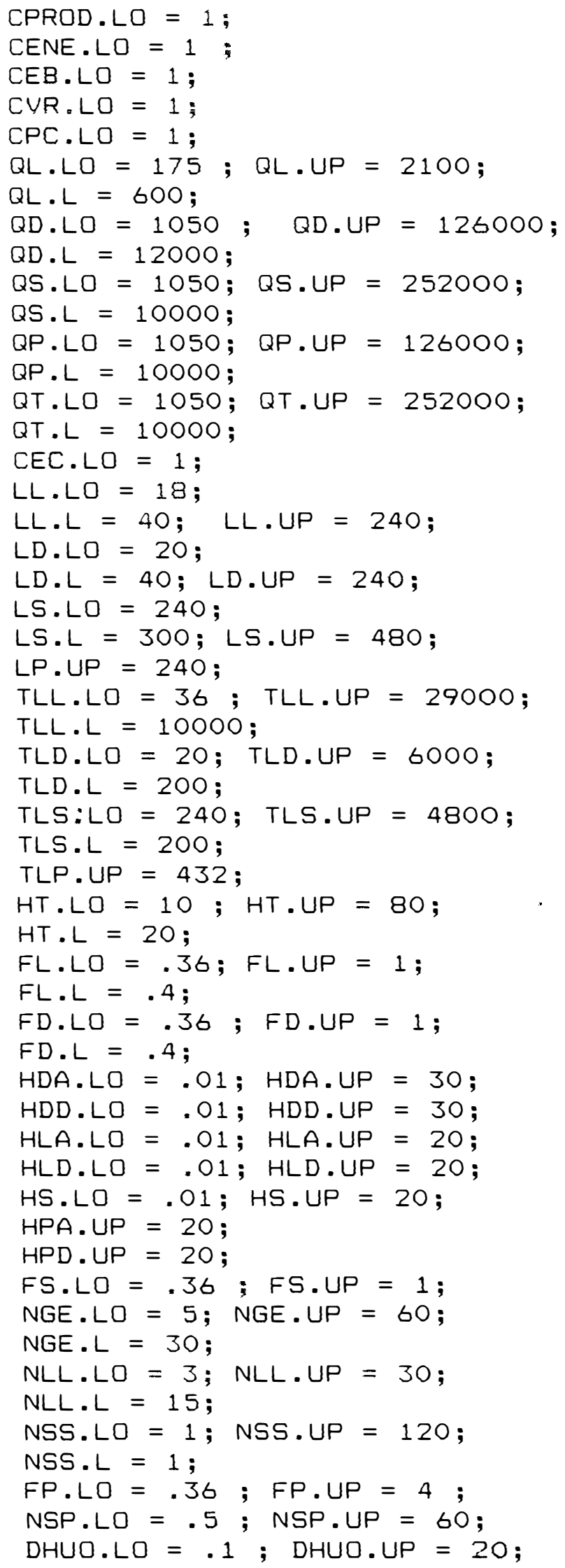




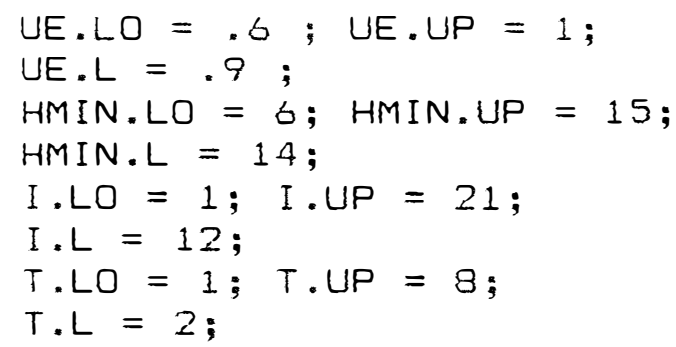

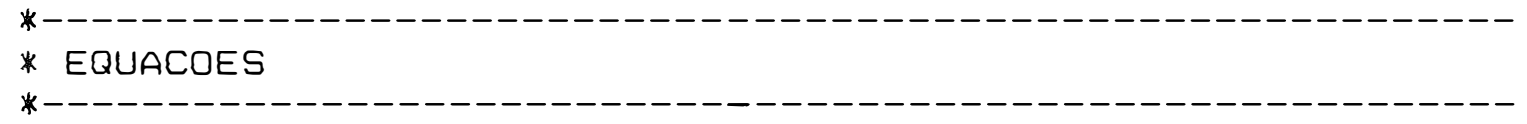

EQUAT IONS

$\begin{array}{ll}\text { EFO } & \text { eq. da função objetivo } \\ \text { ERBRUTA } & \text { eq. da receita bruta } \\ \text { ECSIS } & \text { eq CSIS } \\ \text { ECSIS1 } & \text { eq CSIS1 } \\ \text { ECSIST } & \text { eq. custo do sistema de microaspersão } \\ \text { ECVR } & \text { eq. do custo de valvulas e registros } \\ \text { ECPC } & \text { eq. custo do painel de controle } \\ \text { ECEC } & \text { eq. custo da estação de controle } \\ \text { EQT } & \text { eq vazão total } \\ \text { ECEB } & \text { eq. custo da estaça de bombeamento } \\ \text { ECENE } & \text { eq. custo da energia elétrica } \\ \text { ETE } & \text { eq. total microaspersores } \\ \text { ETLL } & \text { eq. comprimento total de linhas laterais } \\ \text { ELL } & \text { eq. cálculo de LL } \\ \text { ETLD } & \text { eq. comprimento total linhas de derivação } \\ \text { ELD } & \text { eq. cálculo de LD } \\ \text { ETLS } & \text { eq. comprimento total linha secundaria } \\ \text { ELS } & \text { eq. cálculo de LS } \\ \text { ETLP } & \text { eq. total de linha principal } \\ \text { ELP } & \text { eq. cálculo de LP } \\ \text { EHT } & \text { eq. cálculo da perda carga total } \\ \text { ENGE } & \text { eq. cálculo de NGE } \\ \text { ENLL } & \text { eq. cálculo de NLL } \\ \text { EHLA } & \text { eq. cálculo de HLA } \\ \text { EFL } & \text { eq. cálculo de FL } \\ \text { EHLD } & \text { eq. cálculo de HLD } \\ \text { EHDA } & \text { eq. cálculo de HDA } \\ \text { EFD } & \text { eq. cálculo de FD } \\ \text { EHDD } & \text { eq. cálculo de HDD } \\ \text { EHS } & \text { eq. cálculo de HS } \\ \text { EFS } & \text { eq. cálculo de FS } \\ \text { EHPA } & \text { eq. cálculo de HPA } \\ \text { EFP } & \text { eq. cálculo de FP } \\ \text { ENSP } & \text { eq. cálculo de NSP } \\ \text { EHPD } & \text { eq. cálculo de HPD } \\ \text { ECPROD } & \text { eq. do custo de produção } \\ \text { ERLAT } & \text { restriça referente a linha lateral } \\ \text { ERDER } & \text { restrição referente à linha derivação } \\ & \end{array}$




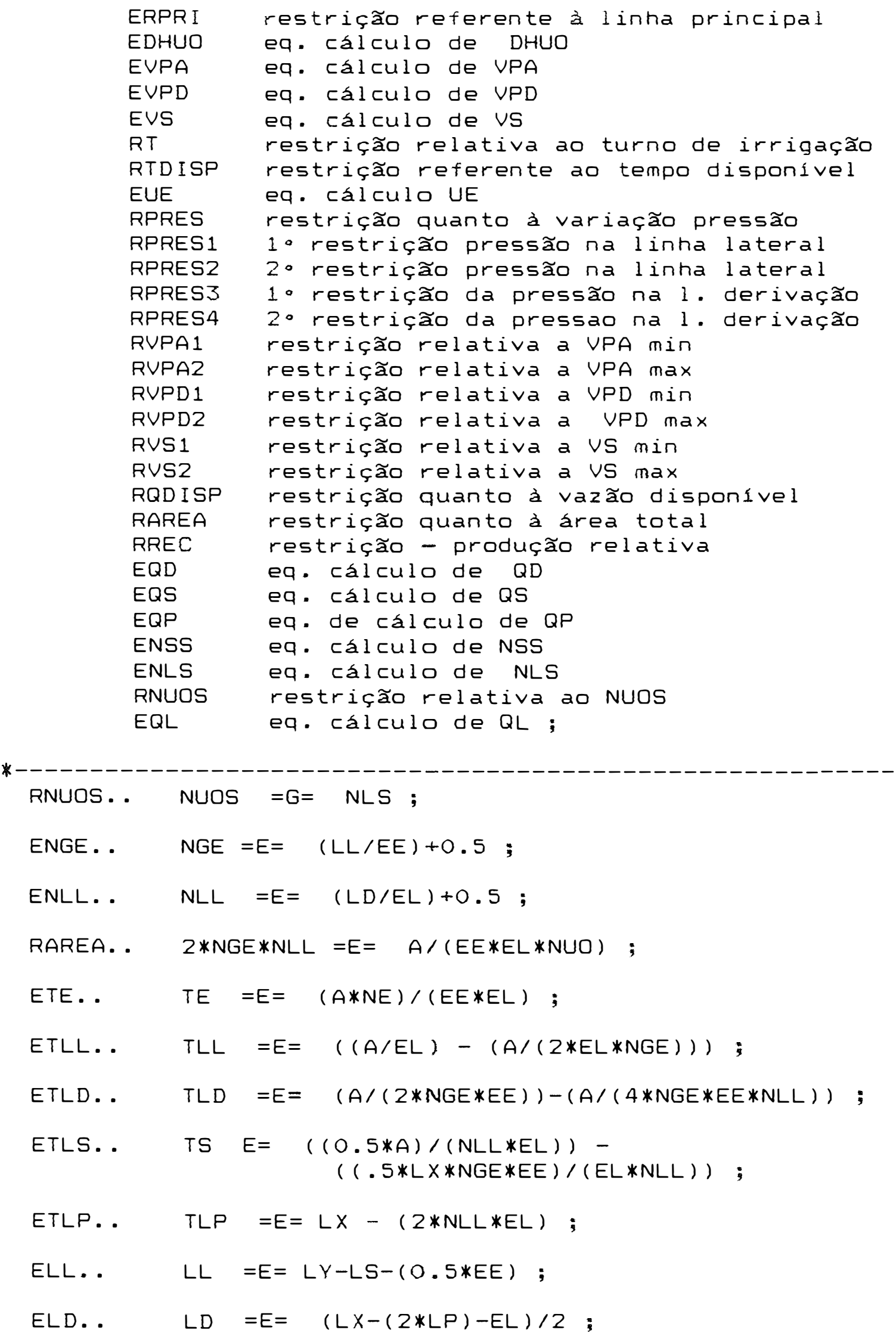




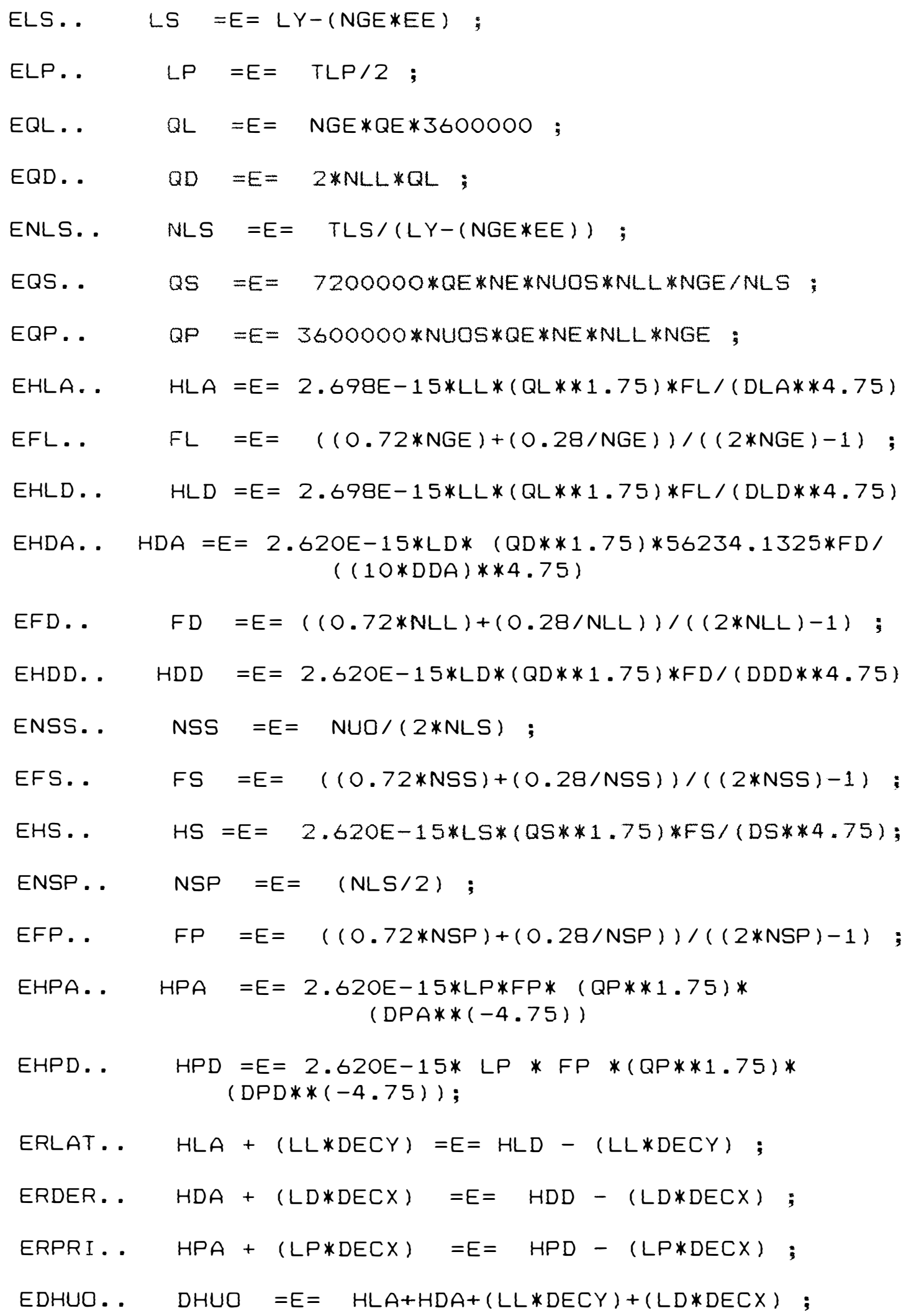




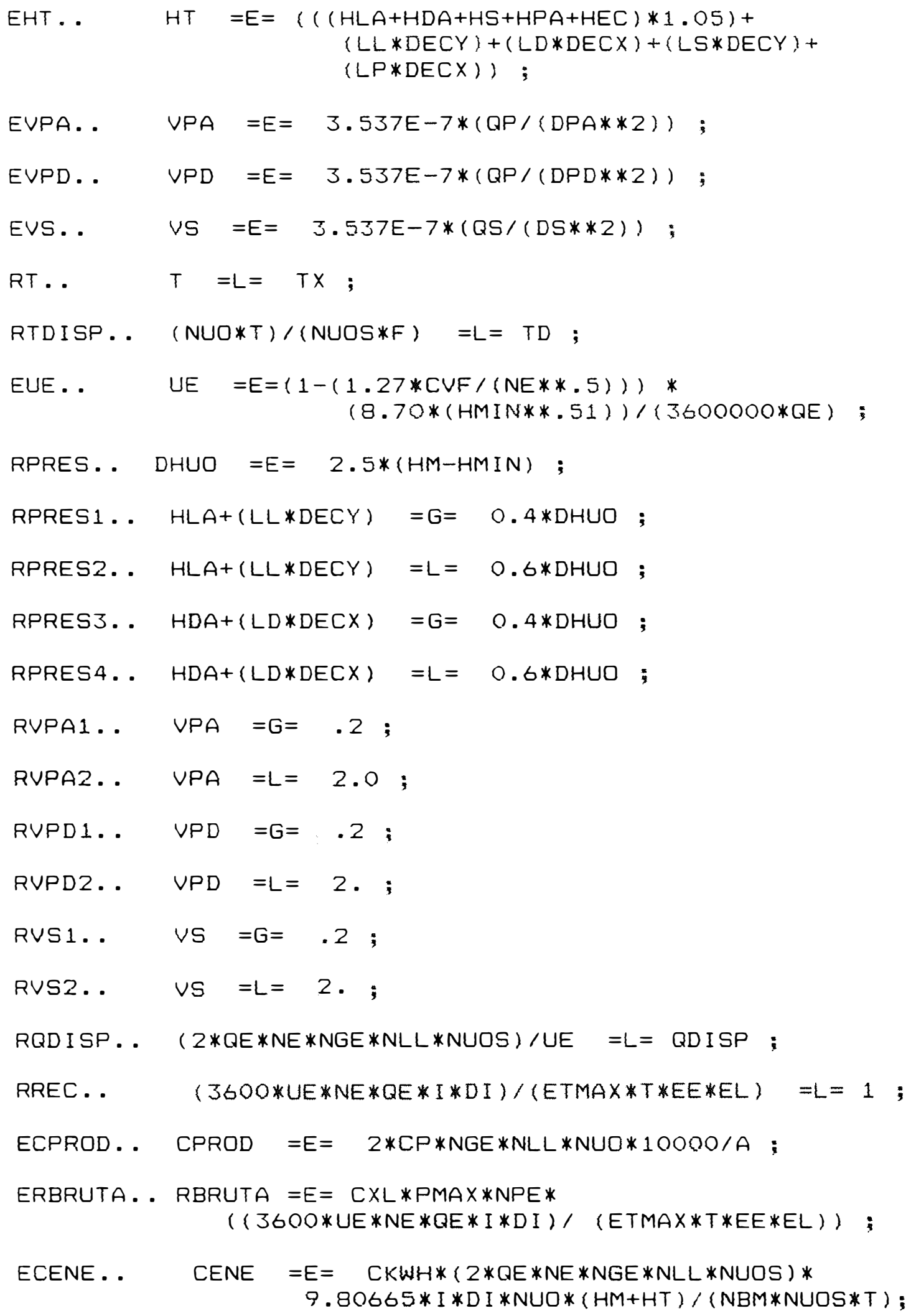




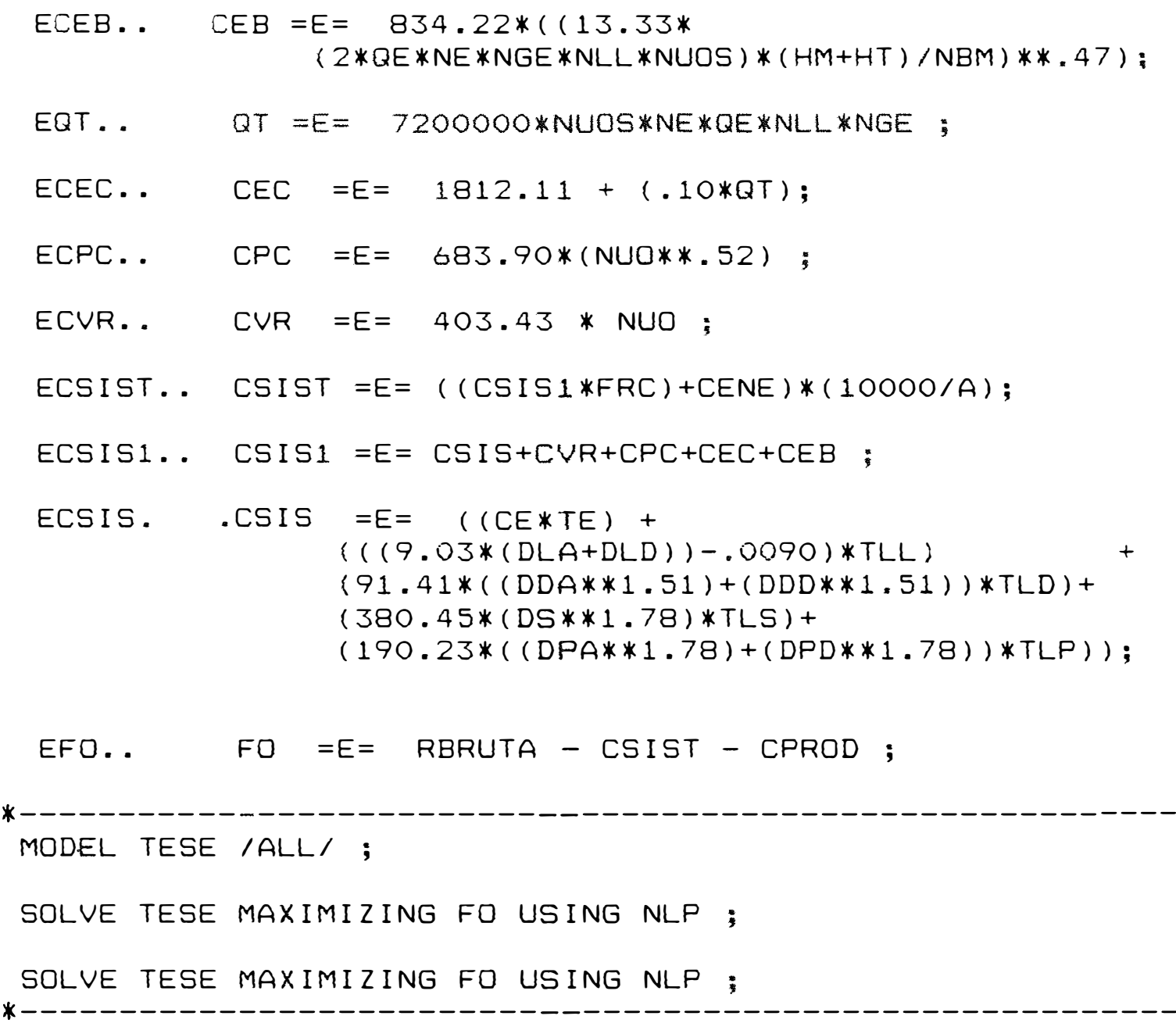


100.

APENDICE 2 


\begin{tabular}{|c|c|c|c|c|c|c|c|c|c|c|c|c|c|c|c|}
\hline \multirow[t]{2}{*}{ VARLAVEL } & \multicolumn{15}{|c|}{ CONFIGURACAO } \\
\hline & 1 & 2 & 3 & 4 & 5 & 6 & 7 & 8 & 9 & 10 & 31 & 12 & 13 & 14 & 15 \\
\hline$A(h a)$ & 8.294 & 8.294 & 8294 & 8.294 & 8229 & 8,294 & 8.294 & 8.294 & 8.294 & 8.294 & 8.294 & 8,294 & 8.294 & 8294 & 8.294 \\
\hline$L \times(m)$ & 288 & 288 & 288 & 288 & 288 & 288 & 288 & 288 & 288 & 288 & 288 & 288 & 144 & 144 & 144 \\
\hline$L Y(m)$ & 288 & 288 & 288 & 288 & 288 & 286 & 288 & 288 & 288 & 288 & 288 & 288 & 576 & 576 & 576 \\
\hline QE (Wh) & 35 & 35 & 35 & 35 & 56 & 56 & 56 & 56 & 87 & 87 & 87 & 87 & 35 & 35 & 35 \\
\hline DEC $(\%)$ & $D$ & 1 & 3 & 5 & 0 & 1 & 3 & 5 & 0 & 1 & 3 & 5 & 0 & 1 & 3 \\
\hline DECY $(\%)$ & 0 & 1 & 3 & 5 & 0 & 1 & 3 & 5 & 0 & 1 & 3 & 5 & 0 & 1 & 3 \\
\hline FO(US'Ma ano) & 2902 & 2897 & 2884 & 2866 & 2867 & 2863 & 2849 & 2829 & 2825 & 2821 & 2805 & 2788 & 2878 & 2870 & 2848 \\
\hline CSISTIUS\$Mo.ano] & 366 & 370 & 384 & 401 & 400 & 405 & 419 & 438 & 442 & 447 & 463 & 480 & 390 & 397 & 420 \\
\hline RBAUT USSMh and & 4624 & 4624 & 4624 & 4624 & 4624 & 4624 & 4624 & 4624 & 4624 & 4624 & 4624 & 4624 & 4624 & 4624 & 4624 \\
\hline CPROD-USSha and & 1356 & 1356 & 1356 & 1356 & 1356 & 1356 & 1356 & 1356 & 1356 & 1356 & 1356 & 1356 & 1356 & 1356 & 1356 \\
\hline NUO & 4 & 4 & 4 & 4 & 6 & 6 & 6 & 6 & 8 & 8 & 8 & $B$ & 4 & 4 & 4 \\
\hline NUOS & 1 & 1 & 1 & 1 & 1 & 1 & 1 & 1 & 1 & 1 & 1 & 1 & 1 & 1 & 1 \\
\hline NLS & 1 & 1 & 1 & 1 & 1 & 1 & 1 & 1 & 1 & 1 & 1 & 1 & 1 & 1 & 1 \\
\hline \multicolumn{16}{|l|}{$\operatorname{LP}(m)$} \\
\hline $\mathrm{LL}(\mathrm{m})$ & 70 & 70 & 70 & 70 & 46 & 46 & 46 & 46 & 34 & 34 & 34 & 34 & 142 & 142 & 142 \\
\hline $\operatorname{LD}(m)$ & 140 & 140 & 140 & 140 & 140 & 140 & 340 & 140 & 140 & 140 & 140 & 140 & 68 & 68 & 68 \\
\hline$L S(m)$ & 216 & 216 & 216 & 216 & 240 & 240 & 240 & 240 & 252 & 252 & 252 & 252 & 432 & 432 & 432 \\
\hline CENE (USS/ano) & 420 & 452 & 549 & 688 & 442 & 474 & 560 & 727 & 450 & 492 & 554 & 738 & 450 & 504 & 696 \\
\hline CEB (US\$) & 1827 & 1883 & 2017 & 2162 & 1906 & 1963 & $2092 !$ & 2262 & 2088 & 2149 & 2263 & 2465 & 1891 & 1905 & 2220 \\
\hline CVR(US\$) & 1613 & 1613 & 1613 & 1613 & 2420 & 2420 & 2420 & 2420 & 3227 & 3227 & 3227 & 3227 & 1614 & 1674 & 1614 \\
\hline CPC (US & 1406 & 1406 & 1406 & 1406 & 1736 & 1736 & 1736 & 1736 & 2016 & 2016 & 2016 & 2016 & 1406 & 1406 & 1406 \\
\hline CECR & 4000 & 40801 & 4080 & 4000 & 4231 & 4231 & 4231 & 4231 & 4631 & 4631 & 4631 & 4631 & 40001 & 40001 & 4080 \\
\hline$\pi(m)$ & 10000 & 10080 & 10080 & 10080 & 9936 & 9936 & 9936 & 9936 & 9792 & 9792 & 9792 & 9792 & 10224 & 10224 & 10224 \\
\hline \multicolumn{16}{|l|}{$\pi P(m)$} \\
\hline$\pi D(m)$ & 560 & 560 & 560 & 560 & 840 & 840 & 840 & 840 & 1120 & 1120 & 1120 & 1120 & 272 & 272 & 272 \\
\hline$\pi L S(m)$ & 216 & 216 & 216 & 216 & 240 & 240 & 240 & 240 & 252 & 252 & 252 & 252 & 432 & 432 & 432 \\
\hline HT (mca) & 26.07 & 28.74 & 35.66 & 43.71 & 27.12 & 29.84 & 36.32 & 45.6 & 28.84 & 31.62 & $37.07 !$ & 47.46 & 29.16 & 33.97 & 47.13 \\
\hline HDA (mca) & 3.18 & 2,31 & 1.6 & 1,33 & 4.29 & 328 & 1.6 & 1.56 & 5,29 & 4.08 & 1.6 & 2.06 & 2.58 & 2.13 & 2.66 \\
\hline $\mathrm{HDO}$ (mca) & 3.18 & 5.11 & 10 & 15,33 & 4.29 & 6,08 & 10 & 15,56 & 5,29 & 6,86 & 10 & 16,06 & 2.59 & 3,49 & 6.74 \\
\hline HLA (mca) & 3.53 & 2.88 & 2.12 & 2.05 & 3.19 & 2.72 & 2.49 & 3.41 & 3.52 & 3,31 & 2.85 & 4.34 & 3.89 & 2.8 & 2.79 \\
\hline HLD (mca) & 3.53 & 4.29 & 6.32 & 9.05 & 3.19 & 3.64 & 5.25 & 8.01 & 3.52 & 3.99 & 4.89 & 7.74 & 3.89 & 5.64 & 11.31 \\
\hline \multicolumn{16}{|l|}{$D P A(m)$} \\
\hline \multicolumn{16}{|l|}{$D P D(m)$} \\
\hline$D L D(m)$ & 0,014 & 0.013 & 0.012 & 0.011 & 0.013 & 0.013 & 0.012 & 0.011 & 0.013 & 0.013 & 0,012 & 0.011 & 0.021 & 0,019 & 0,016 \\
\hline $\mathrm{DDA}(\mathrm{m})$ & 0.062 & 0.066 & 0.07 & 0.074 & 0.059 & 0.063 & 0.073 & 0.073 & 0.06 & 0,063 & 0.077 & 0.073 & 0.056 & 0.056 & 0,055 \\
\hline$D D D(m)$ & 0.062 & 0.056 & 0,048 & 0.044 & 0.059 & 0.055 & 0.05 & 0.045 & 0,06 & 0,057 & 0.053 & 0.048 & 0.056 & 0.052 & 0.046 \\
\hline NGE & 18 & 18 & 18 & 18 & 12 & 12 & 12 & 12 & 9 & 9 & 9 & 9 & 36 & 36 & 36 \\
\hline NLL & 18 & 18 & 18 & 18 & 18 & 18 & 18 & 18 & 18 & 18 & 18 & 18 & 9 & 9 & 9 \\
\hline NSS & 2 & 2 & 2 & 2 & 3 & 3 & 3 & 3 & 4 & 4 & 4 & 4 & 2 & 2 & 2 \\
\hline$Q L(M n)$ & 630 & 630 & 630 & 630 & 672 & 672 & 672 & 672 & 783 & 783 & 783 & 783 & 1260 & 1260 & 1260 \\
\hline$Q D(n)$ & 22680 & 22000 & 22680 & 22680 & 24192 & 24192 & 24192 & 24192 & 28188 & 28188 & 28188 & 28188 & 222680 & 22680 & 22860 \\
\hline $\mathrm{HS}$ (mca) & 3.12 & 3.12 & 3.07 & 2.56 & 3.35 & 3.36 & 3.33 & 3.18 & 3.66 & 3.67 & 3.68 & 3.51 & 6.29 & 6.31 & 6.1 \\
\hline OS (Lh) & 22680 & 22680 & 22680 & 22680 & 24192 & 24192 & 24192 & 24192 & 28188 & 28188 & 28188 & 28188 & 22680 & 22600 & 22680 \\
\hline \multicolumn{16}{|l|}{ HPA (mca) } \\
\hline \multicolumn{16}{|l|}{$\mathrm{QP}(\mathrm{l} / \mathrm{h})$} \\
\hline OT $(M / h)$ & 22680 & 222680 & 22680 & 22660 & 24192 & 24192 & 24192 & 24192 & 28188 & 28188 & 28188 & 28188 & 22600 & 22880 & 22600 \\
\hline \multicolumn{16}{|l|}{ NSP } \\
\hline \multicolumn{16}{|l|}{ HPO (mca) } \\
\hline DHUO (mce) & 6.71 & 7.29 & 10.02 & $\mid 13,89$ & 7,48 & 7.86 & 9.67 & 14.26 & 8,87 & 9.13 & 9,67 & 15.1 & 6,47 & 7.03 & 11.74 \\
\hline \multicolumn{16}{|l|}{$V P A(m / s)$} \\
\hline$V P D(m / s)$ & & & & & & & & & & & & & & & \\
\hline$V S(\mathrm{~m} / \mathrm{s})$ & 1.38 & 1,38 & 1.37 & 1.35 & 1.49 & 1.49 & 1.48 & 1.46 & 1.64 & 1.64 & 1.28 & 1.61 & 1.39 & 1.39 & 1.37 \\
\hline TE & 2592 & 2592 & 2532 & $2592 !$ & 2592 & 2592 & 2592 & 2592 & 2592 & 2592 & 2592 & 2592 & 2592 & 2592 & 2592 \\
\hline$D S(m)$ & 0.076 & 0.076 & 0.077 & 0.077 & 0.076 & 0.076 & 0.076 & 0.077 & 0.078 & 0,078 & 0.078 & 0.079 & 0.076 & 0.076 & 0.077 \\
\hline$D L A(m)$ & 0.014 & 0.015 & 0.016 & 0.016 & 0.013 & 0.014 & 0.074 & 0.013 & 0.013 & 0.013 & 0.014 & 0.013 & 0.021 & 0.022 & 0.022 \\
\hline UE & 0.84 & 0.83 & 0.79 & 0.73 & 0.82 & 0.81 & 0.79 & 0.72 & 0.82 & 0.81 & 0.8 & 0.72 & 0.84 & 0.83 & 0.7 \\
\hline HMIN (mca) & 12.32 & 12.08 & 10.99 & 9.44 & 12.01 & 11.86 & 11.13 & 9.29 & 11.48 & 11.35 & 11.13 & 8.56 & 12,41 & 12.19 & 10.3 \\
\hline $1(h)$ & 20.73 & 8.48 & 13.86 & 21 & 15.1 & 6.11 & 8.31 & 17.1 & 3.2 & 5.38 & 3.87 & 10.95 & 5.58 & 4.45 & $12.7 \varepsilon$ \\
\hline$T$ (dia) & 4.68 & 1.9 & 2.95 & 4.14 & 5.32 & 2.14 & 2.81 & 5.27 & 1.75 & 2.93 & 5.32 & 5.32 & 1.27 & 1 & 2.63 \\
\hline
\end{tabular}




\begin{tabular}{|c|c|c|c|c|c|c|c|c|c|c|c|c|c|c|c|}
\hline \multirow[t]{2}{*}{ VARLAVEL } & \multicolumn{15}{|c|}{ CONFIGURACAO } \\
\hline & 16 & 17 & 18 & 19 & 20 & 21 & 22 & 23 & 24 & 25 & 26 & 27 & 28 & 29 & 30 \\
\hline$A(h a)$ & 8234 & 8.294 & 8,294 & 8,294 & 8,294 & 8.294 & 8.284 & 8,294 & 8.294 & 8,294 & 8.294 & 8,294 & 8,294 & 8,234 & 8,234 \\
\hline$\cup \times(m)$ & 144 & 144 & 144 & 144 & 144 & 144 & 144 & 144 & 144 & 192 & 192 & 192 & 192 & 192 & 192 \\
\hline $1 Y(m)$ & 576 & 576 & 576 & 576 & 576 & 576 & 576 & 576 & 576 & 432 & 432 & 432 & 432 & 432 & 432 \\
\hline OE $(l / h)$ & 35 & 56 & 56 & 56 & 56 & 87 & 87 & 87 & 87 & 35 & 35 & 35 & 35 & 56 & 56 \\
\hline$D E Q \times(\%)$ & 5 & 0 & 1 & 3 & 5 & 0 & 1 & 3 & 5 & 0 & 1 & 3 & 5 & 0 & 1 \\
\hline DECY $\{\%\}$ & 5 & 0 & 1 & 3 & 5 & 0 & 1 & 3 & 5 & 0 & 1 & 3 & 5 & 0 & 1 \\
\hline FOn'Ss/ha anoli & 2708 & 2850 & 2829 & 2637 & 2402 & 2816 & 2808 & 2788 & 2707 & 2890 & 2886 & 2870 & 2850 & 2862 & 2856 \\
\hline [CSIST TUSSMa ano) & 447 & 417 & 428 & 448 & 483 & 451 & 460 & 460 & 532 & 375 & 381 & 397 & 418 & 406 & 412 \\
\hline RBRUT US $\$$ Mha.end & 4571 & 4624 & 4674 & 4441 & 4241 & 4624 & 4624 & 4624 & 4595 & 4624 & 4624 & 4624 & 4624 & 4624 & 4624 \\
\hline CPAOD US \$Ma and & 1356 & 1356 & 1356 & 1306 & 1356 & 1356 & 1356 & 1356 & 1356 & 1356 & 1356 & 1356 & 1356 & 1356 & 1356 \\
\hline NUO & 4 & 8 & 8 & 8 & 8 & 12 & 12 & 12 & 12 & 4 & 4 & 4 & 4 & 6 & 6 \\
\hline NUOS & 1 & 1 & 1 & 1 & 1 & 1 & 1 & 1 & 1 & 1 & 1 & 1 & 1 & 1 & 1 \\
\hline NLS & 1 & 1 & 1 & 1 & 1 & 1 & 1 & 1 & 1 & 1 & 1 & 1 & 1 & 1 & 1 \\
\hline \multicolumn{16}{|l|}{$L P(m)$} \\
\hline$L L(m)$ & 142 & 7 & 70 & 70 & 70 & 46 & 46 & 46 & 46 & 16 & 106 & 106 & 106 & 70 & 70 \\
\hline$L D(m)$ & $\infty$ & 68 & 68 & 68 & 58 & 68 & 68 & 68 & 68 & 92 & 92 & 92 & 92 & 92 & 92 \\
\hline $\mathrm{LS}(\mathrm{m})$ & 432 & 504 & 504 & 504 & 504 & 528 & 528 & 528 & 528 & 324 & 324 & 324 & 324 & 360 & 350 \\
\hline CENE (USS/ano) & 908 & 390 & 440 & 563 & 631 & 442 & 495 & 501 & 653 & 432 & 472 & 593 & 741 & 448 & 490 \\
\hline CEB (US\$) & 2426 & 1628 & 1724 & 1935 & 2042 & 1728 & 1822 & 1996 & 2076 & 1856 & 1929 & 2009 & 2283 & 1930 & 2008 \\
\hline OVR(US\$) & 1614 & 3227 & 3227 & 3227 & 3227 & 4841 & 4841 & 4841 & 4849 & 1614 & 1614 & 1614 & 1614 & 2427 & 2421 \\
\hline CPC (US\$) & 1406 & 2016 & 2076 & 2016 & 2016 & 2490 & 2490 & 2490 & 2490 & 1406 & 1406 & 1406 & 1406 & 1736 & 1736 \\
\hline CEC(US\$) & 4080 & 3627 & 3627 & 3627 & 3627 & 3691 & 369 & 3691 & 3691 & 4000 & 4080 & 4000 & 4080 & 4231 & 4231 \\
\hline$T L L(m)$ & 10224 & 10080 & 10060 & 10000 & 10060 & 9936 & 9936 & 9936 & 9936 & 10176 & 10176 & 10176 & 10176 & 10080 & 10000 \\
\hline \multicolumn{16}{|l|}{$\pi P(m)$} \\
\hline$\pi(m)$ & 272 & 544 & 544 & 544 & 544 & 816 & 816 & 816 & 816 & 368 & 368 & 368 & 368 & 552 & 552 \\
\hline$\pi S(m)$ & 432 & 504 & 504 & 504 & 504 & 528 & 528 & 528 & 528 & 324 & 324 & 324 & 324 & 360 & 360 \\
\hline$H T$ (mca) & 60 & 25.15 & 30.35 & 42.99 & 50 & 28.98 & 3426 & 44.8 & 50 & 27.4 & 31.04 & 40.11 & 49.69 & 28.22 & 32.05 \\
\hline HDA (mca) & 3.19 & $1.03 !$ & 0.42 & 0.11 & 0.09 & 2.87 & 2.25 & 1.25 & 0.133 & 2,56 & 1.82 & 1.17 & 0.98 & 2.85 & 2,18 \\
\hline $\mathrm{HDO}$ (mca) & 10 & 1,03 & 1.78 & 4,19 & 6,89 & 2,87 & 3,61 & 5,33 & 7 & 2,56 & 3,66 & 6,69 & 10.18 & 2,85 & 4,12 \\
\hline HLA (mca) & 2.79 & 1.55 & 0.94 & 0.94 & 0.94 & 3.24 & 2.71 & 1.43 & 0.67 & 3.84 & 3.05 & 2.47 & 1.56 & 3.95 & 328 \\
\hline HLD (mca) & 16.99 & 1.55 & 2.34 & 5.14 & 7.94 & 3.24 & 3.08 & 4.19 & 5.27 & 3.84 & 5.17 & 8.83 & 12.56 & 3.95 & 4.68 \\
\hline \multicolumn{16}{|l|}{$D P A(m)$} \\
\hline \multicolumn{16}{|l|}{$D P D(m)$} \\
\hline $\operatorname{DLD}(\mathrm{m})$ & 0.015 & 0.02 & 0.018 & 0.015 & 0.014 & 0.016 & 0.015 & 0.015 & 0.014 & 0.017 & 0,016 & 0.015 & 0.014 & 0.016 & 0.016 \\
\hline$D D A(m)$ & 0.053 & 0.062 & 0.075 & 0.1 & 0.104 & 0.051 & 0.054 & 0.061 & 0.097 & 0.053 & 0.064 & 0.07 & 0.073 & 0.059 & 0.063 \\
\hline$D D D(m)$ & 0,042 & 0.062 & 0.056 & 0.046 & 0.042 & 0.051 & 0,048 & 0.045 & 0.042 & 0.059 & 0.055 & 0.048 & 0.044 & 0.058 & 0.055 \\
\hline NGE & 36 & 18 & 18 & 18 & 18 & 12 & 12 & 12 & 12 & 27 & 27 & 27 & 27 & 18 & 18 \\
\hline NUL & 9 & 9 & 9 & 9 & 9 & 9 & 9 & 9 & 9 & 12 & 12 & 12 & 12 & 12 & 12 \\
\hline NSS & 2 & 4 & 4 & 4 & 4 & 6 & 6 & 6 & 6 & 2 & 2 & 2 & 2 & 3 & 3 \\
\hline$O L(M)$ & 1260 & 1008 & 1008 & 1008 & 1008 & 1044 & 1044 & 1044 & 1044 & 945 & 945 & 345 & 945 & 1008 & 1008 \\
\hline$O D(n)$ & 22680 & 18144 & 18144 & 18144 & 18744 & 18792 & 18792 & 18792 & 18792 & 22680 & 22680 & 22800 & 22080 & 24192 & 2419 \\
\hline HS (mco) & 5.6 & 6.37 & 6.43 & 6.54 & 1.01 & 6.5 & 6.55 & 6.65 & 1.24 & 4.71 & 4.72 & 4,65 & 4.53 & 5.07 & 5.1 \\
\hline $05(t h)$ & 22680 & 18144 & 18144 & 18144 & 18144 & 18792 & 18792 & 18792 & 18792 & 22680 & 22680 & 22680 & 22560 & 24192 & 2419 \\
\hline \multicolumn{16}{|l|}{ HPA (mca) } \\
\hline \multicolumn{16}{|l|}{$Q P(h / h)$} \\
\hline OT $(M h)$ & 22680 & 18144 & 18144 & 18144 & 18144 & 18792 & 18792 & 18792 & 18792 & 22680 & 22680 & 22680 & 22680 & 24192 & 2419 \\
\hline \multicolumn{16}{|c|}{ 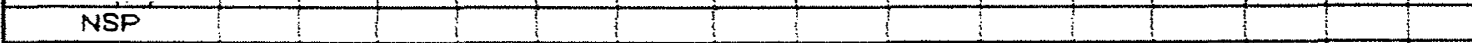 } \\
\hline \multicolumn{16}{|l|}{ HPD (mca) } \\
\hline DHUO (mca) & 16,48 & 2.59 & 2.74 & 5,19 & 7,93 & 6,1 & 6,1 & 6,1 & 6.5 & 6,39 & 5.85 & 9.58 & 12,84 & 6,8 & 7,08 \\
\hline \multicolumn{16}{|l|}{$V P A(m / s)$} \\
\hline VPD $(\mathrm{m} / \mathrm{s})$ & & & & & & & & & & & & & & & \\
\hline$V \mathrm{~s}(\mathrm{~m} / \mathrm{s})$ & 1.32 & 1.38 & 1.38 & 1.39 & 0.64 & 1.43 & 1.44 & 1.45 & 0.71 & 1,38 & 1.39 & 1.38 & 1.36 & 1.5 & 1.5 \\
\hline TE & 2592 & 2592 & 2592 & 2592 & 2592 & 2592 & 2592 & 2592 & 2592 & 2592 & 2592 & 2592 & 2592 & 2592 & 2598 \\
\hline$D S(m)$ & 0.078 & 0.058 & 0.068 & 0.068 & 0.101 & 0.068 & 0.068 & 0.068 & 0.096 & 0.076 & 0.076 & 0.076 & 0.077 & 0076 & 0.07 \\
\hline$D L A(m)$ & 0,022 & 0.02 & 0.022 & 0.022 & 0.022 & 0.016 & 0.016 & 0.019 & 0.022 & 0.017 & 0.018 & 0.019 & 0.02 & 0.016 & 0.01 \\
\hline UE & 0.69 & 0.88 & 0.88 & 0.85 & 0.81 & 0.85 & 0.85 & 0.85 & 0.85 & 0.84 & 0.84 & 0.8 & 0.75 & 0.83 & 0.82 \\
\hline HMIN (mce) & 8.41 & 13,97 & 13,9 & 1292 & $\mid 11,83$ & 12.56 & $\mid 1256$ & 12,56 & 12.4 & 12,44 & $\mid 12,26$ & 11,17 & 9,87 & 12,28 & 12,1 \\
\hline $1(h)$ & 8.18 & 5,33 & 7.99 & 2.62 & 10.49 & 2.84 & 5.87 & 1.75 & 1.75 & 21 & 4.44 & 4.66 & 21 & 7,12 & 7.99 \\
\hline$T$ (dia) & 1,56 & 2.03 & 3.04 & 1 & 4 & 1.62 & 3.36 & 1 & 1 & 4.7 & 1 & 1 & 423 & 2.54 & 283 \\
\hline
\end{tabular}




\begin{tabular}{|c|c|c|c|c|c|c|c|c|c|c|c|c|c|c|c|}
\hline \multirow[t]{2}{*}{ VARIAVEL } & \multicolumn{15}{|c|}{ CONFIGURACAO } \\
\hline & 31 & 32 & 33 & 34 & 35 & 36 & 37 & 38 & 39 & 40 & 41 & 42 & 43 & 44 & 45 \\
\hline$A(h \theta)$ & 8.294 & 8.294 & 8.294 & 8.294 & 8.294 & 8,294 & 8.294 & 8.294 & 8,294 & 8,294 & 8,294 & 8,294 & 8.294 & 8.294 & 8,294 \\
\hline$L \times(m)$ & 192 & 192 & 192 & 192 & 192 & 192 & 576 & 575 & 576 & 578 & 578 & 578 & 576 & 578 & 576 \\
\hline $\operatorname{LY}(\mathrm{m})$ & 432 & 432 & 432 & 432 & 432 & 432 & 144 & 144 & 144 & 144 & 144 & 144 & 144 & 144 & 144 \\
\hline QE (l/h) & 56 & 56 & 87 & 87 & 87 & 87 & 35 & 35 & 35 & 35 & 56 & 56 & 56 & 56 & 87 \\
\hline DECX(\%) & 3 & 5 & 0 & 1 & 3 & 5 & 0 & 1 & 3 & 5 & $a$ & 1 & 3 & 5 & 0 \\
\hline DECY $(\%)$ & 3 & 5 & 0 & 1 & 3 & 5 & 0 & 1 & 3 & 5 & 0 & 1 & 3 & 5 & 0 \\
\hline Fansshenof & 2840 & 2820 & 2821 & 2814 & 2795 & 2723 & 289 & 2869 & 2834 & & 2838 & 2833 & 2792 & & 2785 \\
\hline CSISTIUSS/Aso.and & 428 & 448 & 447 & 453 & 473 & 544 & 377 & 398 & 434 & & 430 & 434 & 476 & & 482 \\
\hline FBRUT US \$ tha and & 4624 & 4624 & 4624 & 4624 & 4624] & 4624 & 4624 & 4623 & 4624 & & 4624 & 4624 & 4624 & & 4624 \\
\hline CPROD USShro and & 1356 & 1356 & 1356 & 1356 & 1356 & 1356 & 1356 & 1356 & 1356 & & 1356 & 1356 & 1356 & & 1356 \\
\hline NUO & 6 & 6 & 12 & 12 & 12 & 12 & 4 & 4 & 2 & & 4 & 4 & 4 & & 6 \\
\hline NuOS & 1 & 1 & 1 & 1 & 1 & 2 & 1 & 1 & 1 & & 1 & 1 & 1 & & 1 \\
\hline NLS & 1 & 1 & 1 & 1 & 1 & 1 & 1 & 1 & 1 & & 1 & 1 & 1 & & 1 \\
\hline \multicolumn{16}{|l|}{$\operatorname{LP}(m)$} \\
\hline$L L(m)$ & 70 & 70 & 34 & 34 & 34 & 34 & 34 & 34 & 70 & & 34 & 34 & 34 & & 22 \\
\hline$L D(m)$ & 92 & 92 & 32 & 92 & 92 & 92 & 284 & 284 & 284 & & 284 & 284 & 284 & & 284 \\
\hline$L S(m)$ & 360 & 360 & 396 & 396 & 3966 & 396 & 108 & 108 & 72 & & 108 & 108 & 108 & & 120 \\
\hline CENE (US\$/ano) & 604 & 726 & 425 & 464 & 543 & 684 & 401 & 395 & 519 & & 470 & 509 & 628 & & 476 \\
\hline CEB (US\$) & 2180 & 2338 & 1696 & 1768 & 1904 & 2876 & 1789 & 1790 & 2790 & & 2327 & 2387 & 2537 & & 2393 \\
\hline CVR(US\$) & 2420 & 2427 & 4841 & 4841 & 4841 & 4841 & 1614 & 1614 & 807 & & 1614 & 1614 & 1674 & & 2420 \\
\hline CPC (US\$) & 1736 & 1736 & 2490 & 2490 & 2450 & 2490 & 1406 & 1406 & 981 & & 1406 & 1406 & 1406 & & 1736 \\
\hline CEC(US\$) & 4231 & 4231 & 3691 & 3691 & 3691 & $55 \pi$ & 4080 & 4000 & 6348 & & 5441 & 5441 & 5441 & & 5571 \\
\hline$\pi(m)$ & 10000 & 10000 & 9792 & 9792 & 9792 & 9792 & 9792 & 9792 & 10000 & & 9792 & 9792 & 9792 & & 9504 \\
\hline \multicolumn{16}{|l|}{$\operatorname{TLP}(\mathrm{m})$} \\
\hline$\pi D(m)$ & 552 & 552 & 1104 & 1104 & 1104 & 1104 & 1136 & 1136 & 568 & & 1136 & 1136 & 1136 & & 1704 \\
\hline$\pi \mathrm{S}(\mathrm{m})$ & 360 & 360 & 396 & 396 & 396 & 396 & 108 & 108 & 72 & & 108 & 108 & 108 & & 120 \\
\hline HT (mca) & 41.04 & 50 & 27.26 & 31.19 & 39.04 & 50 & 2425 & 24,3 & 35.52 & & 27.91 & 30.3 & 36,38 & & 28.97 \\
\hline HDA (mce) & 1.67 & 0.8 & 3.55 & 2,72 & 0,9 & 0,8 & 3.93 & 0.58 & 0.99 & & 5,86 & 3.87 & 0,59 & & 6.37 \\
\hline HDD (mca) & 7.19 & 10 & 3.55 & 4.56 & 6,42 & 10 & 3.93 & 6.26 & 18,03 & & 5,86 & 9.55 & 17,63 & & 6,37 \\
\hline HLA (mce) & 2.44 & 1.99 & 2.55 & 2.12 & 1.42 & 1.9 & 2,62 & 1.34 & 4.24 & & 3.9 & 4.13 & 5,05 & & 425 \\
\hline HLD (mco) & 6.64 & 8.99 & 2.55 & 2.8 & 3.46 & 5.3 & 2.52 & 2.62 & 8.44 & & 3.9 & 4.81 & 7.1 & & 4.25 \\
\hline \multicolumn{16}{|l|}{$D P A(m)$} \\
\hline \multicolumn{16}{|l|}{$\mathrm{DPD}(\mathrm{m})$} \\
\hline DLD $(\mathrm{m})$ & 0.015 & 0.014 & 0.014 & 0.014 & 0.013 & 0.012 & 0.01 & 0.01 & 0.012 & & 0,011 & 0.01 & 0.01 & & 0.07 \\
\hline$D D A(m)$ & 0.066 & 0.078 & 0.052 & 0.055 & 0.069 & 0.071 & 0.068 & 0.102 & 0.118 & & 0.875 & 0,081 & 0,121 & & 0.074 \\
\hline$D D D(\mathrm{~m})$ & 0.049 & 0,046 & 0.052 & 0,049 & 0,046 & 0,042 & 0.068 & 0.062 & 0,064 & & 0.075 & 0,067 & 0,059 & & 0.074 \\
\hline NGE & 18 & 18 & 9 & 9 & 9 & 9 & 9 & 9 & 18 & & 9 & 9 & 9 & & 6 \\
\hline NLL & 12 & 12 & 12 & 12 & 12 & 12 & 36 & 36 & 36 & & 36 & 36 & 36 & & 36 \\
\hline NSS & 3 & 3 & 6 & 6 & 6 & 6 & 2 & 2 & 1 & & 2 & 2 & 2 & & 3 \\
\hline OL (n) & 1008 & 1008 & 783 & 783 & 783 & 783 & 315 & 315 & 630 & & 504 & 504 & 504 & & 522 \\
\hline$Q D(1 / h)$ & 24192 & 24192 & 18792 & 16792 & 18792 & 18792 & 22680 & 22680 & 45360 & & 36288 & 36288 & 36288 & & 37584 \\
\hline HS (mce) & 5.06 & 4,97 & 4.86 & 4.89 & 4.95 & 5.06 & 1.56 & 1.57 & 1.42 & & 1.82 & 1.8 & 1.73 & & 1.97 \\
\hline QS (l/h) & 24192 & 24192 & 18792 & 18792 & 18792 & 18792 & 22680 & 22580 & 45360 & & 36288 & 36288 & 36208 & & 37584 \\
\hline \multicolumn{16}{|l|}{ HPA (mca) } \\
\hline \multicolumn{16}{|l|}{$Q P(l / h)$} \\
\hline OT $(l / h)$ & 24192 & 24192 & 18792 & 18792 & 18792 & 37568 & 22600 & 22680 & 45360 & & 36288 & 36288 & 36288 & & 37584 \\
\hline NSP & & & & & & & & & & & & & & & \\
\hline \multicolumn{4}{|l|}{ HPD (mca) } & & & & & & & & & & & & \\
\hline DHUO (mca) & 8.97 & 10.9 & 6.1 & 6.1 & 6.1 & 9 & 6,54 & 5.7 & 15,85 & & 9.76 & 11,18 & 15.18 & & 10.62 \\
\hline \multicolumn{16}{|l|}{$\mathrm{VPA}(\mathrm{m} / \mathrm{s})$} \\
\hline \multicolumn{16}{|l|}{$V P D(\mathrm{~m} / \mathrm{s})$} \\
\hline$V S(\mathrm{~m} / \mathrm{s})$ & 1.49 & 1.48 & 1.43 & 1.44 & 3.44 & 1.75 & 1.38 & 1.38 & 1.5 & & 1.57 & 1.66 & 1.63 & & 1.79 \\
\hline TE & 2592 & 2592 & 2592 & 2592 & 2592 & 2592 & 2552 & 2592 & 2592 & & 2592 & 2592 & 2592 & & 2592 \\
\hline$D S(m)$ & 0.076 & 0.076 & 0.068 & 0.068 & 0.068 & 0.087 & 0.076 & 0.076 & 0.101 & & 0,088 & 0.088 & 0.099 & & 0.086 \\
\hline$D L A(m)$ & 0.018 & 0.019 & 0.014 & 0.015 & 0.016 & 0.015 & 0.01 & 0.011 & 0.013 & & 0.011 & 0.011 & 0.01 & & 0.01 \\
\hline UE & 0.8 & $0 . \pi$ & 0.85 & 0.85 & 0.85 & 0.81 & 0.84 & 0.85 & 0.7 & & 0.78 & 0.76 & 0.7 & & 0.79 \\
\hline $\mathrm{HMIN}$ (mca) & 11,41 & 10,64 & 12.56 & 12.56 & 12,56 & 11.4 & 12,38 & 12.72 & 8.56 & & 11,1 & 10.53 & 8,93 & & 10,75 \\
\hline$f(h)$ & 6.7 & 16.09 & 3.37 & 3,3 & 9.31 & 1.83 & 21 & 7.43 & 13.07 & & 15.68 & 16.18 & 17.63 & & 6.72 \\
\hline$T$ (dia) & 2.3 & 5.32 & 1.93 & 1.89 & 5.32 & 1 & 4.75 & 1.71 & 3.6 & & 5.3 & 5.32 & 5.32 & & 3,56 \\
\hline
\end{tabular}




\begin{tabular}{|c|c|c|c|c|c|c|c|c|c|c|c|c|c|c|c|}
\hline \multirow[t]{2}{*}{ VARRLAVEL } & \multicolumn{15}{|c|}{ CONFIGURASEO } \\
\hline & 46 & 47 & 48 & 49 & 50 & 51 & 52 & 53 & 54 & 55 & 56 & 57 & 58 & 59 & 60 \\
\hline A (ha) & 8294 & 8.294 & 8.294 & 8.294 & 8294 & 8.294 & 8.294 & 8.294 & 8,294 & 8.294 & 8294 & 8.294 & 8.294 & 8294 & 8,294 \\
\hline$L \times(m)$ & 576 & 576 & 576 & 432 & 432 & 432 & 432 & 432 & 432 & 432 & 432 & 432 & 432 & 432 & 432 \\
\hline$L Y(m)$ & 144 & 144 & 144 & 192 & 152 & 192 & 192 & 192 & 192 & 192 & 192 & 192 & 192 & 192 & 192 \\
\hline QE $(1 / n)$ & 87 & 87 & 87 & 35 & 35 & 35 & 35 & 56 & 56 & 56 & 56 & 87 & 87 & 87 & 87 \\
\hline DECX(\%) & 1 & 3 & 5 & D & 1 & 3 & 5 & 0 & 1 & 3 & 5 & 0 & 1 & 3 & 5 \\
\hline DECY $(\%)$ & 1 & 3 & 5 & 0 & 1 & 3 & 5 & 0 & 1 & 3 & 5 & 0 & 1 & 3 & 5 \\
\hline FORUSs/heanol| & $2 m$ & 2747 & & 2901 & 2897 & 2861 & 2795 & 2058 & 2855 & 2834 & 2711 & 2800 & 2803 & 2773 & 2753 \\
\hline CSISTRUSSthomol| & 490 & 520 & & 367 & 377 & 407 & 472 & 409 & 413 & 433 & 499 & 460 & 465 & 494 & 515 \\
\hline RBRUT USSthe and & 4624 & 4624 & & 4624 & 4624 & 4624 & 4624 & 4624 & 4624 & 4624 & 4566 & 4624 & 4624 & 4624 & 4624 \\
\hline CPROD USSTho and & 1356 & 1356 & & 1356 & 1356 & 1356 & 1356 & 1356 & 1356 & 1356 & 1356 & 1356 & 1356 & 1356 & 1366 \\
\hline NUO & 6 & 6 & & 4 & 4 & 4 & 4 & 6 & 6 & 6 & 6 & 8 & 8 & 8 & $\theta$ \\
\hline NUOS & 1 & 1 & & 1 & 1 & 1 & 2 & 1 & 1 & 1 & 1 & 1 & 1 & 1 & 1 \\
\hline NLS & 1 & 1 & & 1 & 1 & 1 & 1 & 1 & 1 & 1 & 1 & 1 & 1 & 1 & 1 \\
\hline \multicolumn{16}{|l|}{$L P(m)$} \\
\hline$L(m)$ & 22 & 22 & & 46 & 46 & 46 & 46 & $3 B$ & 30 & 30 & 30 & 22 & 22 & 22 & 22 \\
\hline$L D(m)$ & $2 B A$ & 284 & & 212 & 212 & 212 & 212 & 212 & 212 & 212 & 212 & 212 & 272 & 212 & 212 \\
\hline$L S(m)$ & 120 & 120 & & 144 & 144 & 144 & 144 & 160 & 160 & 160 & 160 & 168 & 158 & 168 & 158 \\
\hline CENE \{USS/anuh & 477 & 654 & & 424 & 456 & 533 & 820 & 457 & 490 & 597 & 764 & 481 & 487 & 597 & 823 \\
\hline CEB (US\$) & 2405 & 2622 & & 1824 & 1871 & 1972 & 3038 & 1913 & 1963 & 2088 & 2235 & 2100 & 2122 & 2238 & 2454 \\
\hline OVRINSS) & 2421 & 2421 & & 1614 & 1614 & 1614 & 1614 & 2421 & 2421 & 2421 & 2421 & 3227 & 3227 & 3227 & 3227 \\
\hline CPC (US\$) & 1736 & 1736 & & 1406 & 1406 & 1406 & 1406 & 1736 & 1736 & 1736 & 1736 & 2017 & 2017 & 2017 & 2017 \\
\hline CEC(US\$) & 5571 & 5571 & & 4080 & 4080 & 1080 & 6348 & 4231 & 4231 & 4231 & 4231 & 4631 & 4637 & 4631 & 4631 \\
\hline$\pi L(m)$ & 9504 & 9504 & & 9836 & 9936 & 9836 & 9836 & 9720 & 9720 & 3720 & 9720 & 9504 & 9504 & 9504 & 9504 \\
\hline \multicolumn{16}{|l|}{$\pi P(m)$} \\
\hline$T L D(m)$ & 1704 & 1704 & & 848 & 848 & 848 & 848 & 1272 & 1272 & 1272 & 1272 & 1696 & 1696 & 1696 & 1696 \\
\hline$\pi \mathrm{L}(m)$ & 128 & 120 & & 144 & 144 & 144 & 144 & 160 & 160 & 160 & 160 & 168 & 168 & 168 & 168 \\
\hline HT (mca) & 29,46 & 38.39 & & 25.87 & 28,19 & 33.3 & 45.54 & 27.43 & 23.8 & 36.11 & 44.07 & 29.42 & 30.42 & 35.83 & 46.85 \\
\hline $\mathrm{HDA}($ mca) & 3.2 & 1,5 & & 4.55 & 3 & 0.21 & 1.23 & 5,35 & 3.75 & 1,46 & 0.14 & 6.37 & 3.92 & 1 & 1.4 \\
\hline $\mathrm{HDD}$ (mca) & 8,88 & 18,54 & & 4,55 & 7.25 & 12,93 & 22,43 & 5,35 & 7,99 & 14,18 & 21,34 & 6,37 & 8,16 & 13,72 & 22.5 \\
\hline HLA (mce) & 381 & 6.02 & & 3.03 & 2.96 & 3 & 5.591 & 3.57 & 3.67 & 4.31 & 5.66 & 425 & 3.87 & 4.25 & 6.9 \\
\hline HLD (mca) & 4.25 & 7.34 & & 303 & 3.88 & 5.76 & 10.19 & 3.57 & 4.27 & 6.11 & 8.66 & 425 & 4.25 & 5.57 & 9.1 \\
\hline \multicolumn{16}{|l|}{$D P A(m)$} \\
\hline \multicolumn{16}{|l|}{$\mathrm{DFD}(\mathrm{m})$} \\
\hline $\mathrm{DLD}(\mathrm{m})$ & 0.01 & 0.009 & & 0.011 & 0.011 & 0,01 & 0.009 & 0.07 & 0.01 & 0,009 & 0,000 & 001 & 0.01 & 0.009 & 0,009 \\
\hline$D D A(m)$ & 0.006 & 0.101 & & 0.062 & 0.068 & 0.119 & 0.082 & 0.062 & 0.066 & 0.081 & 0.133 & 0,063 & 0.07 & 0,053 & 0.086 \\
\hline$D D D(m)$ & 0.069 & 0.059 & & 0.062 & 0,056 & 0.05 & 0.045 & 0.062 & 0.057 & 0.05 & 0,046 & 0.063 & 0.06 & 0.053 & 0.048 \\
\hline NGE & 6 & 6 & & 12 & 12 & 12 & 12 & 8 & 8 & 8 & 8 & 6 & 6 & 6 & 6 \\
\hline NUL & 36 & 36 & & 27 & 27 & 27 & 27 & 27 & 27 & 27 & 27 & 27 & 27 & 27 & 27 \\
\hline NSS & 3 & 3 & & 2 & 2 & 2 & 2 & 3 & 3 & 3 & 3 & 4 & 4 & 4 & 4 \\
\hline$Q L(m)$ & 522 & 522 & & 420 & 420 & 420 & 420 & 448 & 448 & 448 & 448 & 522 & 522 & 522 & 522 \\
\hline$Q D(n n)$ & 37584 & 37584 & & 22680 & 22680 & 22680 & 22680 & 24192 & 24192 & 24192 & 24192 & 28188 & 28188 & 28188 & 28188 \\
\hline HS (mce) & 1.99 & 1.87 & & 2.06 & 2.05 & 2.02 & 2.42 & 2.2 & 2.19 & 2.14 & 2.02 & 2.4 & 2.42 & 2.39 & 2.18 \\
\hline OS $(\mathrm{l} / \mathrm{h})$ & 37584 & 3584 & & 22680 & 22680 & 22680 & 226800 & 24192 & 24192 & 24192 & 24192 & 28188 & 28188 & 28188 & 28188 \\
\hline \multicolumn{16}{|l|}{ HPA (mco) } \\
\hline \multicolumn{16}{|l|}{$Q P(/ / h)$} \\
\hline$O T(h / h)$ & 37584 & 37584 & & 22680 & 22680 & 22680 & 22680 & 24192 & 24192 & 24192 & 24192 & 28188 & 28188 & 28188 & 28188 \\
\hline \multicolumn{16}{|l|}{ NSP } \\
\hline \multicolumn{16}{|l|}{ HPD (mce) } \\
\hline DHUO (mca) & 10.07 & 16.7 & & 7,58 & 8,54 & 10,95 & 19,71 & 8,92 & 9.78 & 13,04 & 17.9 & 10,62 & 10,07 & 12.27 & 20 \\
\hline \multicolumn{16}{|l|}{$V P A(\mathrm{~m} / \mathrm{s})$} \\
\hline$V P D(\mathrm{~m} / \mathrm{s})$ & & & & & & & & & & & & & & & \\
\hline$V s(\mathrm{~m} / \mathrm{s})$ & 1.8 & 1.75 & & 1.38 & 1.37 & 1.36 & 1.77 & 1,48 & 1.48 & 1.46 & 1.43 & 1.63 & 1.63 & 1.52 & 1.56 \\
\hline TE & 2592 & 2592 & & $2592 !$ & 2592 & 2592 & 2592 & 2592 & 2592 & 2532 & 2592 & 2592 & 2592 & 2592 & 2592 \\
\hline$D S(m)$ & 0.086 & 0.087 & & 0.076 & 0.076 & 0.077 & 0.095 & 0.076 & 0,076 & 0.077 & 0.077 & 0.078 & 0.078 & 0,078 & 0.08 \\
\hline$D L A(m)$ & 0.01 & 0.009 & & 0.011 & 0.012 & 0.011 & 0.01 & 0.07 & 0.01 & 0.01 & 0.008 & 0.01 & 0.01 & 0.07 & 0.009 \\
\hline UE & 0.8 & 0.7 & & 0.83 & 0.81 & 0.78 & 0.63 & 0.8 & 0.78 & 0.73 & 0.65 & 0.79 & 0.8 & 0.77 & 0.64 \\
\hline HMIN (mca) & 10,97 & 8.32 & & 11.97 & 11,58 & 10,62 & 7.11 & 11.43 & 11.081 & 9.79 & 784 & 10.75 & 10.97 & 10,09 & 7 \\
\hline $1(\mathrm{~h})$ & 1.87 & 3.48 & & 14.42 & 21 & 4.78 & 9.73 & 155 & 8.54 & 12.43 & 18.47 & 10.03 & 6.82 & 102 & 4.91 \\
\hline$T$ (dia) & 1 & 1.63 & & 3.21 & 4.6 & 1 & 1.66 & 5.32 & 2.89 & 3.93 & 5.28 & 5.32 & 3.55 & 5.25 & 2.12 \\
\hline
\end{tabular}




\begin{tabular}{|c|c|c|c|c|c|c|c|c|c|c|c|c|c|c|c|}
\hline \multirow[t]{2}{*}{ VARLAVEL } & \multicolumn{15}{|c|}{ CONFIGURACAO } \\
\hline & 61 & 62 & 63 & 64 & 65 & 68 & 67 & 68 & 69 & 70 & 71 & 72 & 73 & 74 & 75 \\
\hline$A(h a)$ & 23,04 & 23,04 & 23.04 & 23,04 & 23.04 & 23.04 & 23.04 & 23,04 & 23,04 & 23,04 & 23,04 & 23,04 & 2304 & 23,04 & 23,04 \\
\hline$L \times(m)$ & 480 & 480 & 480 & 480 & 480 & 480 & 480 & 480 & 480 & 480 & 460 & 480 & 240 & 240 & 240 \\
\hline$L Y(m)$ & 480 & 480 & 480 & 480 & 480 & 480 & 480 & 480 & 480 & 480 & 480 & 480 & 360 & 960 & 960 \\
\hline$Q E(M n)$ & 35 & 35 & 35 & 35 & 56 & 56 & 56 & 56 & 87 & 87 & 87 & 87 & 35 & 35 & 35 \\
\hline$D E \propto \times(\%)$ & 0 & 1 & 3 & 5 & 0 & 1 & 3 & 5 & 0 & 1 & 3 & 5 & 0 & 1 & 3 \\
\hline DECY (\%) & 0 & 1 & 3 & 5 & 0 & 1 & 3 & 5 & 0 & 1 & 3 & 5 & 0 & 1 & 3 \\
\hline FO\{US & 2539 & 2939 & 2905 & 2797 & 2914 & 2906 & 2879 & 2782 & 2809 & 2881 & 2854 & 2717 & 2927 & 2901 & 2818 \\
\hline CSISTIUSS/he onol & 329 & 336 & 363 & 470 & 353 & 367 & 386 & 485 & 378 & 386 & 414 & 551 & 347 & 366 & 450 \\
\hline RBRUT US\$ the and & 4624 & 4624 & 4624 & 4624 & 4624 & 4624 & 4624 & 4624 & 4624 & 4624 & 4624 & 4624 & 4624 & 4624 & 4624 \\
\hline CPROD USSMs and & 1356 & 1356 & 1356 & 1356 & 1356 & 1356 & 1356 & 1356 & 1356 & 1356 & 1356 & 1356 & 1305 & 1356 & 1356 \\
\hline NuO & 4 & 4 & 4 & 12 & 6 & 6 & 6 & 10 & 10 & 10 & 10 & 12 & 10 & 10 & 12 \\
\hline NUOS & 1 & 1 & 1 & 4 & 1 & 1 & 1 & 2 & 1 & 1 & 1 & 2 & 2 & 2 & 3 \\
\hline NLS & 1 & 1 & 1 & 1 & 1 & 1 & 1 & 1 & 1 & 1 & 1 & 1 & 1 & 1 & 1 \\
\hline \multicolumn{16}{|l|}{$L P(m)$} \\
\hline$U(m)$ & 118 & 118 & 118 & 38 & 78 & 78 & 78 & 46 & 46 & 46 & 46 & 38 & 34 & 94 & 78 \\
\hline$L D(m)$ & 236 & 236 & 236 & 236 & 236 & 236 & 236 & 236 & 236 & 236 & 236 & 236 & 116 & 116 & 116 \\
\hline LS (m) & 360 & 360 & 360 & 440 & 400 & 400 & 400 & 432 & 432 & 432 & 432 & 440 & $B 64$ & 864 & 830 \\
\hline CENE (USSIano) & 1284 & 1447 & 2003 & 2958 & 1356 & 1517 & 2119 & 2985 & 1418 & 1583 & 2167 & 2772 & 1176 & 1409 & 1845 \\
\hline CEB (US\$) & 3050 & 3796 & 3546 & 4570 & 31821 & 3334 & 3711 & 4467 & 3138 & 3286 & 3647 & 4971 & 2737 & 2980 & 3666 \\
\hline CVR(US\$) & 1614 & 1614 & 1674 & 4841 & 2421 & 2427 & 2427 & 4034 & 4034 & 4034 & 4034 & 4841 & 4034 & 4034 & 4841 \\
\hline CPC (US\$) & 1406 & 1406 & 1406 & 2490 & 1736 & 1736 & 1736 & 2264 & 2265 & 2265 & 2265 & 2490 & 2265 & 2255 & 2490 \\
\hline CECRS\$) & 8112 & 8112 & 8112 & 10212 & 6532 & 8532 & 8532 & 5876 & 8076 & 8076 & 8076 & 12252 & 6852 & 5052 & 8112 \\
\hline$\pi(m)$ & 28320 & 28320 & 28320 & 27360 & 28000 & 28000 & 28000 & 27600 & 27600 & 27600 & 37600 & 27360 & 28200 & 28200 & 28000 \\
\hline \multicolumn{16}{|l|}{$\operatorname{TLP}(\mathrm{m})$} \\
\hline$\pi D(m)$ & 944 & 544 & 944 & 2832 & 1416 & 1416 & 1416 & 2360 & 2360 & 2360 & 2360 & 2832 & 1160 & 1160 & 1392 \\
\hline $\operatorname{TLS}(\mathrm{m})$ & 360 & 360 & 360 & 440 & 400 & 400 & 400 & 432 & 432 & 432 & 432 & 440 & 864 & 864 & 880 \\
\hline HT (mca) & 28.94 & 33.54 & 45.56 & 62.92 & 30.14 & 34.79 & 47.54 & 62.32 & 31.95 & 36,8 & $49,6 ?$ & 50 & 28.62 & 37.28 & 50 \\
\hline HDA (mca) & 3.78 & 2.5 & 1.7 & 0.2 & 5.06 & 3.53 & 1,93 & 0.2 & 6,51 & 4,54 & 2,53 & 0.2 & 1.33 & 0.31 & 0.25 \\
\hline $\mathrm{HDD}$ (mca) & 3,78 & 7,221 & 15,86 & 23,8 & 5,06 & 8,25 & 16,09 & 238 & 6.51 & 9.26 & 16.7 & 23,8 & 1,33 & 2.63 & 7,21 \\
\hline HLA (mco) & 4.53 & 3.42 & 2.37 & 6.1 & 4.08 & 3.26 & 3.66 & 5.7 & 4.34 & 4.14 & 5.03 & 6.1 & 2 & 0.911 & 0.55 \\
\hline HLD (mca) & 4.53 & 5.78 & 3.39 & 9.9 & 4.08 & 4.82 & 8.34 & 10.3 & 4.34 & 5.06 & 7.79 & 8.9 & 2 & $2.79 !$ & 5.23 \\
\hline \multicolumn{16}{|l|}{$\mathrm{DPA}(\mathrm{m})$} \\
\hline \multicolumn{16}{|l|}{$\mathrm{DPD}(\mathrm{m})$} \\
\hline DLD $(m)$ & 0.018 & 0.017 & 0.015 & 0.008 & 0.017 & 0.017 & 0.015 & 0.011 & 0.015 & 0.014 & 0.013 & 0.011 & 0.019 & 0.017 & 0.014 \\
\hline$D D A(m)$ & 0.096 & 0.105 & 0.114 & 0.12 & 0.093 & 0.1 & 0.114 & 0.152 & 0.066 & 0.093 & 0.105 & 0.167 & 0.074 & 0.1 & 0.009 \\
\hline$D D D(m)$ & 0.096 & 0.084 & 0.071 & 0.044 & 0.093 & 0.084 & 0.073 & 0,056 & 0.086 & 0,08 & 0.07 & 0.061 & 0,074 & 0,064 & 0.049 \\
\hline $\mathrm{NGE}$ & 30 & 30 & 30 & 10 & 20 & 20 & 20 & 12 & 12 & 12 & 12 & 10 & 24 & 24 & 20 \\
\hline $\mathrm{NUL}$ & 30 & 30 & 30 & 30 & 30 & 30 & 30 & 30 & 30 & 30 & 30 & 30 & 15 & 15 & 15 \\
\hline NSS & 2 & 2 & 2 & 6 & 3 & 3 & 3 & 5 & 5 & 5 & 5 & 6 & 5 & 5 & 6 \\
\hline$Q L(n)$ & 1050 & 1050 & 1050 & 350 & 1120 & 1120 & 11201 & 672 & 1044 & 1044 & 1044 & 870 & 840 & 840 & 700 \\
\hline$Q D(4 / n)$ & 53000 & 63000 & 63000 & 21000 & 67200 & 67200 & 67200 & 40320 & 62640 & 62640 & 62640 & 52200 & 25200 & 25200 & 21000 \\
\hline HS (mce) & 4.26 & 4.22 & 3.99 & 4.62 & 4.57 & 4.55 & 4.23 & 4.45 & 4.58 & 4.57 & 4.34 & 1.84 & 8.93 & 9.05 & 1.13 \\
\hline $\operatorname{OS}(\mathrm{Vh})$ & 6300 & 63000 & 63000 & 84000 & 67200 & 67200 & 67200 & 86640 & 62640 & 62540 & 62840 & 104400 & 50400 & 50400 & 63000 \\
\hline \multicolumn{16}{|l|}{ HPA (mca) } \\
\hline \multicolumn{16}{|l|}{$Q P(V / h)$} \\
\hline OT $(h h)$ & 63000 & 63000 & 63000 & 84000 & 67200 & 67200 & 67200 & 80640 & 62640 & 62640 & 52640 & 104400 & 50400 & 50400 & 63000 \\
\hline \multicolumn{16}{|c|}{ 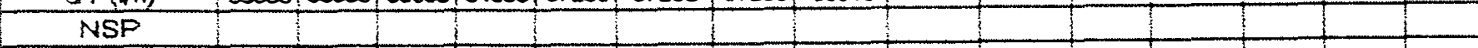 } \\
\hline \multicolumn{16}{|l|}{$\mathrm{HPD}$ (mca) } \\
\hline DHUO (mca) & 8,31 & 9,46 & 14,63 & 20 & 9,14 & 9,93 & 15,01 & 20 & 10.85 & 11,5 & 16,02 & 20 & 3,33 & 3,33 & 6,62 \\
\hline \multicolumn{16}{|l|}{$\operatorname{VPA}(\mathrm{m} / \mathrm{s})$} \\
\hline$V P D(\mathrm{~m} / \mathrm{s})$ & & & & & & & & & & & & & & & \\
\hline$V s(m / s)$ & 1.66 & 1.65 & 1.62 & 1.99 & 1.79 & 1.79 & 1.74 & 1.92 & 1.82 & 1.81 & 1.78 & 1.43 & 1.7 & 1.7 & 0.76 \\
\hline TE & 7200 & 7200 & 7200 & 7200 & 7200 & 7200 & 72000 & 7200 & 7200 & 7200 & 7200 & 7200 & 7200 & 7200 & 7200 \\
\hline$D S(m)$ & 0.116 & 0.116 & 0.117 & 0.122 & 0.115 & 0.115 & 0.117 & 0.122 & 0.11 & 0.111 & 0.112 & 0,161 & 0.103 & 0.102 & 0.177 \\
\hline$\overline{D L A}(\mathrm{~m})$ & 0.018 & 0.019 & 0.021 & 0.009 & 0.017 & 0.018 & 0.018 & 0.012 & 0.015 & 0.015 & 0.014 & 0.012 & 0.019 & 0.022 & 0.022 \\
\hline UE & 0.82 & 0.8 & 0.72 & 0.63 & 0.79 & 0.78 & 0.7 & 0.62 & 0.79 & 0.78 & 0.71 & 0.64 & 0.88 & 0.88 & 0.84 \\
\hline HMIN (mca) & 11.68 & 1122 & 9.15 & 7 & 11.34 & 11.03 & 3 & 7 & 10.66 & 10.4 & 8.59 & 7 & 13.67 & 13.67 & 12.35 \\
\hline $1(h)$ & 13.99 & 21 & 21 & 18,3 & 15.6 & 15.22 & 17.55 & 13.4 & 6.42 & 1.92 & 11.15 & 9.64 & 21 & $13.7 \pi$ & 27 \\
\hline$T$ (dia) & 3 & 4.52 & 4.07 & 3.1 & 5.32 & 5.13 & 5.32 & 3.57 & 3.39 & 1 & 5.31 & 4.16 & 5 & 3.27 & 4.75 \\
\hline
\end{tabular}




\begin{tabular}{|c|c|c|c|c|c|c|c|c|c|c|c|c|c|c|c|}
\hline \multirow[t]{2}{*}{ VARIAVEL } & \multicolumn{15}{|c|}{ CONFIGURACAO } \\
\hline & 76 & 77 & 78 & 79 & 80 & 81 & 82 & 83 & 84 & 85 & 86 & 87 & 88 & 89 & 90 \\
\hline A (ha) & 23.04 & 23.04 & 23,04 & 23,04 & 23,04 & 23.04 & 23,04 & 23.04 & 23,04 & 23,04 & 23.04 & 23.04 & 23,04 & 23,04 & 23,04 \\
\hline$L \times(m)$ & 240 & 240 & 240 & 240 & 240 & 240 & 240 & 240 & 240 & 950 & 960 & 960 & 360 & 360 & 560 \\
\hline$L Y(m)$ & 360 & 960 & 960 & 960 & 360 & 960 & 960 & 960 & 960 & 240 & 240 & 240 & 240 & 240 & 240 \\
\hline $\mathrm{QE}(\mathrm{M} / \mathrm{M})$ & 35 & 56 & 56 & 56 & 56 & 87 & 87 & 87 & 87 & 35 & 35 & 35 & 35 & 56 & 56 \\
\hline DEC $\times(\%)$ & 5 & 0 & 1 & 3 & 5 & 0 & 1 & 3 & 5 & 0 & 1 & 3 & 5 & 0 & 1 \\
\hline DECY $(\%)$ & 5 & $B$ & 1 & 3 & 5 & $B$ & 1 & 3 & 5 & 0 & 1 & 3 & 5 & $B$ & 1 \\
\hline FORSS/ha anoli & 2826 & 2889 & 2865 & 2842 & 2804 & 2889 & 2874 & 2819 & 2781 & 2928 & 2919 & & & 2867 & 2881 \\
\hline CSISTRUSShe anoli & 442 & 379 & 403 & 425 & 463 & 379 & 393 & 449 & 486 & 338 & 348 & & & 380 & 386 \\
\hline RBRUT USSTho.end & 4624 & 4624 & 4624 & 4624 & 4624 & 4624 & 4624 & 4624 & 4624 & 4624 & 4624 & & & 4624 & 4624 \\
\hline CPROD USS he and & 1356 & 1356 & 1356 & 1356 & 1356 & 1356 & 1356 & 1356 & 1356 & 1356 & 1356 & & & 1356 & 1356 \\
\hline NUO & 12 & 16 & 16 & 12 & 12 & 12 & 12 & 20 & 20 & 4 & 4 & & & 12 & 12 \\
\hline NUOS & 3 & 2 & 2 & 2 & 2 & 1 & 1 & 2 & 2 & 1 & 1 & & & 2 & 2 \\
\hline NLS & 1 & 1 & 1 & 1 & 1 & 1 & 1 & 1 & 1 & 1 & 1 & & & 2 & 2 \\
\hline$L P(m)$ & & & & & & & & & & & & & & 240 & 240 \\
\hline$L(m)$ & 78 & 58 & 58 & 78 & 78 & 78 & 78 & 46 & 46 & 58 & 58 & & & 38 & 38 \\
\hline$L D(m)$ & 116 & 116 & 116 & 116 & 116 & 116 & 116 & 116 & 116 & 476 & 476 & & & 236 & 236 \\
\hline$L S(m)$ & 860 & 900 & 900 & 890 & 880 & 880 & 880 & 912 & 912 & 180 & 180 & & & 200 & 200 \\
\hline CENE (US S/ano) & 3049 & 1159 & 1402 & 2345 & 3134 & 1300 & 1545 & 2324 & 2927 & 1332 & 1571 & & & 1424 & 1571 \\
\hline CEB@US\$ & 4422 & 2718 & 2972 & 4098 & 4571 & 2863 & 3111 & 3991 & 4370 & 3048 & 3198 & & & 3256 & 3382 \\
\hline OVR(US\$) & 4841 & 6455 & 6455 & 4841 & 4841 & 4841 & 4841 & 8069 & 8069 & 1614 & 1614 & & & 4841 & 4841 \\
\hline CPCRS\$ & 2490 & 2892 & 2892 & 2490 & 2490 & 2490 & 2490 & 3247 & 3247 & 1406 & 1406 & & & 2490 & 2490 \\
\hline CEC (USS) & 8112 & 5852 & 68521 & 8532 & 8532 & 7032 & 7032 & 8078 & 8076 & 8112 & 8112 & & & 8532 & 8532 \\
\hline$\pi(m)$ & 28000 & 27840 & 27840 & 28000 & 28000 & 28000 & 28000 & 27600 & 27600 & 27840 & 27840 & & & 27360 & 27360 \\
\hline$T L P(m)$ & & & & & & & & & & & & & & 480 & 480 \\
\hline $\operatorname{TLD}(\mathrm{m})$ & 1392 & 1856 & 1856 & 1392 & 1392 & 1392 & 1392 & 2320 & 2320 & 1904 & 1904 & & & 2832 & 2832 \\
\hline$\pi L S(m)$ & 880 & 900 & 900 & 800 & 800 & 880 & 880 & 912 & 912 & 180 & 180 & & & 400 & 400 \\
\hline HT (mca) & 81.89 & 27.98 & 36.98 & 6224 & 82.43 & 31.56 & 40,34 & 63.34 & 80 & 28,88 & 33.51 & & & 32.33 & 36.34 \\
\hline HOA (mce) & 1.1 & 1.34 & 0.274 & 1.66 & 1.31 & 2.78 & 1.43 & 2.42 & 1,36 & 6.26 & 3,37 & & & 5,53 & 3.72 \\
\hline HDD (mca) & 12,7 & 1,34 & 2,59 & 8,52 & 12,91 & 2,78 & 3.76 & 9,38 & 12,96 & 6.26 & 12,89 & & & 5,53 & 8,44 \\
\hline HLA (mco) & 1.47 & 1.25 & 0.572 & 2.24 & 1.65 & 3.32 & 2.73 & 2.55 & 2.47 & 4.17 & 4.84 & & & 3.69 & 3.67 \\
\hline HLD (mca) & 9.27 & 1.25 & 1.73 & 6.92 & 3.45 & 3.32 & 4.29 & 5.32 & 7.07 & 4.17 & 6 & & & 3.69 & 4.43 \\
\hline $\operatorname{DPA}(\mathrm{m})$ & & & & & & & & & & & & & & 0.095 & 0,102 \\
\hline $\mathrm{DPD}(\mathrm{m})$ & & & & & & & & & & & & & & 0.095 & 0,002 \\
\hline $\operatorname{DLD}(\mathrm{m})$ & 0.012 & 0.019 & 0.017 & 0.015 & 0.014 & 0.021 & 0.02 & 0.014 & 0.013 & 0.012 & 0.011 & & & 0.012 & 0.071 \\
\hline DDA $(\mathrm{m})$ & 0.072 & 0.074 & 0.103 & 0.079 & 0.083 & 0.083 & 0.095 & 0.071 & 0.08 & 0.1 & 0.114 & & & 0.077 & 0.077 \\
\hline$D D D(m)$ & 0,043 & 0.074 & 0.064 & 0.056 & 0.051 & 0.083 & 0.078 & 0.053 & 0.05 & 0.1 & 0.086 & & & 0.071 & 0.065 \\
\hline NGE & 20 & 15 & 15 & 20 & 20 & 20 & 20 & 12 & 12 & 15 & 15 & & & 10 & 10 \\
\hline $\mathrm{NLL}$ & 15 & 15 & 15 & 15 & 15 & 15 & 15 & 15 & 15 & 50 & 60 & & & 30 & 30 \\
\hline NSS & 6 & 8 & 8 & 6 & 6 & 5 & 6 & 10 & 10 & 2 & 2 & & & 3 & 3 \\
\hline $\mathrm{OL}(\mathrm{m})$ & 700 & 840 & 840 & 1120 & 1120 & 1740 & 1740 & 1044 & 1044 & 525 & 525 & & & 560 & 560 \\
\hline QD (l/h) & 27000 & 25200 & 25200 & 33600 & 33600 & 52200 & 52200 & 31320 & 31320 & 63000 & 53000 & & & 33600 & 33600 \\
\hline HS (mca) & 9.27 & 9.07 & 9.15 & 9.69 & 9.41 & 8.36 & 9.03 & 9.67 & 6.22 & 2.08 & 2 & & & 2.72 & 2.7 \\
\hline QS $(4 h)$ & 63000 & 50400 & 50400 & 67200 & 67200 & 52200 & 52200 & 62640 & 62640 & 53000 & 60300 & & & 33600 & 33600 \\
\hline HPA (mca) & & & & & & & & & & & & & & 3.86 & 2.72 \\
\hline $\mathrm{OP}(\mathrm{l} / \mathrm{h})$ & & & & & & & & & & & & & & 33500 & 33600 \\
\hline OT (l/h) & 63000 & 50400 & 50400 & 67200 & 67200 & 52200 & 52200 & 62640 & 62640 & 63000 & 53000 & & & 67200 & 67200 \\
\hline NSP & & & & & & & & & & & & & & 1 & 1 \\
\hline HPD (mca) & & & & & & & & & & & & & & 3.86 & 7.52 \\
\hline DHUO (mca) & 12.28 & 2,59 & 2.59 & 9.72 & 12.65 & 6.1 & 6.1 & 9.83 & 11,93 & 10.43 & 13,55 & & & 9.22 & 10,12 \\
\hline$V P A(m / s)$ & & & & & & & & & & & & & & 1.33 & 1.15 \\
\hline$V P D(m / s)$ & & & & & & & & & & & & & & 1,33 & 1.76 \\
\hline$V S(\mathrm{~m} / \mathrm{s})$ & 1.84 & 1.74 & 1.75 & 1.91 & 1.89 & 1.73 & 1.74 & 1.91 & 1.59 & 1.64 & 1.62 & & & 1.51 & 1.6 \\
\hline TE & 72001 & 7200 & 7200 & 7200 & 7200 & 7200 & 7200 & 7200 & 7200 & 7200 & 7200 & & & 7200 & 7200 \\
\hline$D S(m)$ & 0.11 & 0.101 & 0,101 & 0.112 & 0,112 & 0.103 & 0.103 & 0.108 & 0.118 & 0.116 & 0.117 & & & 0.006 & 0.006 \\
\hline$D L A(m)$ & 0.018 & 0.019 & 0,022 & 0.098 & 0.021 & 0.021 & 0.022 & 0.017 & 0.017 & 0.012 & 0012 & & & 0,012 & 0.012 \\
\hline UE & 0.76 & 0.88 & 0.88 & 0.78 & 0.74 & 0.85 & 0.85 & 0.8 & $0 . \pi$ & 0.78 & 0.74 & & & 0.79 & 0.78 \\
\hline HMIN (mca) & 10,09 & 1397 & 13,97 & 11,11 & 9,94 & 12.56 & 12.56 & 11.07 & 10.22 & 10,83 & 9,58 & & & 11,31 & 10,95 \\
\hline$T(h)$ & 27 & 2.63 & 13.97 & 15,73 & 16.67 & 3.31 & 9.18 & 3.53 & 1028 & 21 & 21 & & & 2.93 & 15.85 \\
\hline$T$ (dia) & 4.28 & 1 & 5.32 & 5,32 & 5.32 & 5.32 & 5.25 & 1.95 & 5.32 & 4.44 & 4.17 & & & 1 & 5,32 \\
\hline
\end{tabular}




\begin{tabular}{|c|c|c|c|c|c|c|c|c|c|c|c|c|c|c|c|}
\hline \multirow[t]{2}{*}{ VARLAVEL } & \multicolumn{15}{|c|}{ CONFIGURACAO } \\
\hline & 91 & 92 & 93 & 94 & 95 & 96 & 97 & 98 & 99 & 100 & 101 & 102 & 103 & 104 & 105 \\
\hline$A(h a)$ & 23.04 & 23,04 & 23,04 & 23,04 & 23,04 & 23,04 & 23,04 & 23,04 & 23,04 & 23,04 & 23,04 & 23,04 & 23,04 & 23,04 & 23,04 \\
\hline $\mathrm{L} \times(\mathrm{m})$ & 960 & 960 & 960 & 560 & 960 & 960 & 320 & 320 & 320 & 320 & 320 & 320 & 320 & 320 & 320 \\
\hline$L Y(m)$ & 240 & 240 & 240 & 240 & 240 & 240 & 720 & 720 & 720 & 720 & 720 & 720 & 720 & 720 & 720 \\
\hline$O E(L / h)$ & 56 & 56 & 87 & 87 & 87 & 87 & 35 & 35 & 35 & 35 & 56 & 56 & 56 & 56 & 87 \\
\hline DECX $(\%)$ & 3 & 5 & 0 & 1 & 3 & 5 & 0 & 1 & 3 & 5 & 0 & 1 & 3 & 5 & 0 \\
\hline DECY $(\%)$ & 3 & 5 & 0 & 1 & 3 & 5 & 0 & 1 & 3 & 5 & 0 & 1 & 3 & 5 & $B$ \\
\hline FOR S /he eno) & & & 2841 & 2834 & & & 2925 & 2914 & 2865 & 2830 & 2306 & 2896 & 2863 & 2824 & 2895 \\
\hline 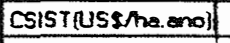 & & & 425 & 433 & & & 342 & 353 & 402 & 438 & 362 & 372 & 404 & 443 & 373 \\
\hline RBRUT USShe ena & & & 4624 & 4624 & & & 4624 & 4624 & 4624 & 4624 & 4623 & 4624 & 4624 & 4624 & 4624 \\
\hline CFROD USSMe and & & & 1356 & 1356 & & & 1356 & 1356 & 1356 & 1356 & 1356 & 1356 & 1356 & 1356 & 1356 \\
\hline NUO & & & 20 & 20 & & & 4 & 4 & 6 & 6 & 6 & 6 & 6 & 12 & 12 \\
\hline NuOS & & & 2 & 2 & & & 1 & 1 & 2 & 2 & 1 & 1 & 1 & 2 & 1 \\
\hline NLS & & & 2 & 2 & & & 1 & 1 & 1 & 1 & 1 & 1 & 1 & 1 & 1 \\
\hline$L P(m)$ & & & 240 & 240 & & & & & & & & & & & \\
\hline$L(m)$ & & & 22 & 22 & & & 178 & 178 & 118 & 118 & 118 & 118 & 118 & 58 & 58 \\
\hline$L D(m)$ & & & 236 & 236 & & & 156 & 156 & 156 & 156 & 156 & 156 & 156 & 156 & 156 \\
\hline$L S(m)$ & & & 216 & 216 & & & 540 & 540 & 500 & 600 & 600 & 600 & 600 & 660 & 660 \\
\hline CENE (US\$/ano) & & & 1465 & 1533 & & & 1363 & 1694 & 1983 & 2865 & 1380 & 1595 & 2212 & 1934 & 1234 \\
\hline CEB (US\$) & & & 3192 & 3276 & & & 3130 & 3378 & 4197 & 4740 & 3239 & 3442 & 3679 & 4316 & 2799 \\
\hline CVR(US\$) & & & 8069 & 8007 & & & 1674 & 1674 & 2421 & 2421 & 2427 & 2427 & 2421 & 4841 & 4841 \\
\hline CPC(USS) & & & 3247 & 3247 & & & 1406 & 1406 & 1736 & 1736 & 1736 & 1736 & 1736 & 2490 & 2490 \\
\hline CEC(US\$) & & & 8076 & 8076 & & & 8112 & 8112 & 10212 & 10212 & 8532 & 8532 & 8530 & 8532 & 70032 \\
\hline$T L L(m)$ & & & 26400 & 26400 & & & 28480 & 28480 & 28320 & 28320 & 28320 & 28320 & 28320 & 27840 & 27840 \\
\hline$\pi \mathrm{T}(\mathrm{m})$ & & & 460 & 460 & & & & & & & & & & & \\
\hline$\pi D(m)$ & & & 4720 & 4720 & & & 524 & 624 & 936 & 936 & 936 & 936 & 936 & 1872 & 1872 \\
\hline$\pi s(m)$ & & & 432 & 432 & & & 540 & 540 & 600 & 600 & 600 & 600 & 600 & 600 & 660 \\
\hline$H T$ (mca) & & & 33.7 & 36.46 & & & 31.46 & 39.62 & 50 & 69.22 & 31.84 & 38.29 & 53.7 & 71.26 & 29.2 \\
\hline HDA (mco) & & & 6.37 & 3,68 & & & 3.43 & 3.06 & 0.64 & 0.87 & 3.38 & 2,35 & 0.64 & 1.3 & 3.46 \\
\hline HDD (mca) & & & 6,37 & 8,4 & & & 3.43 & 6.18 & 10 & 16,47 & 3.38 & 5.47 & 10 & 16.9 & 3.46 \\
\hline HLA (mco) & & & 4.25 & 3.81 & & & 5.15 & 5.15 & 1.83 & 1,28 & 5.02 & 3,87 & 3.84 & 3.17 & 2.64 \\
\hline HLO (mce) & & & 4.25 & 4.25 & & & 5.15 & 8.77 & 8.91 & 1308 & 5.02 & 6.23 & 10,92 & 8.97 & 2.64 \\
\hline$D P A(m)$ & & & 0.093 & 0.009 & & & & & & & & & & & \\
\hline$D P D(m)$ & & & 0.093 & 0,08 & & & & & & & & & & & \\
\hline$D L D(m)$ & & & 0.01 & 0.01 & & & 0.022 & 0.02 & 0.015 & 0.014 & 0,027 & 0.02 & 0.078 & 0.012 & 0.019 \\
\hline$D D A(m)$ & & & 0.067 & 0.075 & & & 0.09 & 0.093 & 0.111 & 0.104 & 0.053 & 0.1 & 0.132 & 0.008 & 10.084 \\
\hline$D D D(m)$ & & & 0.067 & 0.063 & & & 0.03 & 0,08 & 0,062 & 0.056 & 0,093 & 0,084 & 0,074 & 0,051 & 0.084 \\
\hline NGE & & & 6 & 6 & & & 45 & 45 & 30 & 30 & 30 & 30 & 30 & 15 & 15 \\
\hline NLL & & & 30 & 30 & & & 20 & 20 & 20 & 20 & 20 & 20 & 20 & 20 & 20 \\
\hline NSS & & & 5 & 5 & & & 2 & 2 & 3 & 3 & 3 & 3 & 3 & 6 & 6 \\
\hline$O L(n)$ & & & 522 & 522 & & & 1575 & 1575 & 1050 & 1050 & 1680 & 1680 & 1680 & 840 & 1305 \\
\hline$O D(L / h)$ & & & 31320 & 31320 & & & 63000 & 63000 & 42000 & 42000 & 57200 & 67200 & 67200 & 33200 & $\longdiv { 5 2 2 0 0 }$ \\
\hline HS (mco) & & & 2.74 & 2.76 & & & 6.39 & 6.21 & 5.18 & 7.16 & 6.92 & 6.92 & 6.7 & 6.77 & 6.7 \\
\hline OS $(1 / h)$ & & & 31320 & 31320 & & & 63000 & 63000 & 84000 & 84000 & 67200 & 67200 & 67200 & 67200 & 5220 \\
\hline HPA (mco) & & & 3.75 & 2.57 & & & & & & & & & & & \\
\hline$Q P(M n)$ & & & 31320 & 31320 & & & & & & & & & & & \\
\hline OT $(U h)$ & & & 62640 & 62640 & & & 63000 & 63000 & 84000 & 84000 & 67200 & 67200 & 67200 & 67200 & 5220 \\
\hline NSP & & & 1 & 1 & & & & & & & & & & & \\
\hline HPD (mca) & & & 3.75 & 7.47 & & & & & & & & & & & \\
\hline DHUO (mce) & & & 10.6 & 10.07 & & & 8.58 & 11.54 & 10.69 & 15.85 & 8.4 & 8.96 & 12.7 & 15.17 & 6.1 \\
\hline $\operatorname{VPA}(\mathrm{m} / \mathrm{s})$ & & & 1.29 & 1.12 & & & & & & & & & & & \\
\hline VPO $(\mathrm{m} / \mathrm{s})$ & & & 1.29 & 1.72 & & & & & & & & & & & \\
\hline$V s(\mathrm{~m} / \mathrm{s})$ & & & 1.63 & 1.64 & & & 1,66 & 1.64 & 1.69 & 1.93 & 1,8 & 1.8 & 1,77 & 1,86 & 1.73 \\
\hline$T E$ & & & 7200 & 7200 & & & 7200 & 7200 & 7200 & 7200 & 7200 & 7200 & 7200 & 7200 & 7200 \\
\hline$D S(m)$ & & & 0.082 & 0.082 & & & 0.116 & 0.117 & 0.133 & 0.124 & 0.115 & 0.115 & 0.116 & 0.113 & 0.103 \\
\hline$D L A(m)$ & & & 0.01 & 0.01 & & & 0.022 & 0.022 & 0.022 & 0.023 & 0.027 & 0.022 & 0.022 & 0.015 & 0.019 \\
\hline UE & & & 0.79 & 0.8 & & & 0.87 & $0 . \pi$ & 0.78 & 0.7 & 0.8 & 0.8 & 0.74 & 0.7 & 0.85 \\
\hline HMIN (mce) & & & 10,75 & 10.97 & & & 11.57 & 10.38 & 10.73 & 8.66 & 11.64 & 11.41 & 9.92 & 8.93 & 12.56 \\
\hline (h) & & & 3.16 & 3.86 & & & 13.83 & 11.98 & 20.14 & 27 & 14.14 & 2.92 & 16,68 & 17.62 & 9.31 \\
\hline$T$ (dia) & & & 1.68 & 2.06 & & & 3.02 & 2.48 & 4.24 & 3.96 & 4.9 & 1 & 5.32 & 5.32 & 5.32 \\
\hline
\end{tabular}




\begin{tabular}{|c|c|c|c|c|c|c|c|c|c|c|c|c|c|c|c|}
\hline \multirow[t]{2}{*}{ VARLAVEL } & \multicolumn{15}{|c|}{ CONFIGURACAO } \\
\hline & 106 & 107 & 108 & 109 & 110 & 111 & 112 & 113 & 114 & 115 & 116 & 117 & 118 & 119 & 120 \\
\hline$A(h \theta)$ & 23,04 & 23,04 & 23,04 & 23.04 & 23.04 & 23,04 & 23.04 & 23,04 & 23,04 & 23.04 & 23.04 & 23.04 & 23,04 & 23.04 & 23. \\
\hline$L \times(m)$ & 320 & 320 & 320 & 720 & 720 & 720 & 720 & 720 & 720 & 720 & 720 & 720 & 720 & 720 & 720 \\
\hline$L Y(m)$ & 7220 & 720 & 720 & 320 & 320 & 320 & 320 & 320 & 320 & 320 & 320 & 320 & 320 & 320 & 320 \\
\hline$O E(W h)$ & 87 & 87 & 87 & 35 & 35 & 35 & 35 & 56 & 56 & 56 & 56 & 87 & 87 & 87 & 87 \\
\hline DECX $(\%)$ & 1 & 3 & 5 & 0 & 1 & 3 & 5 & 0 & 1 & 3 & 5 & 0 & 1 & 3 & 5 \\
\hline DECY $(\%)$ & 1 & 3 & 5 & D & 1 & 3 & 5 & 0 & 1 & 3 & 5 & 0 & 1 & 3 & 5 \\
\hline FORSS/henol & 2883 & 2854 & 2821 & 2938 & 2932 & 2849 & & 2886 & 2878 & 2837 & & 2805 & 2850 & 2805 & \\
\hline CSISTIUSShom and & 384 & 413 & 447 & 329 & 336 & 418 & & 362 & 389 & 431 & & 403 & 417 & 462 & \\
\hline RBRUT US\$ he end & 4624 & 4624 & 4624 & 4624 & 4624) & 4624 & & 4624 & 4624 & 4624 & & 4624 & 4623 & 4624 & \\
\hline CPROD US She and & 1356 & 1356 & 1356 & 1356 & 1356 & 1356 & & 1356 & 1356 & 1356 & & 1356 & 1356 & 1356 & \\
\hline NUO & 12 & 10 & 10 & 4 & 4 & 2 & & 4 & 4 & 4 & & 10 & 10 & 8 & \\
\hline NUOS & 1 & 1 & 1 & 1 & 1 & 1 & & 1 & 1 & 1 & & 1 & 1 & 1 & \\
\hline NLS & 1 & 1 & 1 & 1 & 1 & 1 & & 1 & 1 & 1 & & 1 & 1 & 1 & \\
\hline \multicolumn{16}{|l|}{$L P(m)$} \\
\hline$L L(m)$ & 58 & 70 & 70 & 78 & 78 & 158 & & 78 & $7 B$ & 78 & & 30 & 30 & 38 & \\
\hline LD (m) & 156 & 156 & 156 & 356 & 356 & 356 & & $35 \pi$ & 356 & 356 & & 356 & 356 & 356 & \\
\hline$L S(m)$ & 660 & 648 & 648 & 240 & 240 & 160 & & 240 & 240 & 240 & & 288 & 288 & 280 & \\
\hline CENE NUS \$lano) & 1416 & 2154 & 2871 & 1288 & 1438 & 2220 & & 1383 & 1558 & 2370 & & 1510 & 1444 & 2316 & \\
\hline CEB (US\$) & 2987 & 3779 & 4173 & 3032 & 3151 & 4830 & & 3848 & 4005 & 4452 & & 3163 & 3768 & 3991 & \\
\hline CVR(USS) & 4841 & 4034 & 4034 & 1614 & 1674 & 807 & & 1614 & 1614 & 1614 & & 4034 & 4034 & 3227 & \\
\hline CPCNS\$) & 2490 & 2265 & 2265 & 1406 & 1406 & 981 & & 1406 & 1406 & 1406 & & 2264 & 2265 & 2017 & \\
\hline CECRSS? & 7032 & 8076 & 8076 & 8112 & 8112 & 14412 & & 11892 & 11892 & 11892 & & 8076 & 8076 & 9642 & \\
\hline$\pi L(m)$ & 27840 & 28000 & 28000 & 28060 & 28000 & 28440 & & 28080 & 28080 & 28000 & & 27000 & 27000 & 27360 & \\
\hline \multicolumn{16}{|l|}{$\pi P(m)$} \\
\hline$T L D(m)$ & 1872 & 1560 & 1560 & 1424 & 1424 & 712 & & 1424 & 1424 & 1424 & & 3560 & 3500 & 2848 & \\
\hline TLS (m) & 660 & 648 & 548 & 240 & 240 & 160 & & 240 & 240 & 240 & & 298 & 268 & 280 & \\
\hline HT (mce) & 35.73 & 54.75 & 71.11 & 28,39 & 32.11 & 43.44 & & 30.04 & 34.04 & 46.41 & & 32.78 & 32.92 & 47.66 & \\
\hline HDA (mca) & 2.1 & 2.55 & 1.69 & 5.54 & 2.88 & 1,36 & & 6,19 & 3,66 & 1,32 & & 7.95 & 2,88 & 1.32 & \\
\hline HDD (mca) & 5,22 & 11,91 & 17,28 & 5.54 & 10 & 22,72 & & 6.19 & 10.78 & 2258 & & 7,95 & 10 & 22,68 & \\
\hline HLA (mco) & 1.86 & 2.72 & 2.82 & 3.69 & 3.51 & 329 & & 4.13 & 4.04 & 5.66 & & 5.3 & 399 & 6.86 & \\
\hline HLD (mca) & 3.02 & 5.92 & 9.82 & 3.69 & 5.07 & 12.77 & & 4.13 & 5.6 & 10.34 & & 5.3 & 4.59 & 9.14 & \\
\hline \multicolumn{16}{|l|}{$\mathrm{BPA}(\mathrm{m})$} \\
\hline \multicolumn{16}{|l|}{$\mathrm{DPD}(\mathrm{m})$} \\
\hline$D L D(m)$ & 0.018 & 0.017 & 0.016 & 0.075 & 0.014 & 0.017 & & 0.017 & 0.016 & 0.074 & & 0.011 & 0.012 & 0.011 & \\
\hline$D D A(m)$ & 0.094 & 0.006 & 0.105 & 0.037 & 0.111 & 0.168 & & 0.113 & 0.126 & 0.156 & & 0.09 & 0.111 & 0.142 & \\
\hline$D D D(m)$ & $0.0 n$ & 0.069 & 0.064 & 0.097 & 0.086 & 0,093 & & 0.113 & 0.1 & 0.086 & & 0.09 & 0,085 & 0,078 & \\
\hline NGE & 15 & 18 & 18 & 20 & 20 & 40 & & 20 & 20 & 20 & & 8 & 8 & 10 & \\
\hline NUL & 20 & 20 & 20 & 45 & 45 & 45 & & 45 & 45 & 45 & & 45 & 45 & 45 & \\
\hline NSS & 6 & 5 & 5 & 2 & 2 & 1 & & 2 & 2 & 2 & & 5 & 5 & 4 & \\
\hline$Q L(h)$ & 1305 & 1566 & 1566 & 700 & 700 & 1400 & & 1120 & 1120 & 1120 & & 696 & 696 & 870 & \\
\hline$Q D(M / h)$ & 52200 & 62640 & 62640 & 63000 & 63000 & 126000 & & 100800 & 100800 & 100800 & & 62640 & 62640 & 78300 & \\
\hline HS (mca) & 6.75 & 6.89 & 6.6 & 2.81 & 2.77 & 2.47 & & 3.3 & 3.3 & 2.96 & & 2.97 & 3.06 & 2,96 & \\
\hline OS $\{/ / h\}$ & 52200 & 62540 & 62640 & 63000 & 5000 & 126000 & & 10000 & 100800 & 100800 & & 62640 & 62640 & 78300 & \\
\hline \multicolumn{16}{|l|}{ HPA (mca) } \\
\hline \multicolumn{16}{|l|}{$O P(L / h)$} \\
\hline OT $(\mathrm{l} / \mathrm{h})$ & 52200 & 626540 & 52640 & 63000 & 53000 & 126000 & & 100800 & 100800 & 100800 & & 52640 & 62640 & 78300 & \\
\hline \multicolumn{16}{|l|}{$\mathrm{NSP}$} \\
\hline \multicolumn{16}{|l|}{$\mathrm{HPD}$ (mca) } \\
\hline DHUO (mca) & 6.1 & 12,06 & 15,81 & 9,23 & 10,73 & 20.06 & & 10,32 & 12.04 & 20 & & 1325 & 10.73 & 20 & \\
\hline \multicolumn{16}{|l|}{$\operatorname{VPA}(\mathrm{m} / \mathrm{s})$} \\
\hline VPD $(\mathrm{m} / \mathrm{s})$ & & & & & & & & & & & & & & & \\
\hline$V S(\mathrm{~m} / \mathrm{s})$ & 1.73 & 1.82 & 1.78 & 1.65 & 1.64 & 1.85 & & 2 & 2 & 1.91 & & 1.79 & 1.82 & 1.88 & \\
\hline TE & 7200 & 7200 & 72000 & 7200 & 7200 & 7200 & & 7200 & 2200 & 7200 & & 7200 & 7200 & 7200 & \\
\hline$D S(m)$ & 0.103 & 0.11 & 0.111 & 0.116 & 0.116 & 0.155 & & 0.134 & 0.134 & 0.137 & & 0.111 & 0.11 & 0.122 & \\
\hline$D L A(m)$ & 0.02 & 0.021 & 0.021 & 0.015 & 0.015 & 0.023 & & 0.017 & 0.077 & 0,016 & & 0,011 & 0,012 & 0012 & \\
\hline UE & 0.85 & 0.77 & 0.71 & 0.8 & 0.78 & 0.63 & & 0.78 & 0.75 & 0.62 & & 0.75 & 0.79 & 0.64 & \\
\hline HMIN (mca) & 12.56 & 10.18 & 8.68 & 11.31 & 10.77 & 6,98 & & 10.87 & 10.18 & 7 & & 9.7 & 10.71 & 7 & \\
\hline $1(\mathrm{~h})$ & 1.99 & 1.94 & 11.12 & 21 & 18.3 & 21 & & 3 & 16.46 & 11.63 & & 5.7 & 9.47 & 2.32 & \\
\hline$T$ (dia) & 1.14 & 1 & 5.32 & 454 & 3.85 & 3.55 & & 1 & 5.32 & 3.1 & & 2.88 & 5.01 & 1 & \\
\hline
\end{tabular}


109.

APENDICE 3 


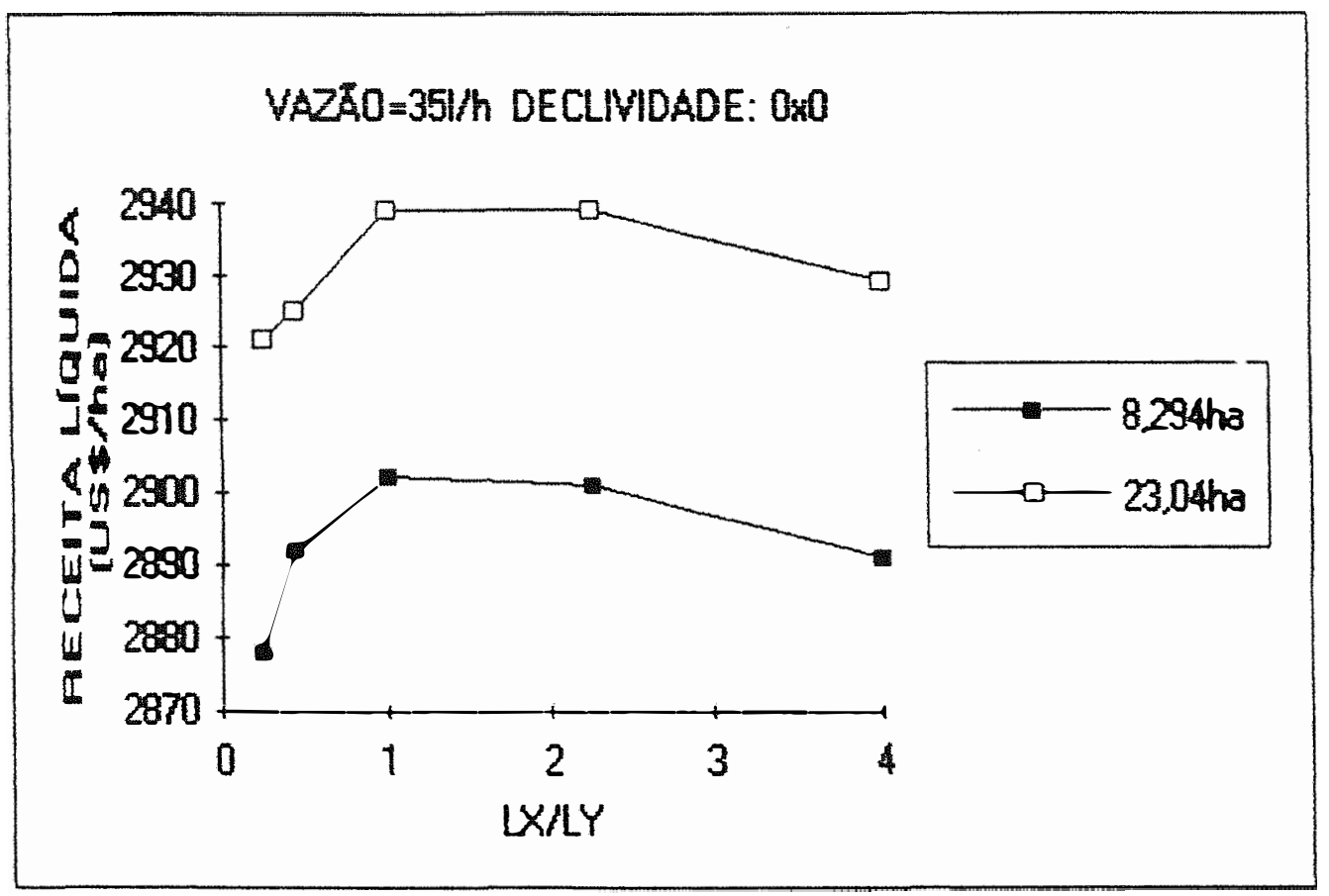

Figura 1 - Receida líquida anual em funçáo do tamanho e do formato da área, para a vazấo de 35 the declividade 0 .

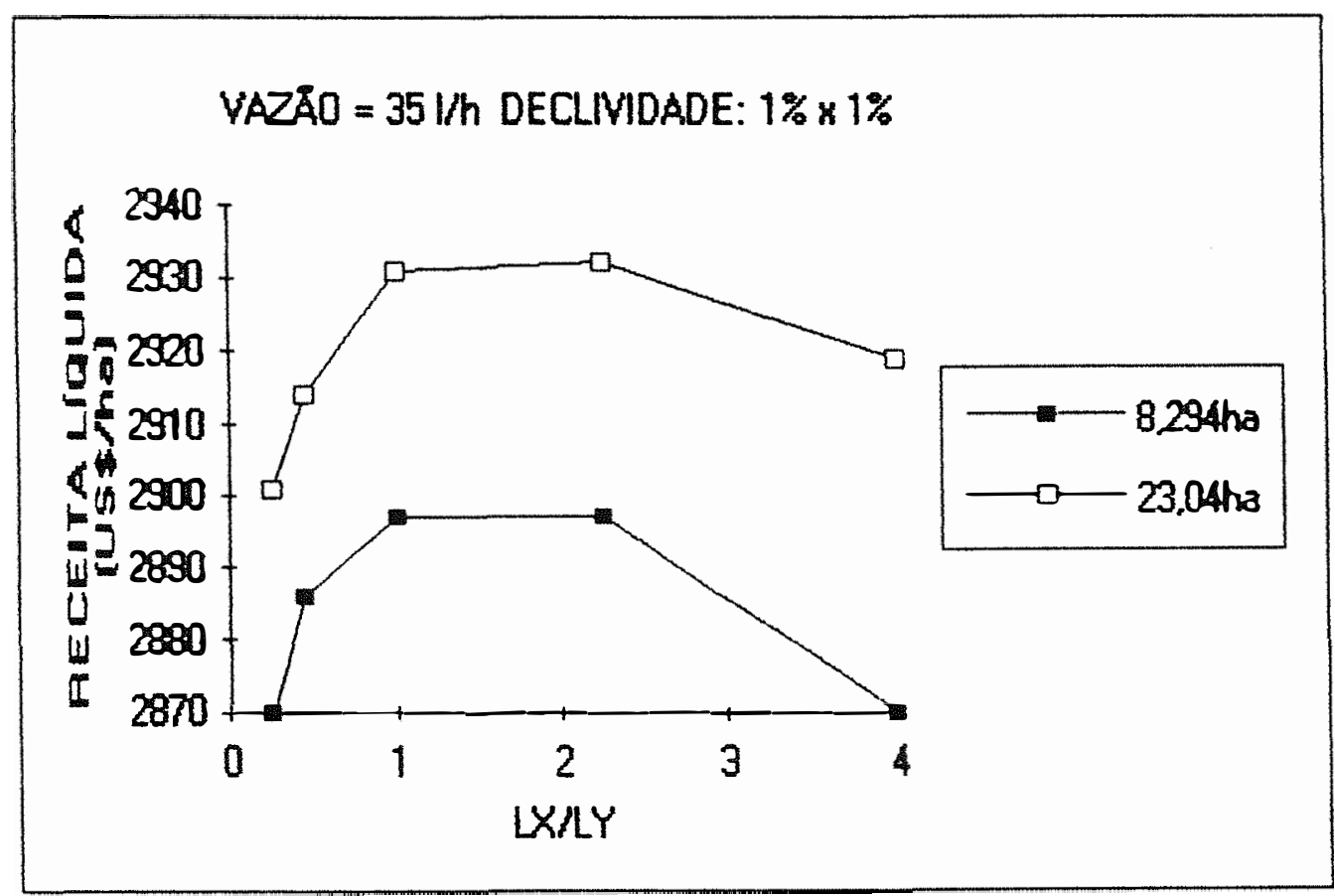

Figua 2 - Receida líquida anual em lungão do lamarho e do formalo ds áres. para a yazẽo de 35 th a dectividade 1\% nas dus dinegios. 


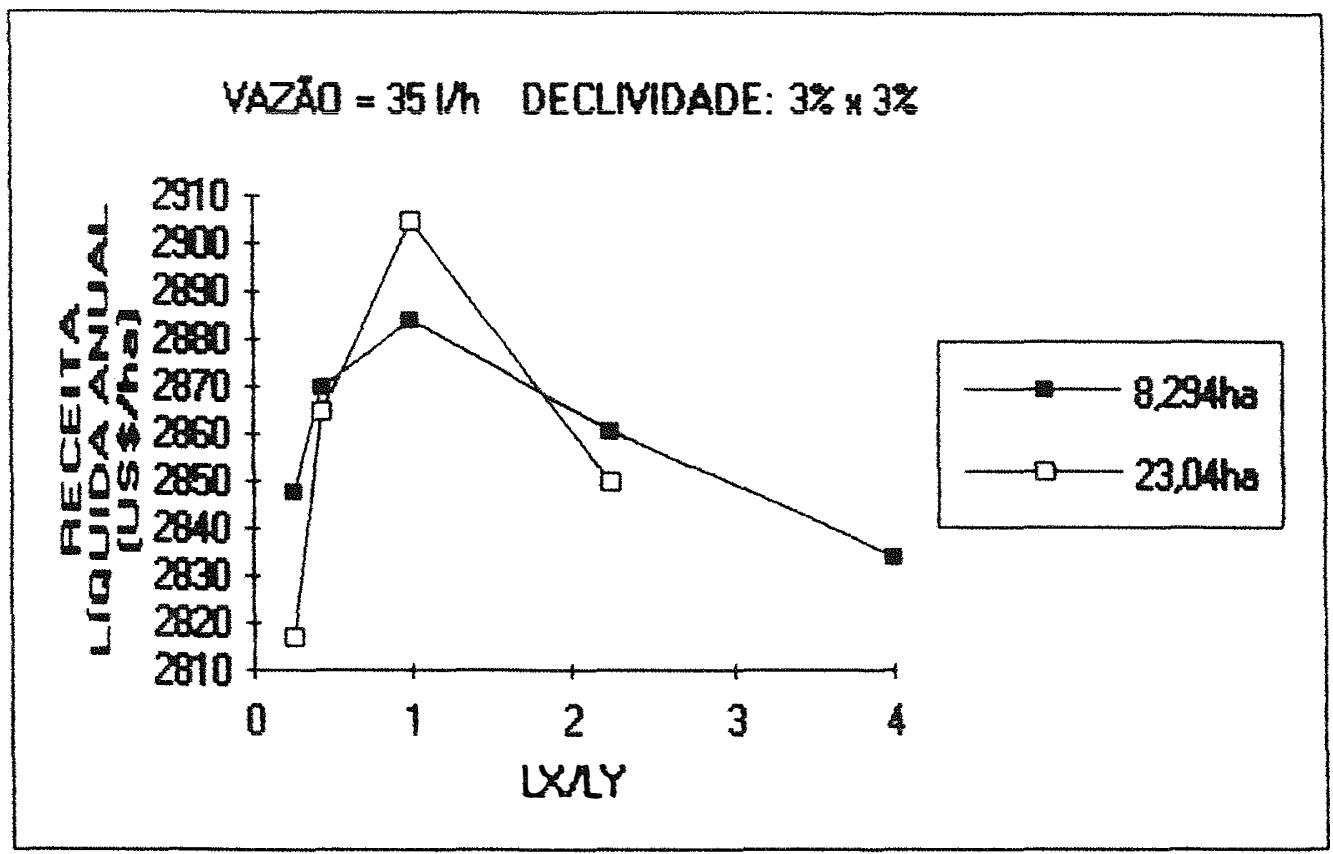

Figua 3 - Receita líquida anual en funcajo do lamanho e do formato da área.

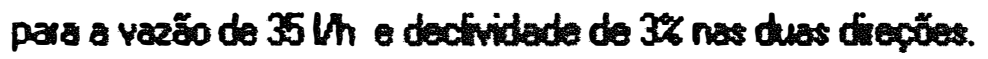

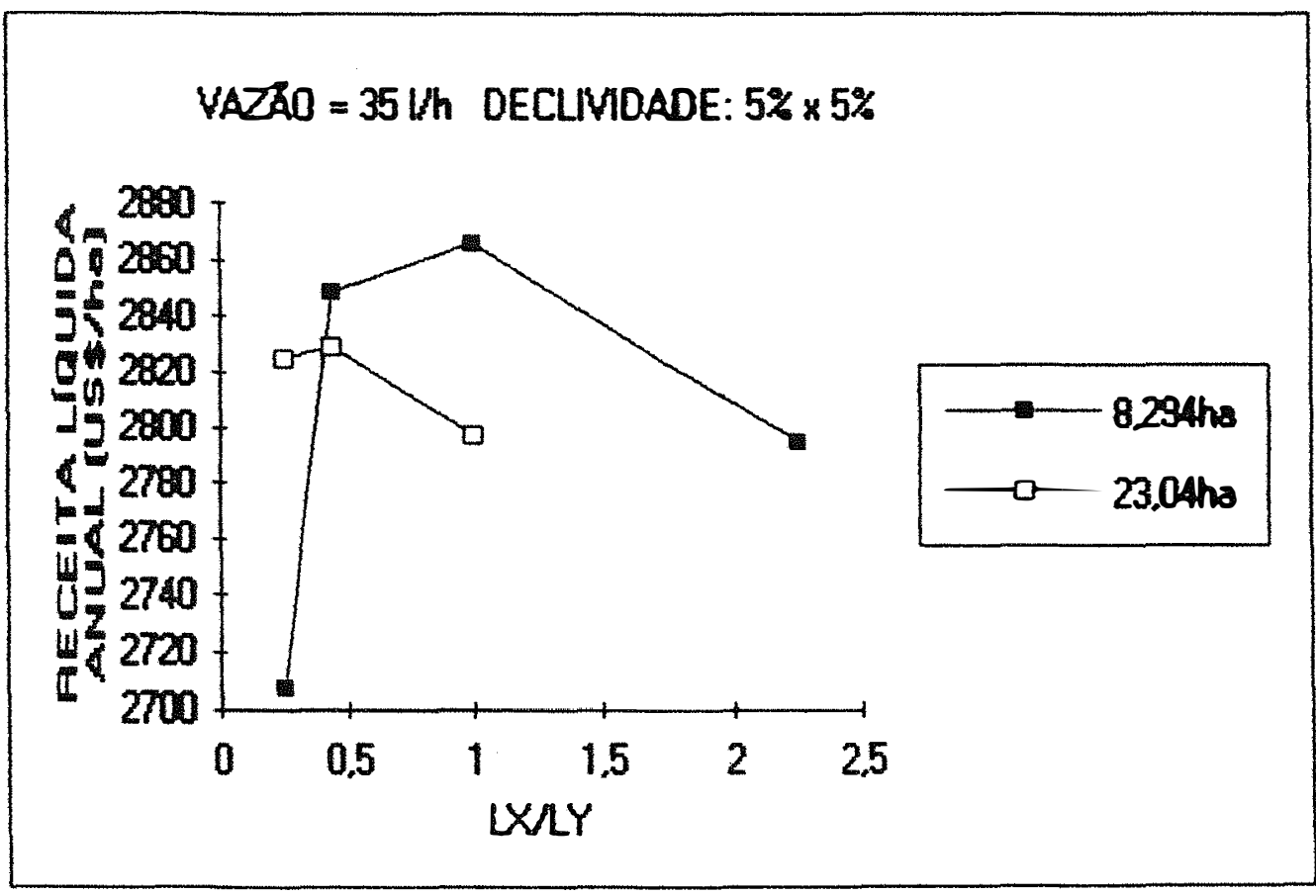

Figura 4 - Receita liquide anual em funcóo do tamanto e do formato da áres. para a yazäo de $35 \mathrm{lh}$ e decifividade $5 \%$ nas dus dieçer. 


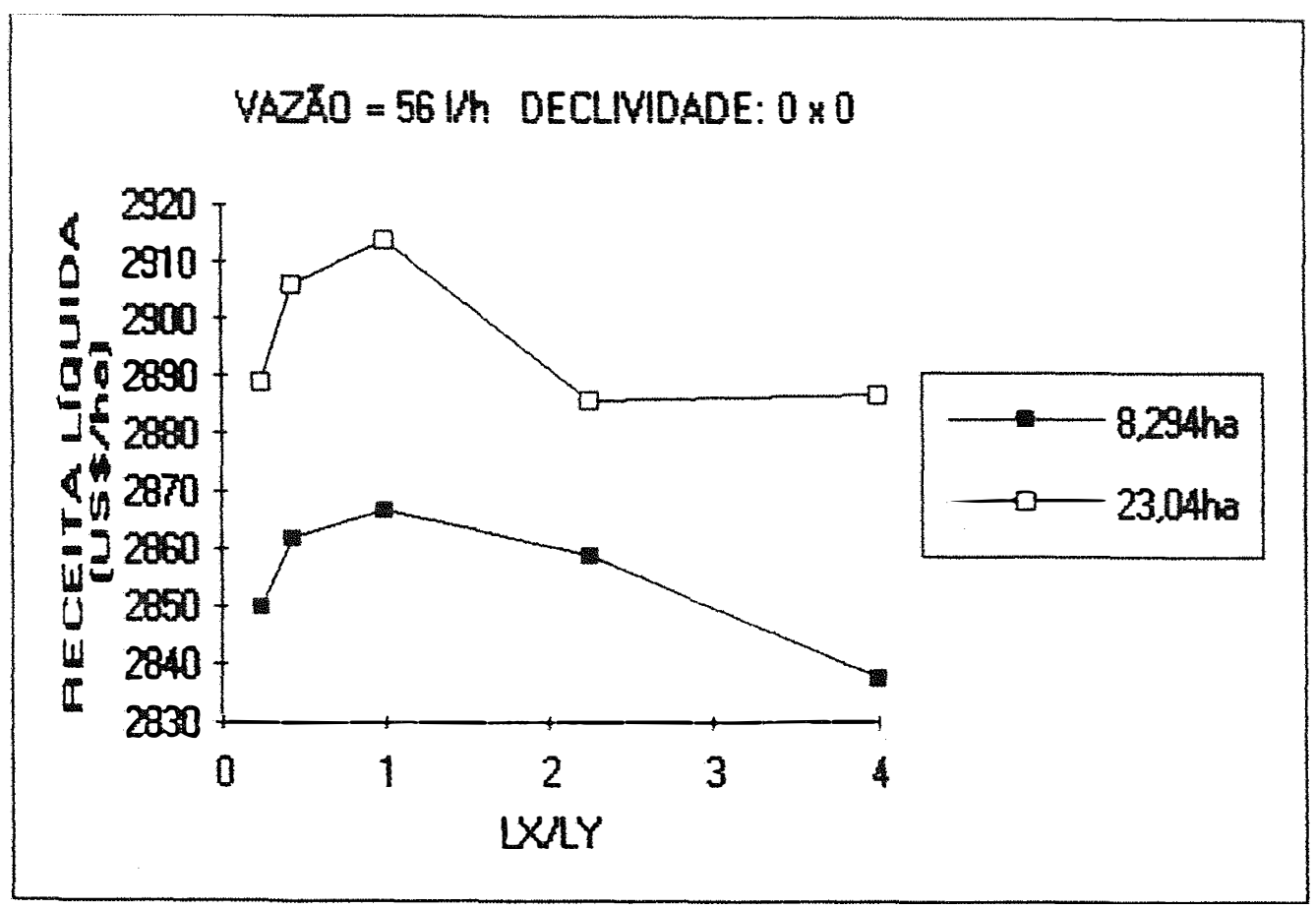

Figura 5- Receida líquida arual en funçấo do tamanho e formato da área, para a yazão 56 the dectividade 0 .

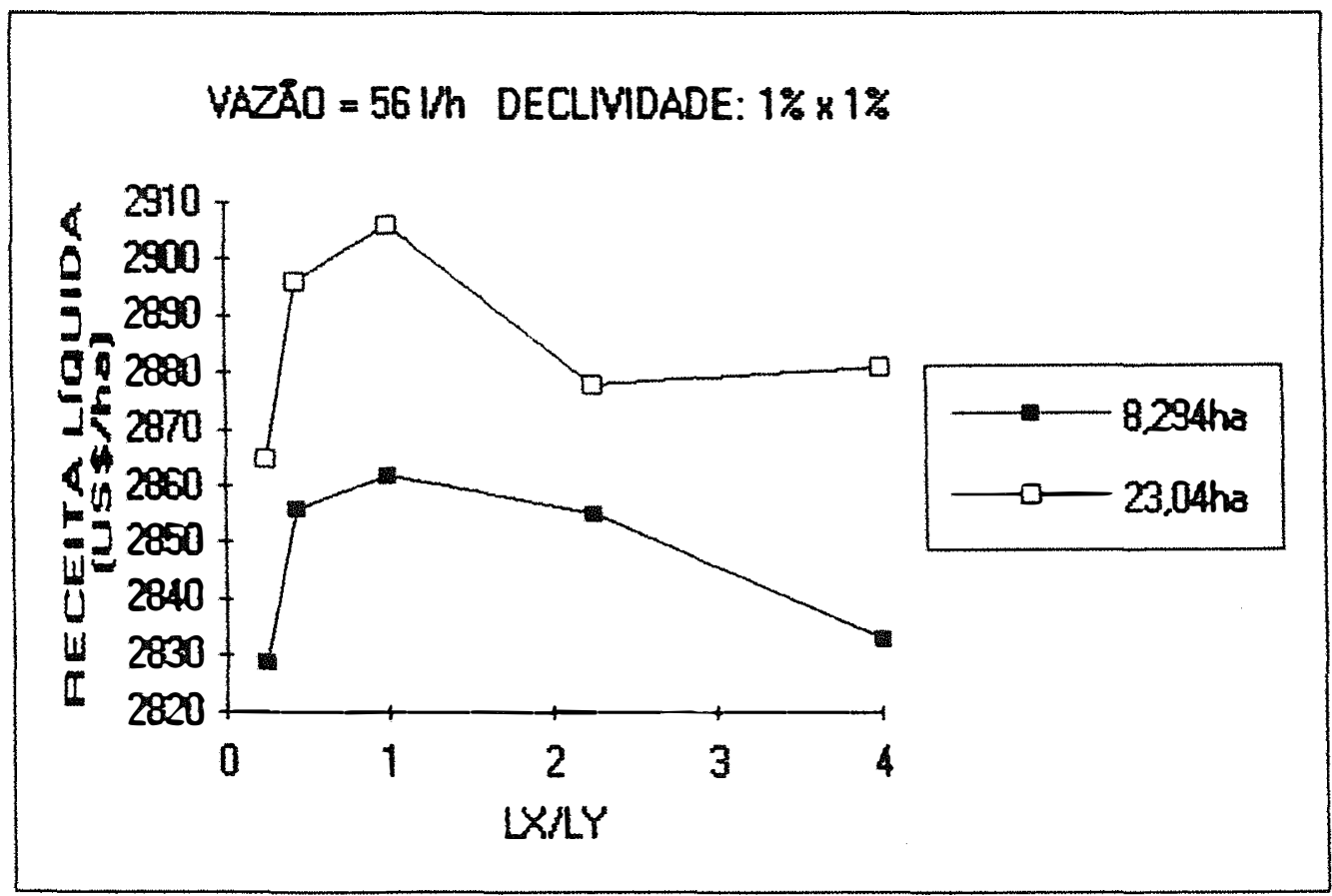

Figura 6 - Receida liquida anuad em função do lamanho e formato da área. para a yazấo de 56 the dectividade de $1 \%$ nas duas dieçöes. 
VAZAZO: $56 \mathrm{I} / \mathrm{h}$ DECLIVIDADE: $3 \%$ : $3 \%$

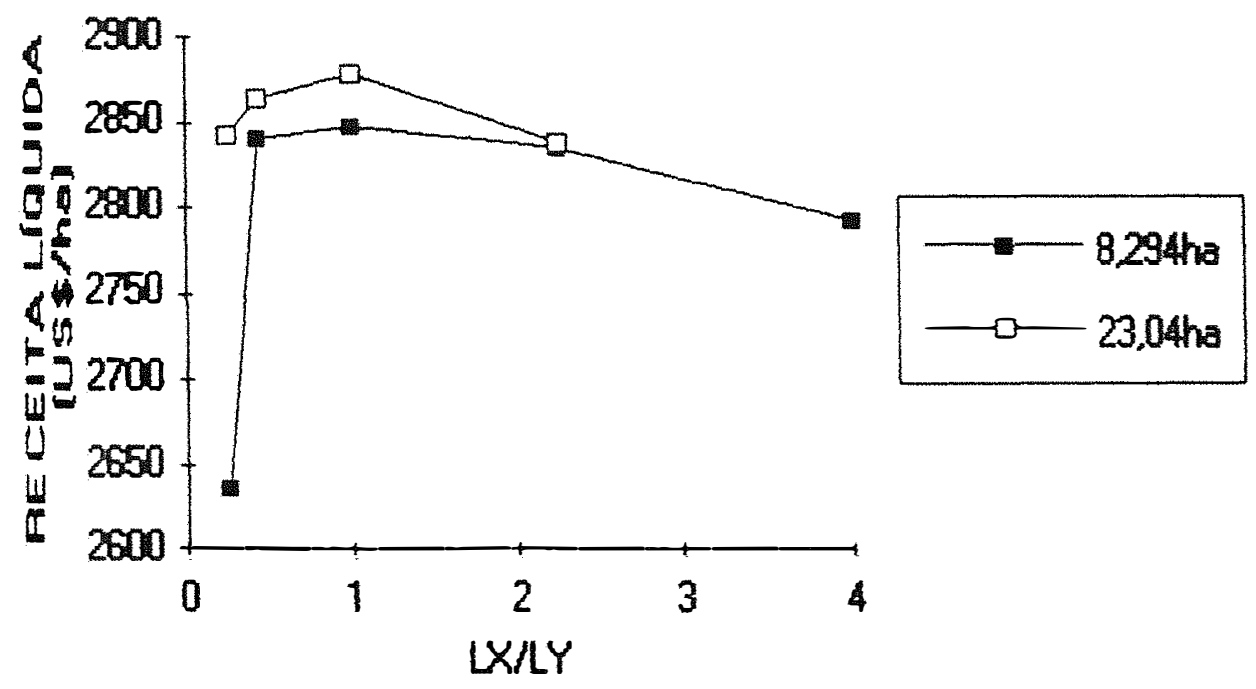

Figusa 7 - Receila líquida anual em funcäo do lamanho e do lomato da área. para a vazăo de 56 the declividade de $3 \%$ nas duas dieçöes.

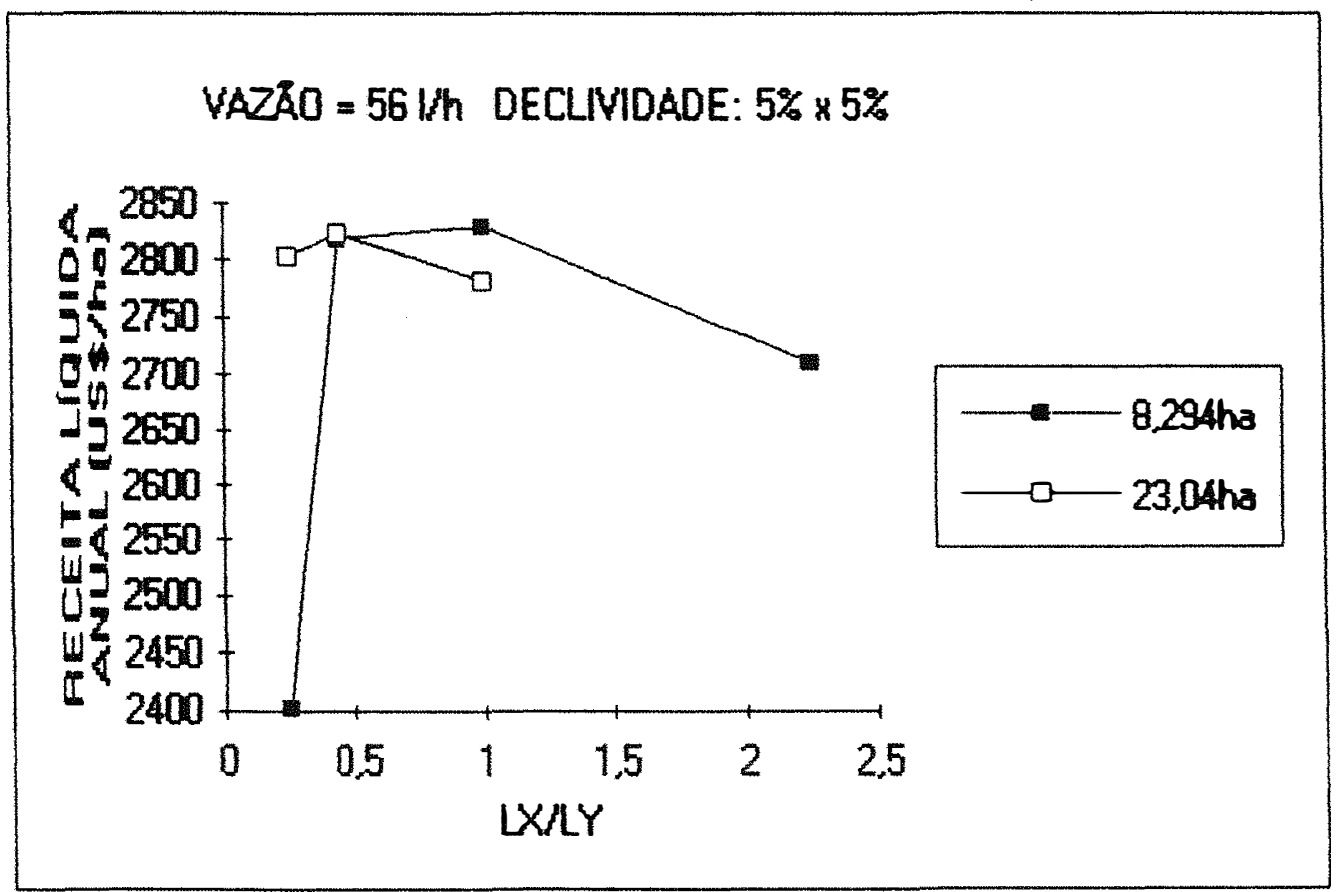

Figua 8 - Receila líquida anual em função do lamanto e do formato da área, para a yazž́o de 56 the declividade de $5 \%$ nas duas dreçổ 


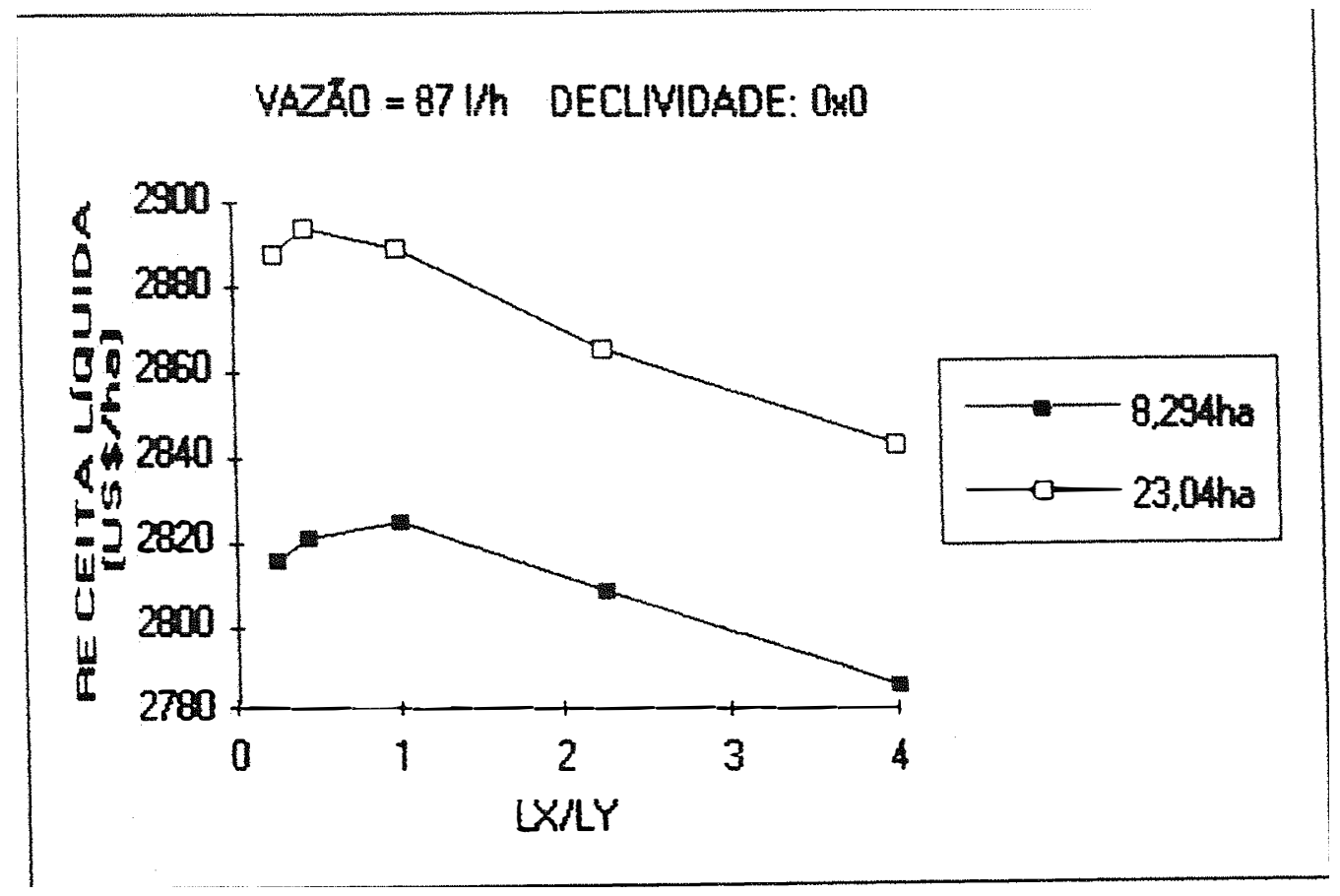

Figua 9- Receika líquida anual em funcão do tamarho e do formato da área. para a vazẫo de 87 the declividade 0 .

VAZKO $=87 \mathrm{l} / \mathrm{h}$ DECLIVIDADE: $1 \% \times 1 \%$

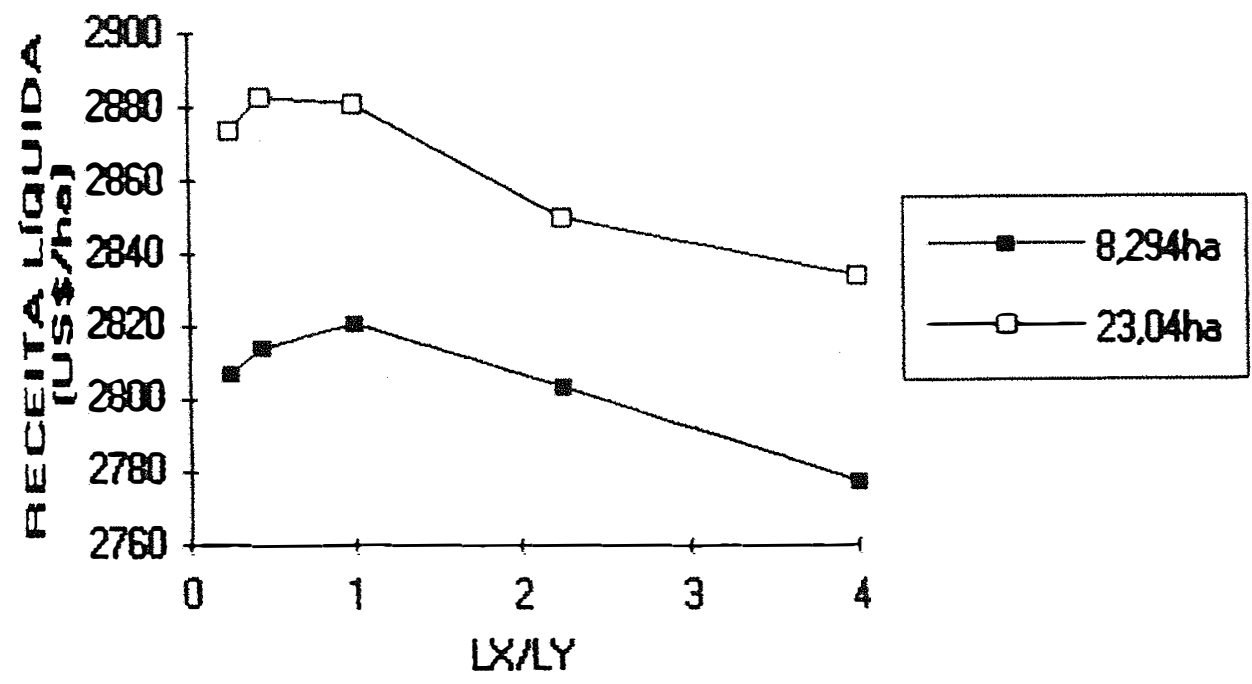

Figur 10 - Receila líquida anual em lunçăo do lamanto e do formato da área, para a vazáo de 87 the declividade 1\% nas duas dregies. 
YAZZ:0: $87 \mathrm{l} / \mathrm{h}$ DECLNIDADE: $3 \% \times 3 \%$
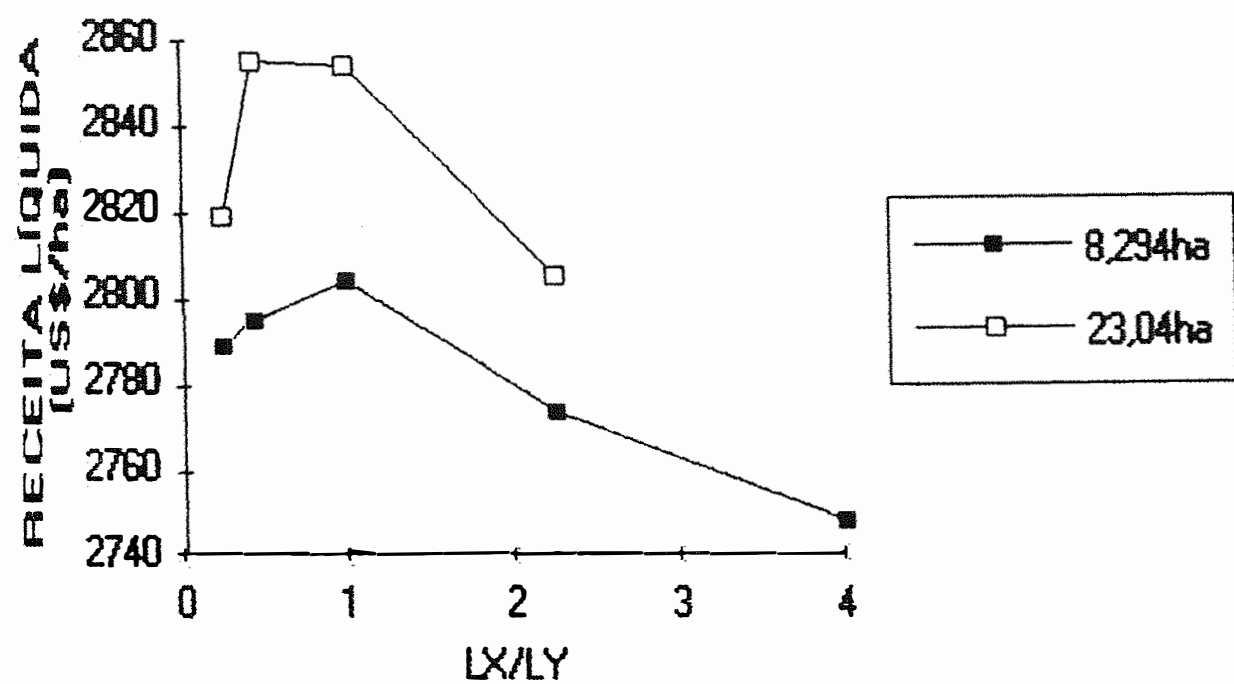

Figua 11 - Receita liquida anual em funç̃o do lamanho e do formato da área. para a vazấo de 87 th e declividade $3 \%$ nas duas dineçües.

VAZAO $=871 / \mathrm{h}$ DECLNIDADE: $5 \% \times 5 \%$

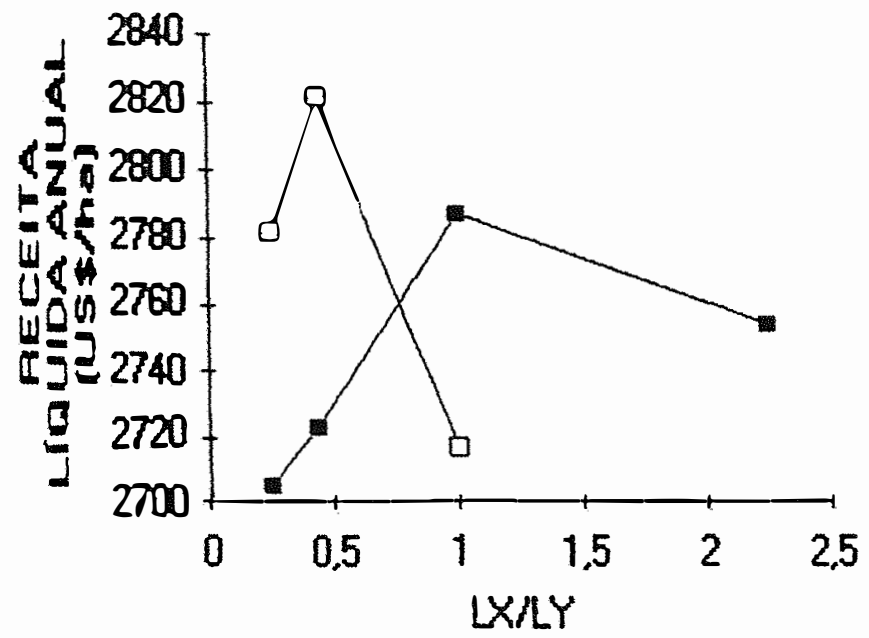

Figura 12 - Receika líquida arual em funç̃o do lamanho e do formato da área, para a yazấo de 87 the e dectividade $5 \%$ nas duas dinecucues. 